\title{
FACILITATING INFORMED LAND-USE DECISIONS THROUGH THE MODELLING OF ECOSYSTEM SERVICE TRADE-OFFS
}

\author{
Nicola Andrea Scott
}

\author{
A thesis submitted to Victoria University of \\ Wellington in partial fulfilment of requirements for \\ the degree of \\ Master of Science
}

2017

School of Geography, Environment and Earth Sciences

Victoria University of Wellington 




\begin{abstract}
Increasing global populations are placing increasing pressure on our natural systems, reducing their capacity to produce the ecosystem services that we rely upon for human wellbeing (World Bank, 2004).

Clarifying the implications of land-use decisions across the range of ecosystem services is fundamental to understanding the trade-offs inherent in land-use options. LUCl (the Land Utilization and Capability Indicator) is an emergent Geographic Information Systems (GIS) based framework developed to enable the mapping of several ecosystem services in a spatially explicit manner. This process enables a clearer understanding of the inter-dependencies between ecosystems and potential implications and trade-offs of management interventions across a range of services.
\end{abstract}

There is however, limited understanding of the impact, utility and credibility of such tools for land-use decision-makers, or of how they perceive the information conveyed. This Thesis considered the impact that presenting information on land-use trade-offs through LUCI had on land-owners at the farm scale.

This research supports previous findings that information alone does not drive behaviour (or decision-making) (Kollmuss, 2002, Fisk, 2011; Kennedy, 2010; Mackenzie-Mohr, 2000; Stern, 2000). Similarly, perceived credibility was not the main driver of decision-making nor is it necessarily rationally based. However without it, voluntary adoption of a new technology or tool is unlikely. Therefore, in seeking to diffuse tools, such as LUCI within a community, process design should take into account the social structures and the characteristics of targeted individuals within that community. The influence of temporal and context specific factors on decision-making provides both barriers and opportunities for technology diffusion. 
The research findings propose that when integrating new tools and technologies within communities, consideration is given to using a suite of tools, mechanisms and theories in concert such as Community-Based Social Marketing (Mackenzie-Mohr, 2011) and Diffusion Theory (Rogers, 2003) to facilitate improved diffusion and uptake by communities. 


\section{Acknowledgements}

The journey travelled in preparing this thesis was not the journey that I expected. Now that it is coming to a close, I realise just how extraordinarily fortunate I have been to take "the road less travelled". There are a number of people that I would like to acknowledge and thank.

Firstly to my participants, all extraordinary people in their own right, I thank you for your honesty, humility, wisdom and patience. Thank you for letting me into your homes and your lives, for your interest and for endless cups of tea and scones. But mostly, thank you for trusting me with your words, I hope that I have done them justice. I wish you and your families well as you traverse the turmoil of a rapidly changing environment.

To Dr Bethanna Jackson, my supervisor, thank you for your time, your patience, your advice and for believing that we would eventually get there. Thank you also for always having an open door, for inviting my participation in the team, but also allowing me the space to juggle my crazy work, family and study commitments.

To Dr Bob Frame, my co-supervisor, thank you for your patience, your humour and for ensuring that I did not try and do everything!

To my managers and colleagues, Carol West, Jeffrey Cornwell and Eric Edwards, thank you for giving me the time to study when I needed it the most. Thank you also for your insights and for letting me forge my own path. To the Department of Conservation, thank you for the financial support and for granting me study leave without which this thesis would not have been possible. 
To Darren my husband, my rock throughout this entire journey, where do I begin? Thank you for endless weekends of solo parenting, for the gentle encouragement and for allowing me the space to work and think. Thank you especially for your inspired Nespresso coffee machine purchase and for the copious quantities of chocolate that got me through many late nights and long weekends of work.

To Sam my son, who has lived with a mother that juggled full time work, travel and part-time study for most of his life. Thank you for your unconditional love. You have a few adventures coming your way my boy, so dust off that backpack, those tramping boots and skis, we have some journeys to take that are long overdue.

To my extended family particularly my siblings, thank you for your patience, humour, support, and your crazy texts, I love you all.

Finally, to my mother, without you this journey would have been a very lonely one. For all the love and support, for chasing me around the Wairarapa with coffee, wherever I may be, thank you. For your delighted smile when I turned up unannounced at often, terribly inconvenient times, thank you. Finally, thank you for endless hours of proofing, your advice and wisdom. I could not have asked for a better travelling companion. 


\section{Table of contents}

INTRODUCTION. 11

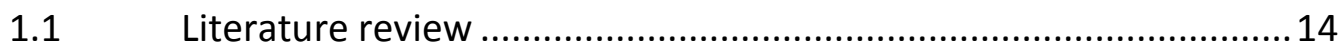

1.2 Research approach and participation .............................................

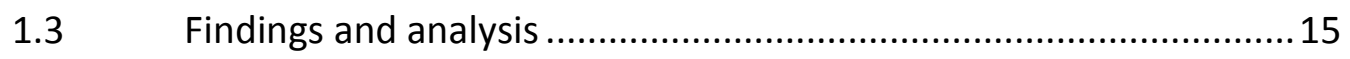

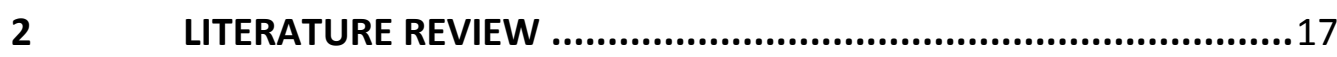

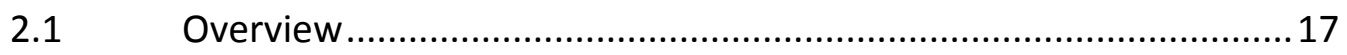

2.2 What are ecosystems and why are they important? ........................18

2.2.1 Increasing demand for ecosystem services coupled with ecosystem

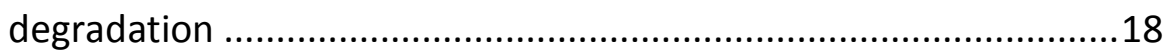

2.2.2 Ecosystem services, their worth, trade-offs and sustainable land-use

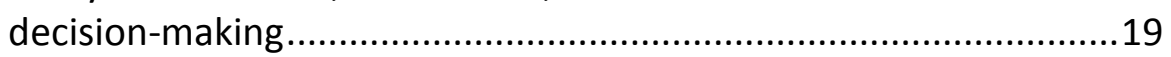

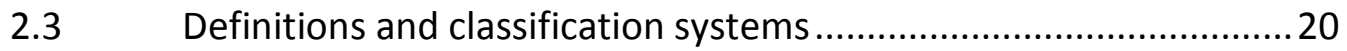

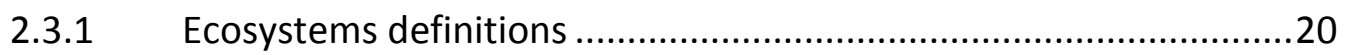

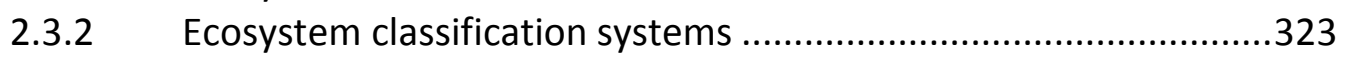

2.4 The importance of dealing with the whole system..........................24

2.4.1 Sustainable land management in the New Zealand context ...........25

2.5 Facilitating environmentally sustainable land-use decisions............28

2.5.1 The human equation .....................................................................28

2.5.2 The role of farmers in improved land-use sustainability ..................29

2.6 Pro-environmental behaviour: tools, theories and mechanisms.....30

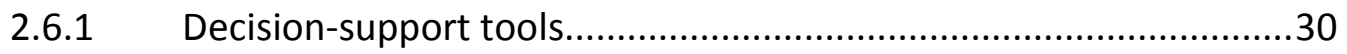

2.6.2 Tools and new technologies ............................................................

2.6.3 Models for pro-environmental behaviour .........................................39

2.6.4 Methods to facilitate pro-environmental behaviour ........................45

2.6.5 Summary and discussion of theories and methods ..........................4 48

2.6.6 Key aspects of the theories and methods to be explored further through the research findings analysis ...........................................53

3 METHODOLOGY AND RESEARCH DESIGN …................................5

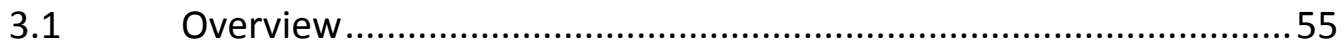

3.2 Epistemology and methodology.................................................. 55

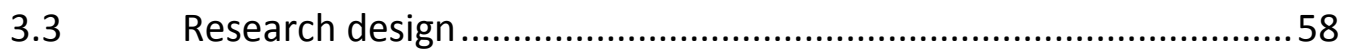

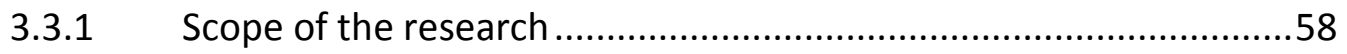

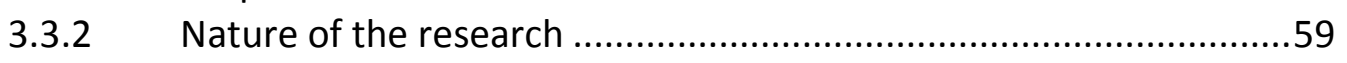

3.4 Method: data collection ...............................................................61

3.4.1 Field Visit 1: data collection and presentation of the phenomenon...

3.4.2 Field visit 2: Presentation of the phenomenon................................63

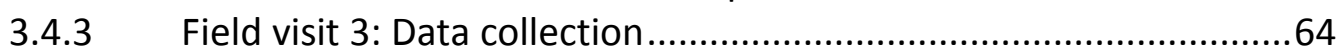

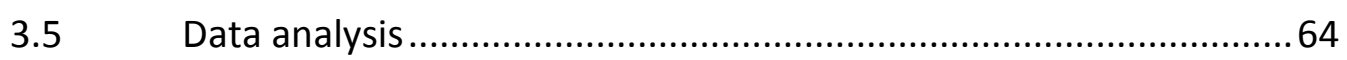

3.5.1 Other techniques considered ..........................................................65 


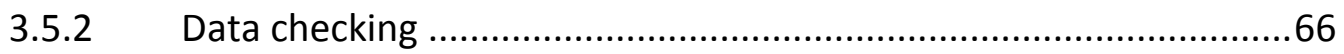

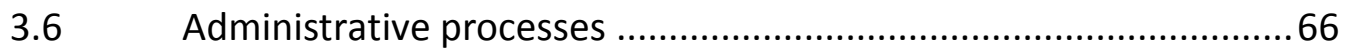

3.6.1 Ethics approval .........................................................................66

3.6.2 Management of the researcher in the process ................................67

3.7 The Participants and study site .................................................. 72

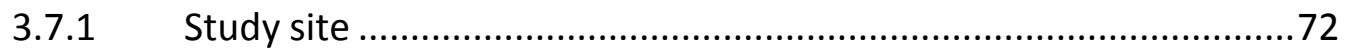

3.7.2 Research participants ..............................................................

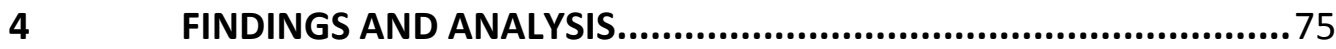

4.1 Part 1: What is LUCl and how does it work ....................................75

4.1.1 Mapping and modelling ecosystem services on farms within the Ruamahanga catchment............................................................... 75

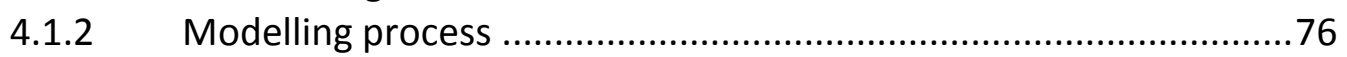

4.1.3 Presentation of LUCl outputs (the maps) ……………………........ 82

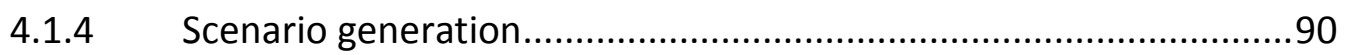

4.1.5 Ground-truthing process ............................................................94

4.1.6 Management options under consideration .....................................94

4.1.7 Areas for further development ....................................................95

4.2 Part 2: Findings and analysis: question analysis...........................105

4.2.1 Theme 1: Experience of the phenomenon ....................................105

4.2.2 Theme 2: Interpretation of the information ................................119

4.2.3 Theme 3: Changes in attitudes and understanding .......................122

4.2.4 Theme 4: Utility of the model ....................................................130

4.3 Part 3: Findings and analysis: thematic analysis ..........................138

4.3.1 Theme 1: Information...............................................................138

4.3.2 Theme 2: Finance, regulation and equity...................................145

4.3.3 Theme 3: Technology and innovation .........................................160

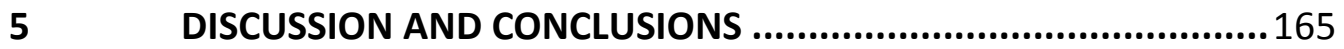

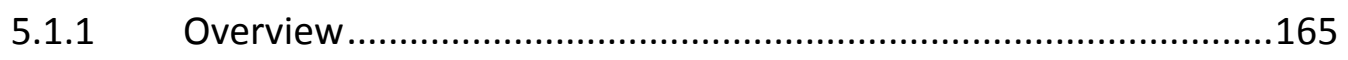

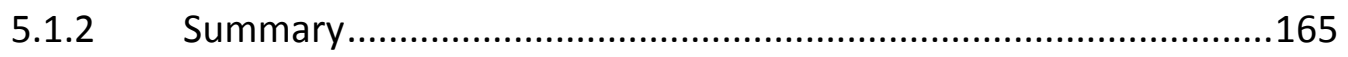

5.1.3 Nature, form and process used for information transfer ..............166

5.1.4 Nature of the information transferred.........................................167

5.1.5 The influence of site specific and temporal issues.........................168

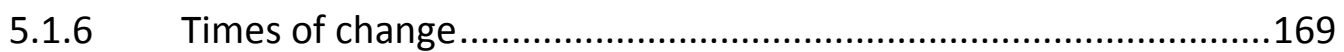

5.1.7 Equity, finance and regulation ..................................................170

5.1.8 Overarching research questions.................................................171

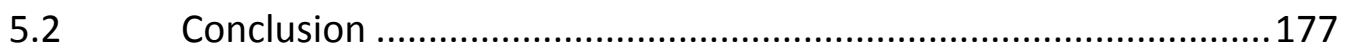

5.3 Limitations of this research .........................................................178

5.3.1 Limitations of: the data, the capability of LUCl version 0.2 and the management interventions considered .......................................179

5.3.2 Limitations in the research design...............................................180

5.4 Further research opportunities ..................................................181

5.4.1 Further research and development ...........................................181 
Appendix A: Research question framework ............................................197

Appendix B: Ethics documentation ..........................................................201

Appendix B.iii:Participant research consent form .....................................205

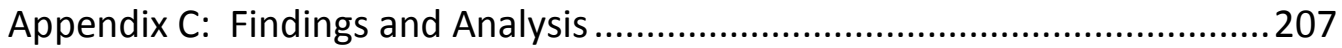

Appendix C.i: Overview of key themes to be considered in Part $2 c$ of the Findings and analysis .207

Appendix C. ii: Overview of key themes and patterns to be considered in Part

2 of the Findings and analysis...................................................210

Appendix D: Maps and scenarios presented to research participant's .........212

Appendix E: Participant field visits between April 2014 and April 2015 .......213 


\section{List of Figures}

Figure 1: Maslow's hierarchy of human needs (Maslow, 1943) .....................40

Figure 2: Stern's (2000) illustration of components of the Value-Belief-Norm (VBN) Theory

Figure 3: Theory of Pro-Environmental Behaviour (Kollmuss \& Agyeman, 2002)

Figure 4: Theory of Innovation Diffusion distribution curve (Kamanski, 2011)

Figure 5: Diffusion Theory: model of five stages of decision-making (Rogers, 2003 , as cited by Sahin, 2006, p.15) .............................................48

Figure 6: Data collection process ................................................................62

Figure 7: Ruamahanga catchment, south east of the lower North Island........72

Figure 8: Illustration of $\mathrm{LUCl}$ processing and the data required at the pre-

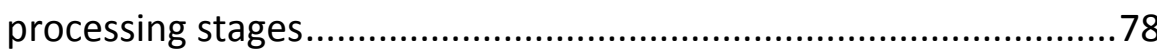

Figure 9: Identification of mitigated land and mitigating features in LUCl Outputs (Jackson et al., 2013a)

Figure 12: LUCl outputs: 1m elevation data: classified accumulated nitrogen 84

Figure 13: Lower Ruamahanga catchment as initially modelled by LUCI...... .87

Figure 14: Lower Ruamahanga catchment as modelled after removal of the lake and inclusion of stop banks

Figure 15: Flood mitigating features: ground-truthed map with existing vegetation ("mitigating features" refers to vegetation)

Figure 16: Flood mitigating features: scenario with existing vegetation removed.

Figure 17: LUCl outputs: classified accumulated nitrogen load with surface drains

Figure 18: LUCl outputs: classified accumulated nitrogen load with surface drains removed. 


\section{List of Tables}

Table 1: Key definitions for ecosystems, ecosystem services and similar

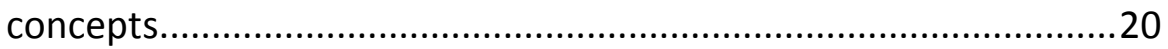

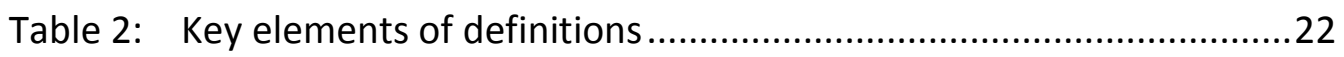

Table 3: Data sources used for this research ..............................................76

Table 4: Elevation data used for the preparation of $\mathrm{LUCl}$ outputs for each of the participant field visits ...............................................................85

Table 5: Participants' views on the accessibility of LUCl outputs ...............107

Table 6: Participants views on credibility of the LUCl outputs prior to and after ground-truthing (GT)

Table 7: Participants' familiarity with the ecosystem services concept as a result of the modelling process.

Table 8: Role of sustainability in decision-making prior to and after research field work ................................................................................128

Table 9: Number of times participants referred to specific decision-drivers

Table 10: Utility of LUCI for others: number of times participants referred to LUCI being useful for other potential users

Table 11: Number of years on the property and references made to various

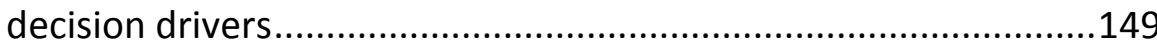

Table 12: Number of times participants referred to regulation

Table 13: Number of time the participants referred to issues of equity and innovation

Table 14: Participant references to finance, regulation and issues associated with equity .159

Table 15: Participant levels of comfort with computers .161 
$P$ a g e | 10 


\section{Introduction}

\section{Research aim}

The aim of this research is to establish the degree to which presenting information on land-use trade-offs through a framework such as LUCI will impact on future land-use decisions by property owners at the farm scale.

There is growing awareness of the importance of ecosystems and ecosystem services in supporting human wellbeing. In 2005, the Millennium Ecosystem Assessment (MEA) brought together a wealth of research on ecosystems and their services and their role in supporting human wellbeing. The MEA (2005) defined ecosystem services as "the result of complex interactions between biotic (living-organisms) and abiotic (chemical and physical) components of ecosystems through the universal driving forces of matter and energy" (p. v). It categorised ecosystem services into: regulating, provisioning, supporting and cultural services (MEA, 2005).

The MEA found that more than $60 \%$ of ecosystems assessed were either being degraded or used unsustainably (MEA, 2005). As global populations continue to increase, we are placing increasing pressure on our natural systems, while at the same time reducing their capacity to produce the services that we rely upon for human wellbeing (World Bank, 2004).

The New Zealand economy is heavily reliant on its natural resource base. In 2012, thirteen of New Zealand's top twenty commodity earners such as: milk products, meat products, and log and wood products etc., were dependent on the provisioning of ecosystems and their services (Eppink et al., 2015; Roberts et al., 2015). These thirteen commodities alone earned $77.4 \%$ of New Zealand's export income for the same year (Roberts et al., 2015).

In 2014 van den Belt and Blake (2014) undertook a literature review of ecosystem services in New Zealand agro-systems. They noted New Zealand 
literature on agro-ecosystems was characterised by fragmentation, the result of the prevailing focus on single services. This single service focus limits the ability to look at the ecosystem service trade-offs inherent in land management decisions (Ausseil et al., 2013).

In 2012, of New Zealand's top twenty export earners, the thirteen commodities that were dependent on natural resources, earned around 77.4\% of New Zealand's export income (Roberts et al., 2015). As such, New Zealand is heavily reliant on natural resources for continued production. As a result, farmers and land-owners have an important role to play in the ongoing management of New Zealand's natural resources. It is therefore important that land-managers in the agricultural sector understand the implications of their land-use decisions across the range of ecosystem services and the tradeoffs inherent in land-use options.

Since the release of the MEA a variety of newly emerging Geographic Information Systems (GIS) based frameworks now allow for the mapping of several ecosystem services in a spatially explicit manner (Bagstad et al., 2013). This process enables a clearer understanding of the inter-dependencies that exist within and between ecosystems at a specific site (Jackson et al., 2013b) and the potential implications of management interventions across a range of services. LUCI (the Land Utilisation and Capability Indicator) is one such tool that is particularly applicable at the farm and catchment scales (Bagstad et al., 2013).

LUCI generates spatially explicit maps focusing on a variety of ecosystem services ( 6 used in this study: phosphorous, nitrogen, carbon, erosion and sediment, flooding and agricultural production). The spatial exploration of multiple ecosystem services (either individually or collectively) helps to illustrate to land-owners, the dynamics of the ecosystems on their properties. Through the use of scenarios, land owners can see how and where small scale management interventions can be used to improve ecosystem service 
provisioning and ecosystem dynamics. $\mathrm{LUCl}$ generates scenarios in real-time and has been developed with a view to supporting interaction and engagement with land owners when considering land-use options (Jackson et al, 2013b).

There is however, limited understanding of the impact, utility and credibility of such tools for land-use decision-makers, and how they perceive the information conveyed through such tools. Therefore, the aim of this research is to establish the degree to which presenting information on land-use tradeoffs through a framework such as LUCI will impact on future land-use decisions by property owners at the farm scale. The research will explore the topic through analysis of the following research questions:

\section{Overarching research questions}

1. Is the information presented through $\mathrm{LUCl}$ accessible and compelling?

2. Is the information presented through LUCI perceived to be credible and robust?

3. How is the information provided through LUCI being interpreted?

4. Are there barriers between information exchange through the modelling process, and the application of that information in land-use decisions, if so what are these?

5. How effective is presenting information through modelling processes such as $\mathrm{LUCl}$ in influencing environmentally sustainable land-use decisions? 


\subsection{Literature review}

The research literature review explores the concept of ecosystem services, why it is important generally, and specifically for New Zealand and the agricultural sector. The review then considers the human element, focusing on pro-environmental behavioural theories, and tools and mechanisms available to facilitate pro-environmental behaviour. The research aim and questions are provided.

\subsection{Research approach and participation}

A qualitative approach was used for this research with data collection and analysis relying heavily on Interpretive Phenomenology, both as a philosophy and a methodological approach. Research participants were exposed to information and potential land management options generated by $\mathrm{LUCl}$, a GIS based ecosystem service trade-off framework. Qualitative science techniques where employed to collect and analyse participant responses to the information conveyed throughout the research.

This research targeted a small sample (5) of farmers in Wairarapa Moana. All participants met the criteria for "early adopters" (Rogers, 2003) and managed, owned or partly owned properties $>50$ ha. The range of land use on participants' properties included dairy, beef and sheep and arable farming.

While early adopters only represent the characteristics of around $13.5 \%$ of the population (Rogers, 2003), it was felt that if the information conveyed through LUCI was not supported by this group, then it would be unlikely to be supported by the other $86.5 \%$ of the farming community. However, given the small and targeted sample used, the results of this research are not readily generalisable. However they do provide an insight into how the information conveyed was perceived and interpreted by a small group of "early adopters". 


\subsection{Findings and analysis}

While this research explores a range of tools, mechanisms and theories for pro-environmental behaviour, none of the theories considered provided a good fit for the research findings. Rather, this research found that the factors that influenced participants' perceptions and decision-making were influenced by: community status and individual attributes (i.e. early adopter characteristics and weighting given to different person specific behavioural drivers), context and temporal factors.

The Discussion and Conclusion brings together the various components of the research. It considers: the themes arising from the analysis, the research questions, and how components of the literature were applied to the findings. 
P a g e | 16 


\section{Literature Review}

\subsection{Overview}

The literature review starts by explaining what ecosystems and ecosystem services are. It then goes on to briefly explore the role of ecosystems services in meeting basic human needs, and the potential impact of land-use decisions on the productivity and functioning of ecosystems and their services. Lastly it provides an overview of ecosystem definitions and classifications.

The next section of the literature review will focus on ecosystems in the New Zealand context, particularly the ecosystem services that support agricultural production and the impact that agricultural production has on those services.

Discussion then turns to the human element in environmental sustainability issues. The role of farmers is given particular consideration, given their dependence on natural resources for their livelihood.

The literature review then focuses on some of the pro-environmental behaviour theories, and some of the tools, mechanisms and methods used to facilitate increased pro-environmental behaviour. Commonalities amongst these theories are discussed along with mixed method approaches (that mix theories, tools and mechanisms), and how they can be used to achieve improved information exchange and diffusion within a community. Finally the review will discuss the use of spatially explicit modelling frameworks as a means to improve information exchange and facilitate proenvironmental behaviour. 


\subsection{What are ecosystems and why are they important?}

Ecosystems are "a dynamic complex of plant, animal and micro-organism communities and their non-living environment interacting as a functional unit" (CBD, 1992). Ecosystems provide a range of services that directly or indirectly support human wellbeing, known as "ecosystem services" (Costanza et al., 1997).

\subsubsection{Increasing demand for ecosystem services coupled with ecosystem degradation}

Research to date indicates that the earth's ecosystems are under pressure and in many cases the direct and indirect impacts from human intervention has significantly impacted their ability to function optimally. In some cases, it has brought these systems close to collapse with potentially significant implications for human wellbeing (Turner II, 2007).

In 2013 , the United Nations predicted ${ }^{1}$ that the human population will increase to 9.6 billion by 2050 (United Nations, 2013). This increase will necessitate a $60 \%$ increase in food production within that time frame (FAO, 2014).

Increasing, or even sustaining current production levels will not be possible without factoring in the ecosystems upon which primary industries depend. To do this effectively, countries will need to have a clear understanding of their ecosystem service needs (both present and future), and the levels of ecosystem protection and function required to maintain those services and enhance the ecosystems upon which they depend.

In 2000, the United Nations Director General (Kofi Annan), initiated work on a global assessment of the world's ecosystems. This project was the first of its

1 "median-variant" projection 
kind, and brought together the work of more than 1,300 scientists globally (van den Belt and Blake, 2014). In 2005, the Millennium Ecosystem Assessment (MEA), the key output of this work was released. The MEA brought together research focusing on the role and importance of ecosystems, their services and human dependence on them (van den Belt and Blake, 2014).

The MEA (2005) found that "approximately $60 \%$ (15 out of 24) of the ecosystem services examined during the Millennium Ecosystem Assessment are being degraded or used unsustainably..... The full costs of the loss and degradation of these ecosystem services are difficult to measure, but the available evidence demonstrates that they are substantial and growing. Many ecosystem services have been degraded as a consequence of actions taken to increase the supply of services, such as food." (p. 1)

\subsubsection{Ecosystem services, their worth, trade-offs and sustainable land-use decision-making}

In 1997, Costanza et al. released an article that for the first time placed a dollar value on the earth's ecosystem services. At that time the figure of "US\$33 trillion" was quoted (p. 253), noting that because many ecosystem services are not captured by financial markets, the value that humans' derive from them often goes unnoticed, and is not adequately taken into account in policy and resource use decisions. While the actual figure of US\$33 trillion was hotly contested (Mansum et al, 2007), the article triggered an important discourse about: the magnitude of services/benefits that humans' derive from natural capital (World Bank, 2004), humanity's dependence on those benefits/services for its survival (de Groot et al., 2002), the equitable distribution of those benefits/services (Lant et al., 2008) and, the need to protect and maintain ecosystems in order to ensure their ongoing functioning (Haines-Young and Potschin, 2008). 
In 2004, the World Bank noted that our understanding of ecosystem dependencies is extremely limited, as is our knowledge of our economy's reliance on ecosystems to sustain our living standards.

\subsection{Definitions and classification systems}

\subsubsection{Ecosystems definitions}

There is an array of definitions for ecosystems and ecosystem services that have been developed in recent years. Key differences include whether biotic ecosystem outputs (e.g. salt, wind, snow) are ecosystem services (HainesYoung and Potschin, 2011) and whether ecosystem services relate only to those services that directly benefit humans (i.e. final ecosystem outputs), or also include the supporting services (i.e. intermediate ecosystem outputs) that underpin all other service categories (Table 1 and Table 2 refer).

Table 1: Key definitions for ecosystems, ecosystem services and similar concepts

\begin{tabular}{|l|l|}
\hline \multicolumn{2}{|l|}{ Ecosystems: } \\
\begin{tabular}{l|l} 
A dynamic complex of plant, animal and micro- \\
organism communities and their living and non-living \\
environment interacting as a functional unit.
\end{tabular} & $\begin{array}{l}\text { Convention } \\
\text { of Biological } \\
\text { Diversity, } \\
1992,\end{array}$ \\
& $\begin{array}{l}\text { Millennium } \\
\text { Ecosystem } \\
\text { Assessment, } \\
\end{array}$ \\
\end{tabular}




\begin{tabular}{|l|l|}
\hline \multicolumn{2}{|l|}{ Natural processes } \\
\hline The result of complex interactions between biotic & de Groot \\
(living-organisms) and abiotic (chemical and & et al., \\
physical) components of ecosystems through the & 2002 \\
universal driving forces of matter and energy & \\
\hline
\end{tabular}

\begin{tabular}{|c|c|}
\hline Ecosystem services: & \\
\hline $\begin{array}{l}\text { The benefits human populations derive directly or } \\
\text { indirectly from ecosystem function }\end{array}$ & $\begin{array}{l}\text { Costanza et } \\
\text { al., } 1997\end{array}$ \\
\hline The benefits people obtain from ecosystems & $\begin{array}{l}\text { Millennium } \\
\text { Ecosystem } \\
\text { Assessment, } \\
2005\end{array}$ \\
\hline $\begin{array}{l}\text { Components of nature, directly enjoyed, } \\
\text { consumed or used to yield human benefit }\end{array}$ & $\begin{array}{l}\text { Boyd \& } \\
\text { Banzhaf, } 2007\end{array}$ \\
\hline $\begin{array}{l}\text { The contributions that ecosystems make to } \\
\text { wellbeing }\end{array}$ & $\begin{array}{l}\text { Common } \\
\text { International } \\
\text { Classification } \\
\text { of Ecosystem } \\
\text { Services } \\
\text { (CICES), 2011, } \\
\text { p. } 2\end{array}$ \\
\hline $\begin{array}{l}\text { The conditions and processes through which } \\
\text { natural ecosystems and the species that make } \\
\text { them up sustain and fulfil human life }\end{array}$ & Dailey, 1997 \\
\hline
\end{tabular}


While the MEA provides the most commonly used definition for the term ecosystem services, economists have raised concern about the utility of the MEA definition for environmental accounting purposes. This is because of the inclusion of "supporting services" or intermediate ecosystem outputs, and the risk of double counting (Boyd and Banzhaf, 2007). On the other hand, the CICES definition considers final ecosystem outputs only. However, both the MEA and CICES include biotic and abiotic ecosystem outputs as ecosystem services.

Table 2: Key elements of definitions

\begin{tabular}{|c|c|c|}
\hline $\begin{array}{c}\text { Outputs covered by the } \\
\text { definitions }\end{array}$ & Biotic only & Biotic and abiotic \\
\hline $\begin{array}{l}\text { Final } \\
\text { ecosystem } \\
\text { outputs only }\end{array}$ & $\begin{array}{l}\text { Boyd \& Banzhaf, } \\
2007\end{array}$ & $\begin{array}{l}\text { Dailey, } 1997 \\
\text { Common } \\
\text { International } \\
\text { Classification of } \\
\text { Ecosystem } \\
\text { Services (CICES), } \\
2011\end{array}$ \\
\hline $\begin{array}{l}\text { Supporting services / } \\
\text { intermediate ecosystem } \\
\text { outputs and final ecosystem } \\
\text { service outputs }\end{array}$ & & $\begin{array}{l}\text { Millennium } \\
\text { Ecosystem } \\
\text { Assessment, } \\
2005 \\
\text { Convention of } \\
\text { Biological } \\
\text { Diversity } \\
\text { Costanza et al, } \\
1997\end{array}$ \\
\hline
\end{tabular}




\subsubsection{Ecosystem classification systems}

The context for classification systems is similarly complex and inconsistent (Haines-Young and Potschin, 2011). The MEA categorised ecosystem services into 4 categories: "provisioning services such as food, water, timber, and fiber; regulating services that affect climate, floods, disease, wastes, and water quality; cultural services that provide recreational, aesthetic, and spiritual benefits; and supporting services such as soil formation, photosynthesis, and nutrient cycling" (MEA 2005, p.v). De Groot et al. (2002) categorised ecosystem services into: regulation functions, habitat functions, production functions, and information functions. More latterly The Economics of Ecosystems and Biodiversity (TEEB) report (de Groot et al., 2010) re-categorised the MEA's categories into: provisioning, regulating, habitat or supporting services, and cultural services. In 2009, CICES attempted to look across all the different categorisation systems and developed a categorisation system under which the sub-categories of many of the other systems could be nested. Their categories included: provisioning, regulating and maintenance, and cultural (Haines-Young and Potschin, 2011).

It was also during this period that researchers began to question the need for a single categorisation system, given the novelty, complexity, site and context specific nature of ecosystem service implementation (Fisher et al., 2007; Haines-Young and Potschin, 2011; de Groot et al., 2010). Rather, an appropriate categorisation system should be selected from the array of options available, based on the context and nature of the circumstances under consideration, (Fisher et al., 2007).

The MEA definitions and classification system will be used for this research because: this research will not entail economic evaluation, the field work will take into account the role of supporting services when considering impact mitigation, and because its definitions and classification are the most commonly used. 
The MEA (2005) defines ecosystems as:

..."a dynamic complex of plant, animal, and micro-organism communities and the non-living environment interacting as a functional unit" (p. v).

The MEA defines ecosystem services as:

"the benefits people obtain from ecosystems" (p.v).

\subsection{The importance of dealing with the whole system}

The inter-linkages between ecosystems and their services has not been well understood in the past, particularly the role of "supporting services" which often go unnoticed, yet underpin the functional integrity of the system as a whole (Lant et al., 2008). Rather ironically, as noted by Lant et al., (2008) "in the long run, the loss of supporting and regulating services undermines efforts to meet increasing demand for marketable provisioning services such as food production" (p. 971).

Given that many ecosystems are interconnected and that increased benefits from one service may result in decreased services from another, fully understanding these inter-dependencies may be key to informing how best to manage for optimal outcomes across all services (Herzig et al., 2013).

Coupling an understanding of ecosystem service trade-offs with spatial planning at a local and regional scale, may serve to enhance (or maintain) the potential benefits derived from our environment whilst minimising, or at least understanding the impacts that an increase in the provisioning of some services will have for others (Herzig et al., 2013). 


\subsubsection{Sustainable land management in the New Zealand context}

\section{Ecosystem services in New Zealand}

In 2012, thirteen of New Zealand's top twenty commodity earners were reliant on the provisioning of ecosystems and their services. These thirteen commodities alone earned $77.4 \%$ of New Zealand's export income for the same year (Robertson et al., 2015).

However, in 2014 van den Belt and Blake noted that "New Zealand has not institutionalised the ecosystem services concept in a cohesive manner in its resource management policy. In this respect the country lags, compared with outcomes from the reviews carried out elsewhere" (e.13).

Furthermore, inconsistent use of terminology, definitions and frameworks further complicates attempts to consider the results of the available research as a collective (van den Belt and Blake, 2014).

\section{New Zealand dependence on ecosystem services}

\section{Overview}

As a country New Zealand is heavily dependent on natural resources for its economic well-being, yet we know very little about the impact and interdependencies of the ecosystems services that underpin our export sector (Roberts et al., 2015).

\section{Agricultural productivity}

Around $40 \%$ of the land area is currently subject to livestock grazing. Over the last two decades New Zealand has experienced significant intensification and expansion of the dairy sector (Foote et al., 2013) coupled with a decrease in the extent of other pastoral farming (i.e. beef and sheep production). During this period earnings from the dairy sector rose from $13 \%$ of total export revenue in 1990 to 25\% in 2012 (Statistics New Zealand, 2013) as cited by 
Foot et al., 2015). In January 2015 alone, New Zealand exports earned NZ\$3.7 billion, with dairy (including milk powder, butter and cheese) contributing NZ\$1.2 billion (Statistics New Zealand, 2015).

Between 2002 and 2012, the number of hectares allocated to dairy farming increased by $17 \%$ (Statistics New Zealand, 2004; 2013); the number of dairy cows increased by $19.4 \%$ with the milk collected increasing by $40 \%$ (Dairy New Zealand, 2013). The increase and intensification of dairy farming in New Zealand has driven increased dependence on irrigation, fertilisers and food supplements (Foote et al., 2015). Between 2002/03 and 2011/12, irrigated land increased from 457,700 ha to 721,400 ha (Corong et al., 2014), and between 1996 and 2012 fertiliser use (mainly urea-based products) increased by $360 \%$ (Foote et al., 2015), which goes some way to accounting for the increased carrying capacity and productivity of dairy farming in New Zealand during this period. However, questions are being raised about the impacts that this level and type of production is having on other ecosystem services (Foote et al., 2015).

\section{Erosion and sediment delivery}

New Zealand has particularly high rates of naturally occurring erosion due to it's "[s]teep slopes, high rates of tectonic activity and volcanism, generally high rainfall and common high-intensity rainstorms" (Basher, 2013, p. 363). However, deforestation and high levels of grazing have increased erosion (Basher, 2013). Estimates indicate that more that 200 million tonnes of soil is washed out to the sea annually, at an estimated cost of NZ\$159 million per annum in direct costs to the country (Jones et al., 2008). Two thirds of the 300,000 ha of New Zealand hill country classified as having "severe to extreme" risk of erosion, is in the North Island (Jones et al., 2008). Forested hillslopes experience just $10 \%$ of the landslides that occur on pasture based hillslopes (Dymond et al., 2005). In addition vegetated stream banks have 
been found to significantly reduce soil erosion into streams during flood events (Dymond et al., 2005).

\section{Land-use configuration in New Zealand}

In 2013, Ausseil et al. modelled ecosystem services (including carbon sequestration, soil erosion and agricultural production) at a national level to optimise overall service delivery. Ausseil et al. (2013) found that current landuse configuration in New Zealand may not be optimal and that there is significant scope to reconfigure the current land-use to achieve better outcomes across all services. Because land-use configuration is not optimal, "waterways are needlessly polluted, [and] stream flows [are] needlessly reduced ..." (Hertzig et al., 2013, p. 512) and increases in one service comes at the cost of decreasing provisioning by others (Ausseil et al., 2013).

Greater attention to the role of ecosystems, such as soil formation and the hydro-dynamics of catchments would help to inform optimal land-use, and improve both environmental sustainability (Aussiel et al., 2013) and the ongoing provisioning of vital ecosystem services, such as water regulation whilst maintaining other services such as production.

\section{Water quality}

By international standards (i.e. when compared with countries such as Asia, Europe, and North America) New Zealand's water quality is comparatively good (Davies-Colley, 2013). However, given the predominance of pastoral land-use, diffuse pollution is impacting on the visual clarity, turbidity, nutrient enrichment and faecal contamination, particularly during peak flow or storm events (Davies-Colley, 2013). The main issues for New Zealand water quality relate to phosphorous and nitrogen loading, sedimentation and faecal contamination (with associated human health impacts) (Davies-Colley, 2013). 
In 2011, the New Zealand Government approved the National Policy Statement for Freshwater Management (NPS-FW) (Ministry for the Environment, 2014). The NPS-FW was updated in 2014. This update provided a framework for fresh water management and the establishment of limits for the abstraction of water and discharges into waterways, to be managed by regional councils (Read, 2014).

\subsection{Facilitating environmentally sustainable land-use decisions}

This section of the Thesis focuses on the social aspect of environmental degradation. It will then consider a range of theories of pro-environmental behaviour and some of the tools, mechanisms and methods for facilitating pro-environmental behaviour. Opportunities for mixed methods approaches will be discussed and particular attention will be paid to the role of information and the diffusion of new technologies within a community to facilitate pro-environmental behaviour.

\subsubsection{The human equation}

There is growing recognition that environmental degradation is a social problem (Quinn and Burbach, 2002; Lokhorst et al., 2011; Mackenzie-Mohr, 2011; Stern 2000). Stern (2000) noted that we do not have a long history of taking environmental protection into account in decision-making.

Furthermore, Stern (2000) argues that historically, environmental degradation has been closely linked with human desires for "physical comfort, mobility, relief from labor, enjoyment, power, status, personal security, maintenance of tradition and family" (p. 408). Finding an optimum balance between meeting human needs and goals, and maintaining the ecological integrity of our environment will be key to ensuring the long-term survival of humanity (Roberts et al., 2015). 
Changing the attitudes and behaviours of land-owners, communities and governments towards their management of natural resources to acknowledge and respect ecological limits will require a shift away from the current prevailing economic growth paradigm (Goodland, 1995; Roberts et al., 2015) where the impacts of growth are not monitored nor taken into account (Goodland, 1995). Facilitating such a significant change in behaviour is both difficult and urgent (Goodland, 1995).

Given the social dimension of environmental degradation, there is growing recognition that both the social and ecological sciences are required to address it (de Snoo et al., 2013, Stern 2000, McKenzie-Mohr, 2000).

\subsubsection{The role of farmers in improved land-use sustainability}

Farmers and the agricultural industry will be key players in meeting increasing food demands. However they are also highly dependent on the ongoing provisioning of certain ecosystem services to sustain future agricultural production (Eppink, 2015). As a result of this close association, the decisions taken by farmers regarding resource and land-use are likely to have a disproportionately significant (positive or negative) impact on the condition of our natural capital (Lokhorst et al. 2011,; Quinn and Burbach, 2008).

However, Lokhorst et al. (2011), goes on to note that "[t]here is only a small body of research on farmers' attitudes and behaviors regarding nature conservation, and this research rarely makes use of social psychological insights or theories" (p. 338). Furthermore, given the predicted increase in agriculture required to feed the globe's increasing population (FAO, 2014), the wise use of natural resources will be key in balancing our increasing food needs against our environmental impacts. 


\subsection{Pro-environmental behaviour: tools, theories and mechanisms}

\section{Overview}

The following section provides a commentary on some of the tools, theories and mechanisms used to understand or facilitate pro-environmental behaviour. The analysis is not intended to assess their effectiveness in achieving environmental outcomes, but rather to explore the research as it relates to how they support pro-environmental behaviour.

\subsubsection{Decision-support tools}

There is an array of tools used to help understand, support and motivate proenvironmental behaviour. This section will consider some of these in further detail.

For the purposes of this research, pro-environmental behaviour is defined as

"behavior that consciously seeks to minimize the negative impact of one's actions on the natural and built world" (Kollmuss and Agyeman, 2002, p. 240).

\section{The use of subsidies to facilitate pro-environmental behaviour}

In 1984 the New Zealand Government removed its agricultural subsidies scheme (Macleod and Moller, 2006). However the New Zealand Government still offers a number of contestable funds into which farmers, landowners and community groups can bid to gain funding support for protecting biodiversity and ecosystems on private land (Department of Conservation, 2015). Environmental subsidy schemes are more heavily used in other parts of the world, particularly in European countries. As a result, there is a significant body of literature available on their use, application and implications for proenvironmental behaviour. 
The agro-environmental scheme operates in Europe. It uses financial incentives to facilitate the provision of specified environmental practices by farmers (Burton et al., 2008). It is considered in the following section in the context of the impacts and benefits of the scheme for pro-environmental behaviour.

The literature on the impact of environmental incentives on behaviour is varied (de Snoo et al., 2013). Kennedy (2010) noted that financial incentives can be useful in the motivation of new behaviours, particularly when the incentive and the target behaviour are closely paired. Furthermore, de Snoo et al. (2013) noted that "financial support will often be necessary to allow the farmer to take such measures and bear the loss in production that may result" (p. 69).

On the other hand, incentivised behaviours are predominantly driven by financial rewards, therefore that behaviour is dependent on the continuation of that incentive (Quinn and Burbach, 2008). Furthermore, in cases where a pro-environmental behaviour would have been performed without a financial incentive, introducing incentives can act to dis-incentivise personal motivation (de Snoo et al., 2013; Evans et al., 2012). Burton et al. (2008) also notes that because of the rules-based framework used for the agri-environmental scheme, there is little opportunity for the participants to show any "farming skill", or indeed to learn about good environmental practices. Evans et al. (2012) further notes that when an action is based on both self-interest, benefits and self-transcendent benefits, rather than resulting in a cumulative value to the participant as you might expect, they appear to cancel each other out with self-motivation or financial incentives trumping self-transcendent motivations.

In summary, while the literature recognises that there have been many positive environmental gains as a result of the agri-environmental schemes, 
there is little evidence that this has resulted in a change in either attitudes or behaviour (de Snoo et al., 2013; Burton et al., 2008).

\section{Mixed methods approaches}

There is a body of literature advocating for incorporating some of the components of behavioural change theory (refer section below), into the design of financial incentive schemes which has begun to emerge (Burton et al., 2008; Lockhurst et al., 2011; de Snoo et al., 2013). The literature notes that agri-environmental payments are linked to outputs and are prescriptive in how those outputs are achieved. Therefore, participant farmers do not have the ability to innovate, or engage with their peers on possible innovative solutions (Burton et al., 2008; de Snoo et al, 2013). Furthermore, Burton et al. (2008) notes that by moving from an output to an outcome-based scheme design, participants would have an opportunity to contribute to how those outcomes are achieved, building a body of knowledge, expertise and collective sector engagement in conservation management.

\section{Law and regulatory controls}

\section{Overview}

As stated previously, New Zealand is in the early stages of implementing a National Policy Statement for Freshwater Management. This new system provides the platform for the regulation of abstraction and discharges into waterways (Ministry for the Environment, 2014).

\section{Legislation and regulatory controls}

There are many examples in the literature of legislative or regulatory environmental schemes (controls). These schemes are predominantly designed on the basis that compliance is motivated by fear of punishment or some other form of negative repercussion (Burton et al, 2008; Kennedy, 2010; de Snoo et al, 2013). However, while legislation can take a long time to implement, its impacts can be inter-generational and it can result in the targeted behaviours becoming embedded in peer-groups helping to normalise 
the behaviour (de Snoo et al., 2013). On the other hand, ongoing rates of environmental degradation would indicate that regulatory schemes are not meeting their objectives in many cases, however removing regulation and relying on voluntary mechanisms alone is also unlikely to work (Burton et al., 2008).

So why does regulation work in some cases and not in others?

While environmental and legislative schemes generally rely on deterrents and enforcement (Kennedy, 2010), high levels of regulatory compliance are often associated with other motivations such as "trust and legitimacy" of both the regulations and regulators (Kennedy, 2010; Mackenzie-Mohr, 2011; Kollmus and Agyeman, 2002). Similarly, the positive recognition of others (Kennedy, 2010) particularly peers (de Snoo et al., 2013; May, 2004; Kennedy, 2010) is a further motivation for compliance. Finally, the ability to engage and influence the situation is an important factor in influencing compliance and proenvironmental behaviour (Kollmuss and Agyeman, 2002).

\section{Mixed methods approaches}

Kennedy (2010) notes that to be more effective, regulation needs to focus on individual behaviours. As such, recognition of the benefits of taking an approach that mixes both environmental regulation and behavioural methods, is growing (Quinn and Burbach, 2008; Kennedy, 2010; MackenzieMohr, 2011). Kennedy (2010) argues that compliance can be improved by targeting individual intrinsic motivations through "the use of norms and other behavioural tools and removal of barriers to sustainable activities" (p. 1142).

In summary, the literature indicates that there are opportunities to improve the efficacy of regulatory controls through leveraging off some of the behavioural methods available to facilitate behavioural change. 


\subsubsection{Tools and new technologies}

Tools and new technologies have an important role to play in facilitating behavioural change. There are a number of emergent tools that help to present information and options for management in a different manner that, if coupled with behavioural tools and methods may facilitate proenvironmental behaviour.

\section{Diffusion of new technologies and the importance of behavioural change}

Much of the literature on managing significant environmental issues, such as climate change mitigation, places significant faith in the development of new technologies to effect the changes required (Spence and Pidgeon, 2009). However, while new technologies are important, they are only part of the equation (Hekkert et al., 2007; Spence and Pidgeon, 2009). Steg and Vlek (2009) noted that for new technologies to succeed they need to be supported by diffusion through social systems and, of necessity, they will require a degree of behavioural change to affect any environmental benefits.

The emergence of a suite of GIS-based frameworks to support land-use decisions is a significant change in the technology available to date, and as a result, the inter-dependencies of ecosystems and their services within a catchment can now be mapped and looked at in a new way. Understanding the role that some of these tools can play in supporting pro-environmental behaviour is the key focus of this Thesis. The next section of this report will consider a range of frameworks available, and their strengths and weaknesses with a view to understanding how they might be strategically used, to facilitate and support pro-environmental behaviour. 


\section{Modelling ecosystem services trade-offs in the context of future scenarios}

\section{planning}

How can we sustainably manage our natural resources to ensure their ongoing, optimum provisioning, if fundamental knowledge about the complex interaction between humans and ecosystems is lacking, or beliefs about this interaction are incorrect?

Ecosystems and their services are complex and inter-dependent. The functioning of one system may have implications for the functioning of another ecosystem (Pollasky et al., 2010), and the provisioning of services can be dependent upon the collective function of multiple points across the system. In order to avoid unintended or sub-optimal outcomes, the system as a whole needs to be managed under "complex systems conditions" (de Groot et al., 2002). To date, the tools available to model ecosystem services have focused on one or two ecosystems services (Herzig et al., 2013) however, considering one or two services within the context of a broader ecosystem often comes at the expense of other related and inter-dependent ecosystems at that site (Aussiel et al., 2013).

Newly emerging GIS-based frameworks now allow for the mapping of several ecosystem services in a spatially explicit manner. These tools allow for the complex inter-dependencies within an ecological system to be mapped, based on best available knowledge (Jackson et al., 2013b; Turner II et al., 2007, Weeks et al., 2014). Furthermore, used effectively, these tools can provide options that optimise across a number of ecosystem services, helping to identify the optimum balance of environmentally sustainable resource use within a catchment, and supporting informed and transparent decisionmaking. 
Ecosystem-decision support tools and their relative strengths and weakness

In 2013, Bagstad et al. identified 17 tools specifically designed to assess the relative value of ecosystem services and noted that "[t]he majority of ecosystem service tools seek to quantify services and their trade-offs at a landscape scale in order to support scenario analysis using simplified underlying biophysical models" (p. 32) (note that scenario development is discussed in more detail in the following section of this report).

Of the 17 tools identified, seven used spatially explicit information and are in the public domain: ARIES, Co\$ting Nature, EcoServe, InVEST, LUCI, MIMES, and SoIVES. Of these seven, SoIVES is the only model that incorporates both cultural and economic valuation, while ARIES, InVEST and MIMES all incorporate economic valuation, in addition to non-monetary valuations (Bagstad et al., 2013). Increased complexity and outputs require increased and finer scale data, and time to generate scenarios. Therefore, balancing stakeholders need for the timely provision of accurate information with the levels of detail and complexity required will become a key element of designing scenario processes and considering the appropriate modelling tools to be used in a given situation (Sarkar et al., 2006).

While InVest, ARIES, MIMES and LUCI all allow for the generation of alternate management scenarios (Bagstad et al., 2013), LUCl is the only one of these models that is currently sufficiently streamlined to allow for scenarios to be modelled in near-real-time as part of a stakeholder negotiation process (Bagstad et al., 2013; Jackson et al., 2013b).

Of the six models that use spatially explicit frameworks, InVEST and ARIES appear to have had more field testing while for others testing is more limited (Bagstad, 2013). This is primarily due to their emergent nature (Bagstad et al., 2013, Jackson et al., 2013). In the New Zealand context MIMES and LUCI have been tested. In addition, a locally developed model LUMASS (Land-Use 
Management Support System) has also had some testing in the New Zealand context (Herzig et al, 2013). A further tool not considered in Bagstad et al's (2013) analysis is OVERSEER. OVERSEER is used extensively in the New Zealand context to calculate nutrient budgets (including nutrient inputs and outputs), at the farm scale (Read, 2014). While OVERSEER allows for the exploration of alternative management scenarios it only considers nutrient flows, and it only targets productive farming systems (including pastoral and cropping (fruit, vegetable and arable) farms) (Dunbier et al., 2013).

Each of these models has its niche (Bagstad et al., 2013), and of those that use GIS, most attempt to analise the ecological factors contributing to the provisioning of a varying numbers of ecosystem services. These studies use landscape dynamics to inform the exploration of how various factors impact on ecosystem service provisioning (Villa et al., 2009). LUCI falls into this category of tool. A few of the models attempt to identify and map the human beneficiaries of ecosystem service provisioning (ARIES and to a degree InVEST).

It is notable that there are a range of models available, and that they all have relative strengths and weaknesses. In his 2013 review Bagstad et al., focused on "use feasibility rather than specifically favoring one or more tools due to the diversity of decision contexts, user needs, ongoing evolution of tools and need for more comparative testing"(e.36).

In summary, appropriate modelling tools should be selected based on the question under consideration, the level of detail required, and the nature of the base data and technical expertise available (Vigerstol and Aukema, 2011). Consideration also needs to be given to the outputs required, i.e. whether scenarios and trade-off modelling is required. Ultimately, the model selected needs to take into account the target audience and stakeholder perceptions (Vigerstol and Aukema, 2011). 


\section{The role of scenarios in land-use planning}

\section{What is scenario planning?}

The benefits of using scenarios in land-use planning is two-fold. Firstly, it can help to consider a variety of future outcomes and to understand the route to achieving preferred outcomes through land management decision-making. Secondly, scenario generation uses a systems approach, allowing participants to better understand the trade-offs implicit in land management decisions (Peterson et al., 2001; Geneletti, 2007).

Future scenarios can help to establish long-term community priorities, test assumptions and help to reveal the costs, benefits or trade-offs of certain land-use decisions (Herzig et al., 2013).

Futures scenarios are also considered a useful process for community engagement, allowing communities to clarify: differences of opinion; the implications of some stakeholder assumptions at the systems, goals and proposed policy levels; the nature, type and scale of change required to reach a certain endpoint; and the implications and trade-offs associated with reaching proposed outcomes (Peterson et al., 2001; Hertzig et al., 2013).

Ultimately, while future scenarios-planning processes allow for a high level of uncertainty in how people and systems re-act and adapt to certain situations, they also seek to establish and make explicit certainties, assumptions and inter-dependencies, so that they can also be taken into account in decisionmaking (Geneletti, 2007).

\section{Mixed methods}

Many of the newly emergent GIS based frameworks have the capability for scenario generation, allowing for the exploration of various alternate management options and their relative trade-offs. Herzig et al. (2013) noted that "[u]sing computer tools that systematically consider a range of scenarios, 
objectives, constraints, and stakeholder or societal preferences helps decisionmakers gain insight into the full spectrum of feasible solutions"(p.520).

\subsubsection{Models for pro-environmental behaviour}

\section{Overview}

There are a large number of pro-environmental behaviour models that have been developed. This section of the review will discuss a selection of those models. It will then look more closely at the recurring issues of "information" and "perceived behavioural control", noting that both of these themes will be considered as part of the analysis and discussion sections of this report.

\section{Hierarchy of human needs}

In 1943, Abraham Maslow developed a hierarchy of human needs, to explain the drivers of human motivation. The premise that underpins this hierarchy is that humans are primarily driven to meet their own subsistence needs. As humans move up the hierarchy of needs their motivations change and it is only when all other needs have been met that humans will consider "transcendence" or "altruistic" behaviours. Historically, in applying Maslow's hierarchy, pro-environmental behaviour has been categorised as a "transcendent need". 


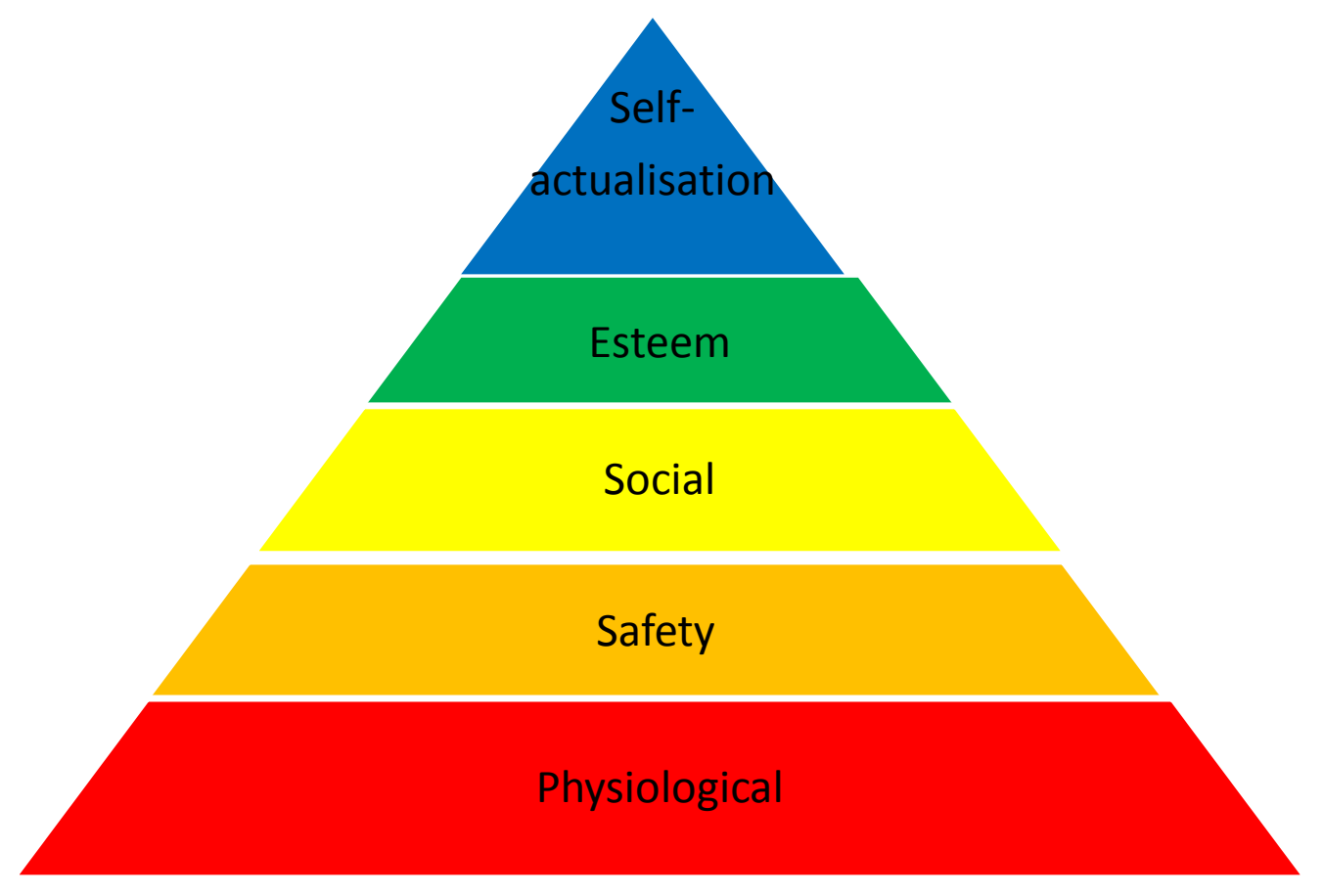

Figure 1: Maslow's hierarchy of human needs (Maslow, 1943)

\section{Limitations}

Since its publication in 1943, Maslow's hierarchy of human needs has received considerable criticism noting the lack of empirical evidence to support it. However it also continues to be widely used (Greenberg and Baron 2003, p. 195, as cited by Kaur, 2013).

\section{Rationalist models}

Behavioural change $=$ environmental knowledge + environmental attitude (Kollmuss and Agyeman, 2002).

This theory is based on the notion that understanding an issue or problem, coupled with a positive environmental attitude will be sufficient to drive proenvironmental behaviour. This theory is based on the premise that people are rational and that information and attitude are sufficient motivators of behaviour change (Kollmuss and Agyeman, 2002; Hargreaves, 2011). 
Limitations

Research indicates that environmental knowledge and environmental attitude alone will not drive pro-environmental behaviour, (Kollmuss and Agyeman, 2002; Quinn and Burbach, 2008) and that behaviour is not necessarily rational (Hargreaves, 2011).

Value-Belief-Norm (VBN) Theory

Behaviour Change $=$ ability to act + values + beliefs + personal norms (Stern, 2000)

A further breakdown of the component parts of VBN Theory includes:

- $\quad$ Value = biospheric, altruistic and egoistic values.

- $\quad$ Beliefs = ecological world view, perceived adverse consequences for valued objects, and perceived ability to be able to reduce threat to valued objects.

- Pro-environmental behaviour = classified into 4 categories: activism, non-activism - public sphere behaviours, private sphere behaviours and behaviours within an organisation (this relates to influencing decisions etc.).

The VBN Theory links together the Theory of Value, Norm Activation Theory and the New Environmental Paradigm (Figure 2 refers).

VBN Theory proposes that so long as a subject's ability to act (i.e. perceived behavioural control) is not constrained, that pro-environmental behaviour is the result of personal norms. Norms are activated when a subject perceives adverse consequences to an object that is of value to them, as a result of their behaviour. Effectively the subject takes responsibility for the consequences should they chose to behave in a certain way (Stern, 2000). 


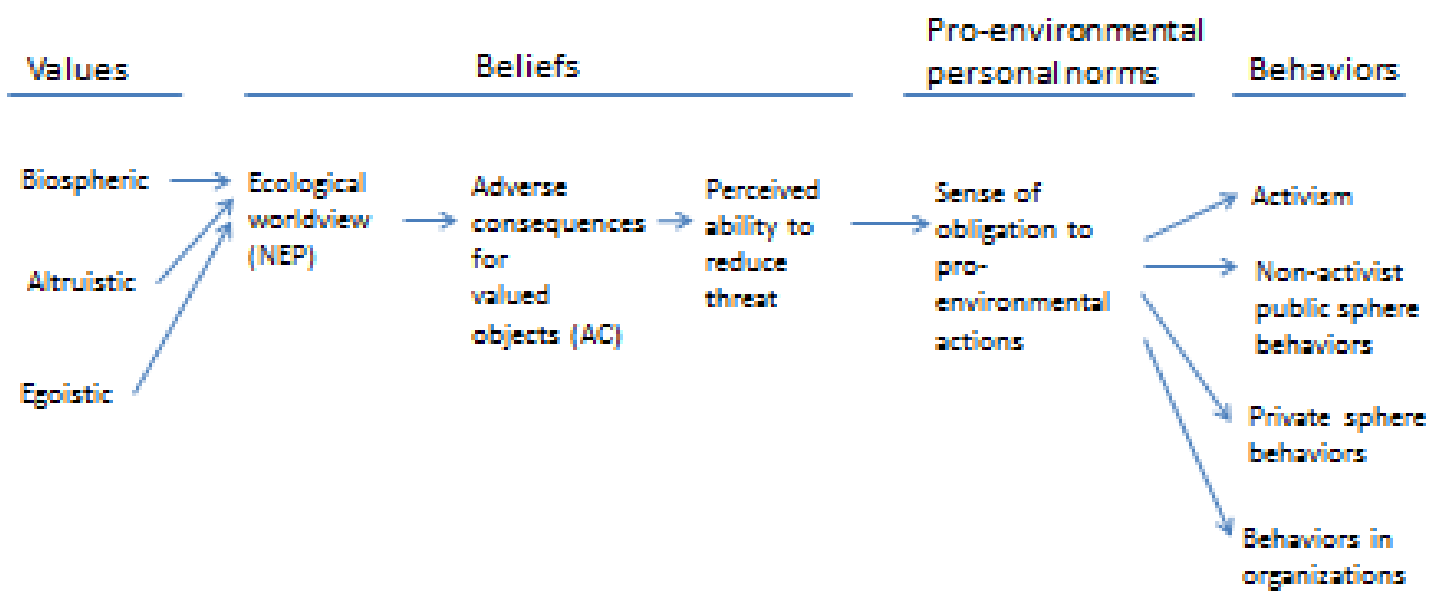

Figure 2: Stern's (2000) illustration of components of the Value-Belief-Norm (VBN) Theory

Steg and Vlek (2009) noted that VNB Theory appeared to apply well when actions were of low cost.

\section{Theory of Planned Behaviour (TPB)}

Behavioural change $=$ intention to act + attitude towards behaviour + social norms + perceived behavioural control (Ajzen, 1991)

The TPB is based on the premise that beliefs about the consequences of a behaviour, coupled with social pressure and the subject's ability to act (perceived behavioural control) will influence behaviour (Ajzen, 1991, Bamberg and Mosser, 2007). Attitude is seen to influence behaviour indirectly through behavioural intention (Bamberg and Mosser, 2007).

Chao (2012), citing Rivis and Sheeran (2003) noted that "TPB is one of the most influential theories regarding the prediction of reasoned behaviours" (p. 438).

Limitations

Chao (2012) notes that while TPB has been tested on many specific behaviours, it has rarely been used to examine group behaviours. Hardeman (2002) notes that while a useful Theory for predicting likely behaviour, TPB is 
not so useful for planning and designing a programme to facilitate behavioural change.

\section{Model of Responsible Environmental Behaviour (MREB)}

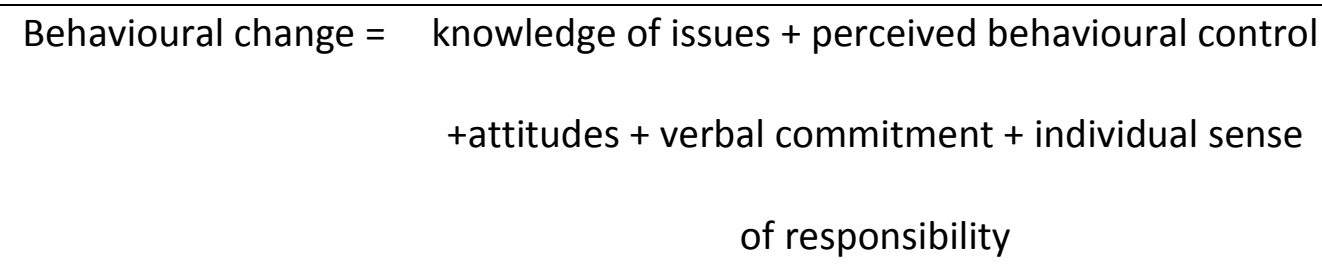

Context and situational factors (Hines et al., 1986)

This model is built on the premise that pro-environmental behaviour is a two stage process, the first is dependent on cognitive variables i.e. knowledge of both issues and action strategies, perceived behavioural control, attitudes and a sense of personal responsibility. The second stage takes into account context and situational factors and, depending on the impact of these factors, pro-environmental behaviour may result (Chao, 2012).

This model recognises the complexity of pro-environmental behaviour noting the feedback loops and barriers that become evident in the situational context.

\section{Limitations}

Kollumus and Agyeman (2002) argue that while all the components of MREB are pre-requisites to pro-environmental behaviour, they do not drive it. It was also noted that this model did not address external factors such as social pressures and opportunities to try different behaviours (Kollmuss and Agyeman, 2002). 


\section{Kollmuss and Agyeman model}

Based on the findings of historical theories such as early rationalist theories, altruism, empathy and pro-social behaviour theory, and sociological models, Kollmuss and Agyeman (2002) developed the following model (

Figure 3) to demonstrate the key attributes and barriers to pro-environmental behaviour, this was commonly referred to as the "environment, values, behaviours gap" (Prager, 2012).

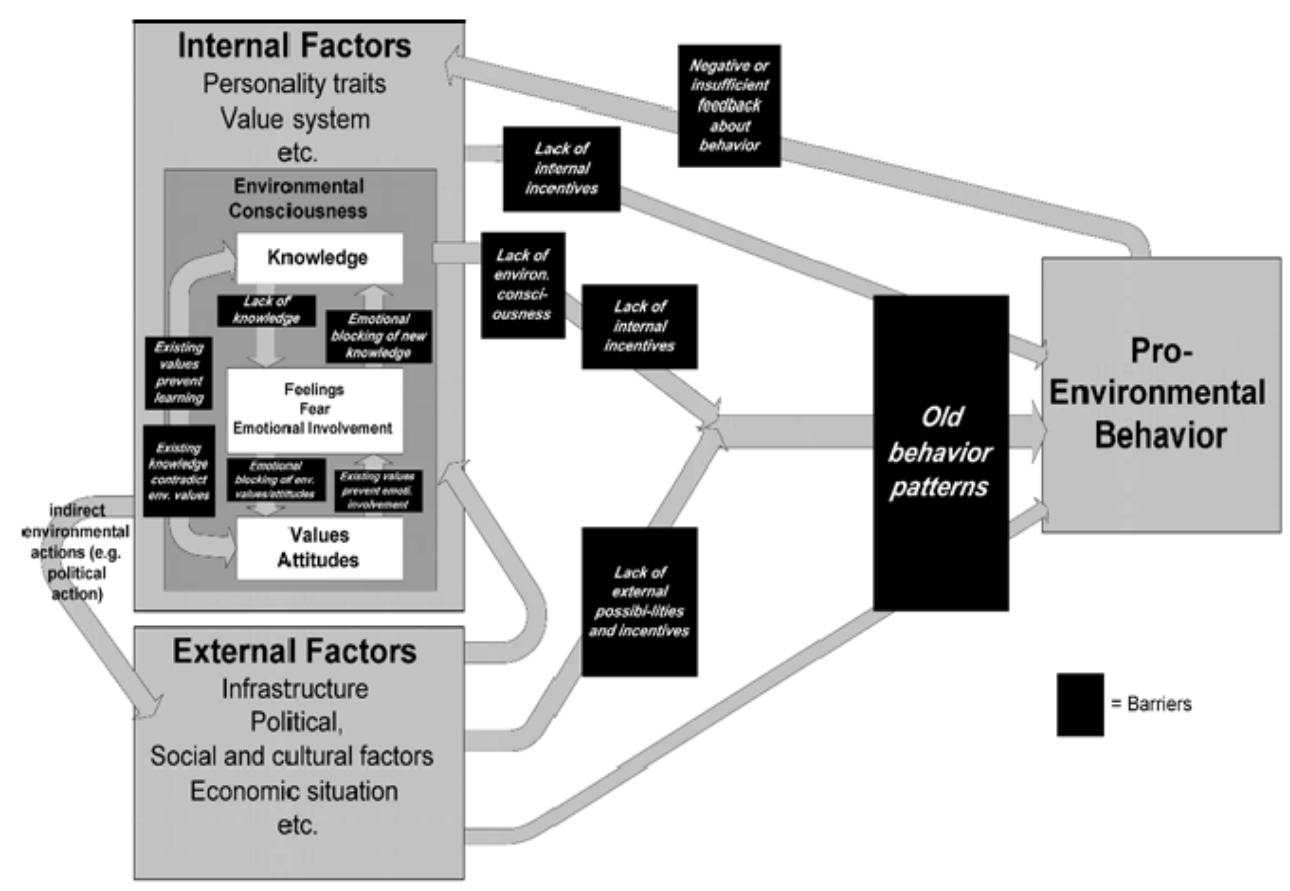

Figure 3: Theory of Pro-Environmental Behaviour (Kollmuss \& Agyeman, 2002)

The Kollmuss and Agyeman (2002) model focuses on the interaction between internal and external influences and barriers, and how these factors impact on pro-environmental behaviour (Gaspar, 2013) 
Limitations

Gaspar (2013) notes that while the Kollmuss and Agyeman (2002) model does take into account internal factors such as personality traits and value systems, it does not take into account internal factors that are unconscious inhibitors of pro-environmental behaviour.

\subsubsection{Methods to facilitate pro-environmental behaviour}

There are a number of methods that have been developed to facilitate proenvironmental behaviour (or behavioural change), building on the theories of pro-environmental behaviour. Some of these methods are discussed in greater detail below.

\section{Social Marketing}

Social marketing uses marketing concepts and techniques to facilitate specific pro-environmental behaviours (Kennedy, 2010; Andreasen, 1995). This method primarily uses information-based advertising to increase awareness of a specific issue, and to effectively sell the benefits of a specific attitude or behaviour (Mackenzie-Mohr, 2000). This technique leverages off robust market research and an in-depth understanding of behavioural patterns of the target audience (Kennedy, 2010).

\section{Limitations}

Early social marketing theories relied on the use of traditional marketing practices to influence consumer preferences, however this process tended to advocate for continued consumption, focusing on the consumption of more sustainable products (Mackenzie-Mohr, 2000). Kennedy (2010) noted that social marketing was often unable to breach the gap between awareness 
raising and actual behaviour change particularly when dealing with complex issues. On a similar vein, research suggests that the provision of information alone is unlikely to change behaviours (Kennedy, 2010; Mackenzie-Mohr, 2000; de Snoo et al., 2013; Kollumus and Agyeman, 2002, Frisk and Larson, 2011).

\section{Community-Based Social Marketing}

Proponents of Community-Based Social Marketing describe it as "a tightly structured program involving removal of barriers to change, attacking multiple drivers of environmental behavior through the use of behavior change tools, and doing so at the community level using direct personal contact" (Kennedy, 2010, p. 1142).

Mackenzie Mohr (2011) provides a stepped guide for the implementation of a Community-Based Social Marketing programme or campaign to change a specified behaviour. This process starts by identifying the behaviour for change and building a programme to minimise identified barriers. Interventions are personalised to both the individuals and the community concerned and leverage off their community norms and social structures to maximise social diffusion (Mackenzie Mohr, 2011; Kennedy, 2010).

The transcript analysis and discussion for this research will reflect heavily on Community-Based Social Marketing techniques as a means to effectively facilitate maximum social diffusion of information and new technologies within communities.

\section{Diffusion Theory}

The tenets of Diffusion Theory were initially discussed by Gabrielle Tarde, a French Sociologist in 1903. Tarde plotted the original diffusion (bell shaped) curve that is synonymous with Diffusion Theory (Towes, 2003 as cited by Kamanski, 2011). The adopter categories were introduced in 1943 by Ryland 
and Gross (Kamanski, 2011), Figure 4 refers. Diffusion Theory was later adopted and further developed by Rogers (Kamanski, 2011).

In essence, Diffusion Theory captures the social processes that occur when people and communities adopt a new innovation, practice, philosophy or idea (Kamanski, 2011).

Diffusion Theory proposes that in order for an innovation to be adopted by a community it needs to: have an advantage over existing technologies (i.e. performance and convenience); align with needs and social norms; be visible to potential adopters; and has the adopter put in the appropriate level of effort into the adoption process (Rogers, 2003).

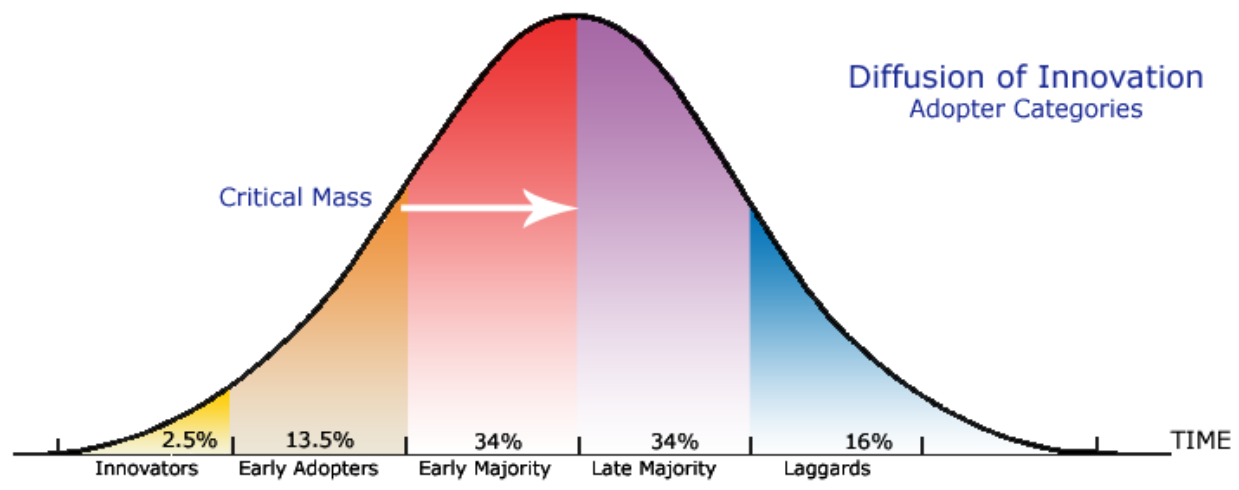

Figure 4: Theory of Innovation Diffusion distribution curve (Kamanski, 2011)

Rogers (2003) described the innovation-decision process as "an informationseeking and information-processing activity, where an individual is motivated to reduce uncertainty about the advantages and disadvantages of an innovation" (as cited by Sahin, 2006, p. 15). Rogers (2003) breaks this process down into five discrete stages as outlined in Error! Reference source not found.Figure 5 . 


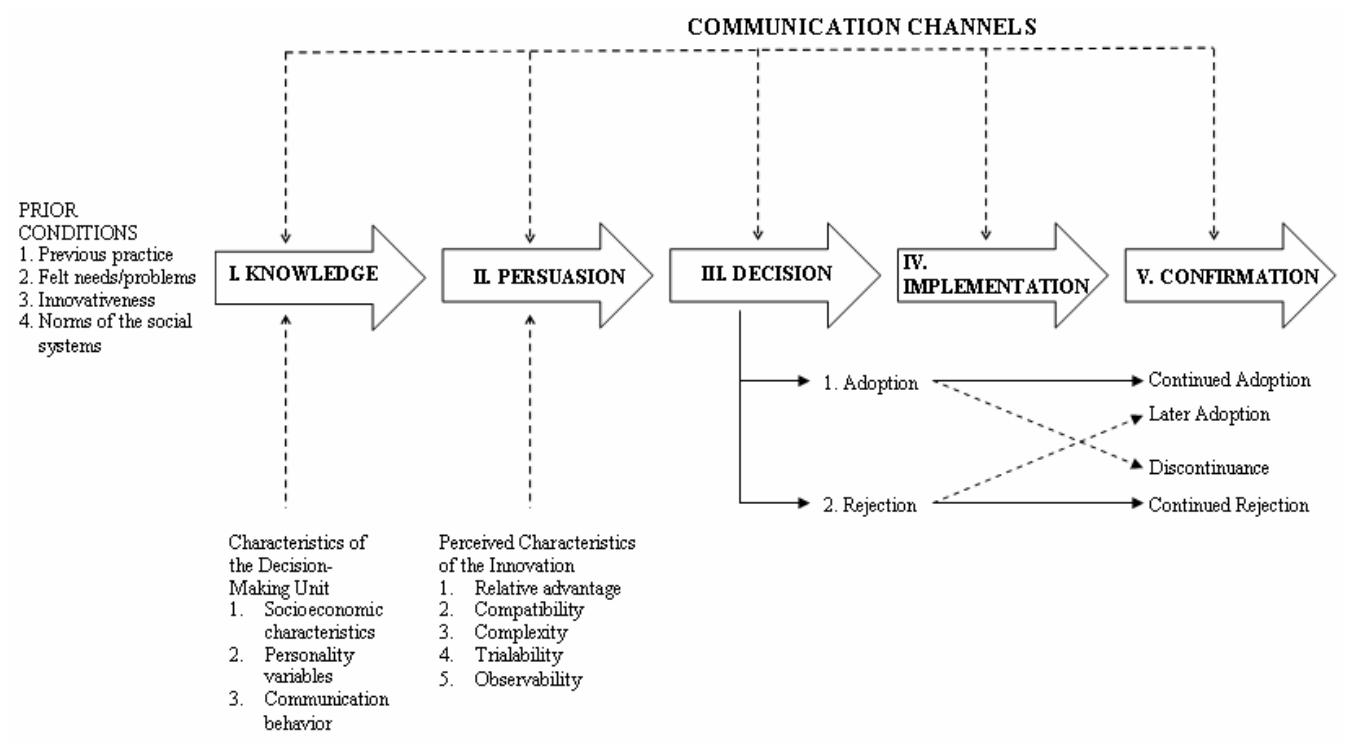

Figure 5: Diffusion Theory: model of five stages of decision-making (Rogers, 2003, as cited by Sahin, 2006, p.15)

Limitations

Fichman (1992) cautions that for Diffusion Theory to be most effective, the adoption process must include voluntary decision making and align with the classical diffusion context.

\subsubsection{Summary and discussion of theories and methods}

The literature discussed above indicates that information and/or proenvironmental attitudes are unlikely to drive pro-social behaviours (Kennedy, 2010; Mackenzie-Mohr, 2000; de Snoo et al., 2013; Kollumus and Agyeman, 2002; Frisk and Larson, 2011). However, the literature also indicates that unless tools such as incentives or regulations are used, both of these elements alone are often insufficient to drive for pro-environmental behaviour (Mackenzie-Mohr, 2000; de Snoo et al., 2013; Kollumus and Agyeman, 2002).

All of the theories and methods discussed identify a suite of (often) common attributes (i.e. perceived behavioural control and feeling responsible for the consequences of a behaviour) that make pro-environmental behaviour more likely. They also concur that there is a suite of context-dependent barriers 
that come into play, to varying degrees, depending on the circumstances (Mackenzie Mohr, 2011; Kennedy, 2010; Kollumus and Agyeman, 2002). Similarly, there appear to be a few common constraints to the theories and models. Notably they are all, to varying degrees, based on the premise that humans are rational decision-makers, and none of the theories and models outlined above take into account the role of institutional/regulatory and social constraints (refer section titled "Law and regulatory control"). There is however, some literature that explores the possibility of using proenvironmental behavioural theories to support the implementation of regulation, in order to facilitate attitudinal change during implementation (Kennedy, 2010; May, 2002; de Snoo et al., 2013; Burton et al., 2008; and Lokhurst et al., 2011), as discussed in the section above.

What can be taken from the literature outlined above is that there is no "one size fits all" theory (Kollumus and Agyeman, 2002; Frisk, and Larson, 2011), and that people behave differently in different circumstances (Frisk and Larson, 2011). Therefore, the theory adopted needs to be selected, based on the context of the situation and the attributes of the target audience. Community-Based Social Marketing recognises this issue and provides the process to allow for and cater to the individuals within a community (Mackenzie- Mohr, 2011).

Based on the above discussion, one could propose that all humans have an underlying suite of personal and individual values, but that these values are quickly trumped or influenced by other context specific factors, and that decisions are the result of the balance struck or weighting given to each of these factors at a particular moment in time.

For the purposes of this review no one theory of pro-environmental behaviour will be used, but rather it will work on the premise that there are a range of potential factors that may be at play, (such as cognitive bias, perceived 
behavioural control and learned helplessness). These factors and the weighting attributed to them in decision-making will be discussed.

\section{The role of information in informing pro-environmental decision-making}

The literature indicates that while the provision of information is a prerequisite for pro-environmental behaviour (an exception is where that behaviour is incentivised), alone, it is insufficient to drive pro-environmental behaviour (Kollmuss and Agyeman, 2002, Fisk and Larson, 2011; Kennedy, 2010; Mackenzie-Mohr, 2000; Stern, 2000). Furthermore, it is noted that when stakeholders are involved in negotiating or finding solutions to issues, they are more likely to accept those solutions (Botequilha-Leitlao and Ahern, 2002; Berkes, 2009). However, within the context of any given situation, there will be a suite of factors that when coupled with information, will dictate the degree to which recipients act upon that information. Some of these factors will serve to incentivise behaviour change while others will serve as barriers to the target behaviour (Mackenzie-Mohr, 2011). Every situation will differ depending on the context of, and suite of factors at play. In addition, there is the further question regarding how individuals will interpret that information, and what factors influence that interpretation.

The following section addresses some of the issues of information interpretation and perceived behavioural control (another recurring prerequisite factor) in more detail.

\section{Issues of control}

A common factor in many of the behavioural theories discussed relates to perceived behavioural control, or the ability to act. There has been a significant amount of research on this issue in the context of global climate change. Mackenzie-Mohr (2011) argues that presenting information that is threatening or arouses fear can result in disengagement if it is not coupled 
with the ability of the individual, or the community as a collective, to effect some change.

Indeed for many of the pro-environmental theories the ability to act is a prerequisite factor without which all other influencing factors are nullified.

Theory of Cognitive Dissonance

In 1957, Festinger developed the Theory of Cognitive Dissonance. This Theory proposes that we become uncomfortable when information threatens our pre-existing mental frameworks, assumptions and values (Festinger, 1957; Kollimus and Agyeman, 2002). In order to reduce cognitive dissonance, information that contradicts existing views is often avoided, resisted or discredited, this is known as assimilation bias (Kobayashi, 2016). Furthermore, we tend to seek out information that supports existing values and views which is known as confirmation bias (Lord and Taylor, 2009).

\section{The theories of Learned Helplessness and Learned Hopefulness}

In 1967, Seligman and Maier found that uncontrollable adverse events can have a cognitive impact on the subjects' ability to act resulting in anxiety, depression and lack of motivation (Zimmerman, 1990). They also found that uncontrollable adverse events had a far greater impact on subjects than controllable adverse events (Maier and Seligman 1976). This research formed the basis of the "Learned Helplessness Theory". Zimmerman (1990) notes the wealth of literature that explores the concept of learned helplessness and the "psychological deficits that result from a perceived lack of control" (p. 71).

Building on the Theory of Learned Helplessness, Zimmerman (1990) proposed a Theory of Learned Hopefulness, based on the notion that empowering experiences that entail the learning of new skills help to develop a sense of control and can have a positive impact on peoples' ability to deal with subsequent adverse situations. This aligns with Burton et al's (2008) findings 
that providing farmers with the ability to develop and display their skills and knowledge contributes to their social standing within their community, thereby building social capital.

\section{Using GIS based modelling frameworks to convey information and facilitate behavioural change}

Some of the newly emergent GIS based tools have the potential to convey complex issues in a more accessible manner. They also allow for the information conveyed to be targeted to the needs of an individual and presented in a visually explicit and interactive manner. Understanding the role of these tools in informing decision-making and how they can be used in conjunction with other tools, methods and theories to influence land-use choices will be important in informing how these tools can best be used in practice. Issues such as perceived credibility, legitimacy and accessibility need to be tested as all of these factors are a pre-requisite to engaging in the information provided. Issues such as whether cognitive dissonance plays a part in credibility and legitimacy will also be an interesting factor to explore.

LUCl is a useful tool to test as it was developed for inter-active use in a stakeholder setting (Bagstad et al., 2013; Jackson et al., 2013b). It was designed to be flexible, accessible and simple (Bagstad et al., 2013; Jackson et al., 2013b) in order to breakdown some of the known barriers to understanding the complex dynamics at play within and between ecosystems. Clarity as to whether these barriers have indeed been overcome and whether other greater barriers remain will help policy and decision-makers understand how best to use these tools and whether other additional support mechanisms need to be developed to facilitate pro-environmental choices.

Therefore, the aim of this research is to establish the degree to which presenting information on land-use trade-offs through a framework such as LUCI will impact on future land-use decisions by property owners at the farm 
scale. This is assessed through analysis of a suite of five research questions.

\section{Overarching Research Questions}

1. Is the information presented through $\mathrm{LUCl}$ accessible and compelling?

2. Is the information presented through $\mathrm{LUCl}$ perceived to be credible and robust?

3. How is the information provided through LUCI being interpreted?

4. Are there barriers between information exchange through the modelling process, and the application of that information in land use decisions, if so what are these?

5. How effective is presenting information through modelling processes such as LUCI in influencing environmentally sustainable land-use decisions?

\subsubsection{Key aspects of the theories and methods to be explored further through the research findings analysis}

This research specifically considers how and why the participants interpreted and perceived the information provided in a certain way. Issues such as cognitive dissonance, confirmation and assimilation bias, perceived behavioural control, temporal events and social norms are all explored with a view to better understanding what factors may be influencing the participant's interpretation of the LUCl outputs.

Furthermore, consideration is also given to the role of participants within their communities, the implications of their status as early adopters (e.g. the attitudes of community leaders may influence how readily new opinions are formed by others) and how their "earlier adopter" characteristics influence 
the interpretation of information. Issues such as the diffusion of information through communities and social systems are also discussed, along with the role of early adopters in conveying such information. Finally, participants' opinions on the likely uptake of the information within their communities are also explored. 


\section{Methodology and research design}

\subsection{Overview}

The following section will provide an overview of the overarching methodologies used for this research and why they were selected. It will summarise the methods used to collect, analyse and interpret the research data and provide the details of the ethics approval granted for this research.

\subsection{Epistemology and methodology}

The emergence of a number of GIS based frameworks to support land-use decisions is a significant change in the technology available to date, and as a result the inter-dependencies of ecosystems and their services within a catchment can now be mapped and looked at in a new way. This research seeks to understand how information is interpreted when presented through these new technologies (GIS frameworks). It is important to note that this research does not propose testing $\mathrm{LUCl}$ as a tool, but rather, will focus on: how a defined sector of the farming community interprets and responds to the information provided by LUCl and what meanings they derive from that information. A qualitative approach will allow for a more in-depth analysis (Leavy, 1994) of the participants experiences when engaging with the information derived from LUCl. As the transfer of information through GIS frameworks such as LUCI is novel, and there are no existing theories to test this (Leavy, 1994; Richards, 2013), a qualitative approach is more appropriate. A qualitative approach allows for the "close-in" examination of social phenomena (Leavy, 1994) which in this case aligns with the aims of this research.

In order to select an appropriate methodology for this research, a short-list of five methodologies were considered including: Ethnography, Grounded Theory, Phenomenology, Discourse Analysis, and Case Studies. When 
considered alongside the aims of this research Ethnography was quickly eliminated because the nature of the data collected through ethnographic techniques did not match well with the aims of the research. Similarly Discourse Analysis was considered and rejected as it was difficult to see how this type of data collection and analysis could be used to inform the research questions. Grounded Theory, Interpretive Phenomenology and the Case Study approaches were all considered more closely.

Richards and Morse (2013) argue that "[t]he explicit Goal of Grounded Theory studies is to develop theory. So reports will feature theory that is limited and local - Theory derived from, and grounded in the data" (p. 64). Grounded Theory attempts to explore a concept through the stages, phases and process emerging from the data, (Richards and Morse, 2013) resulting in a theory encapsulating " a set of concepts that are related to one another as a cohesive whole" (Sbaraini et al., 2011, p.3). Because the aim of this research is purely to understand the meaning that the participants derived from the information, creating a theory was not considered the primary objective, though one that this researcher would happily pursue should it emerge. However, making the development of a new theory the primary objective of the research could fundamentally change the nature of the questions and the aim of the research. For this reason Grounded Theory was effectively parked, but not rejected.

When considering Interpretive Phenomenology, with its intent to discover the meaning that people derive from events or phenomena, there was a close alignment with the aim of the research. Phenomenology is both a philosophy and methodology. Originally the phenomenological heuristic was derived from the work of Husserl who argued that the individual's "lifeworld" was the result of their experiences before any interpretation (Dowling, 2007). Shultz, one of the scientists instrumental in the development of the Phenomenology methodology noted that our reality is based on what aspects of reality we 
decide to interpret and how we decide to interpret them (Turner, 2009). So, in effect, two people can be subject to the same event and have a completely different experience, based on what they decided to interpret and how they interpreted it. For this research I wanted to know what my participants were seeing when they considered the LUCl outputs and what they then did with that information (i.e. how they interpreted it, or not) and why. In addition, given that the nature of the $\mathrm{LUCl}$ outputs are so novel, they would require some interpretation from the researcher. Therefore, the methodology selected would need to acknowledge, allow for and recognise the multiple roles of the researcher in the research process in: presenting and interpreting the information for the participants, data gathering, and interpreting and analysing the research results. Larkin et al. (2006) noted the use of this layered interpretation in phenomenology research, whereby an event is interpreted by the participant which is then interpreted again by the researcher. Interpretive Phenomenology allows for and recognises the interactive role of the researcher through a process of bracketing which will be referred to in more detail in the section titled "Administrative processes".

The processes that the Interpretive Phenomenological Analysis (IPA) uses for data gathering (open-ended interviews, and a range of related information sources including the researchers own experiences) and analysis (primarily thematic) aligned well with the aims of this research.

Using a Case Study approach was also considered, case studies are often clearly defined and used to understand a social structure or process (Richards and Morse, 2013). While elements of this approach were useful for this research the data collection and analysis techniques did not focus on the generation of meaning, as was the case with Interpretive Phenomenology. However, social and situational aspects of engaging in the research and its outputs were of interest and in the case of this research, were used in conjunction with Interpretive Phenomenology. 
In summary, this research will use an Interpretive Phenomenological approach coupled with Case Study and Interpretive Phenomenological methods to conduct inductive qualitative research into how the research participants interpreted information derived from LUCl.

\subsection{Research design}

\subsubsection{Scope of the research}

This research used $\mathrm{LUCl}$ to demonstrate the benefits and implications of different land-use options to a small sample of land owners within a catchment in an interactive and visually explicit manner. Current state and future scenarios were generated and presented. The scenarios modelled sought to: (a) incentivise environmentally sustainable resource management, (b) find an optimal balance between a range of ecosystem services on the participants property (including both provisioning and regulation services), (c) provide the decision-maker with a level of control in the generation of the information by using interactive processes to develop the base information, and (d) provide complex information through compelling visual and accessible scenarios.

A semi-structured interview process was then used to collect data on how participants interpreted and responded to that information. This was coupled with a baseline interview undertaken at the outset of the process to enable the measurement of changing perceptions.

Analysis was undertaken using a thematic approach coupled with more targeted analysis focusing on addressing the research questions (Richards and Morse, 2013). 


\subsubsection{Nature of the research}

\section{Site selection criteria and catchment boundaries}

The Ruamahanga catchment was selected for this research based on the following criteria:

- the catchment reflects a combination of different land-uses

- data availability

- access to regional council information and landowner networks

- proximity to Wellington

Catchments in the Waikato and the East Coast were also considered as possible alternate study sites. However none of these sites met all of the afore-mentioned selection criteria. Therefore these sites were rejected in favour of the Ruamahanga catchment (specifically the Wairarapa Moana subcatchment) which met the selection criteria above.

\section{Criteria for selection of research participants}

Participants were selected based on the following criteria:

- landowners with properties $>50$ ha

- landowners showing a willingness to support and engage in this research

- "early adopters" (Rogers, 2003), based on the information provided by the Greater Wellington Regional Council.

\section{Participant selection - explanation}

Landowners with properties $>50$ ha were selected in order to target participants whose livelihoods were derived primarily from that property.

Ten potential participants were selected by Greater Wellington Regional Council staff based on Rogers (2003) definition for "early adopters" (refer next paragraph). This selection was informed by their regular engagement with the Wairarapa Moana farming community. Participants were reduced to 5 
based on a range of factors including: the time commitment to engage in the research; and catchment boundaries (e.g. only those participants with properties entirely within the Wairarapa Moana catchment were used).

An early adopter is defined as a person who is:

“...respected by his or her peers, and is the embodiment of successful and discrete use of new ideas.... the early adopter knows that to continue to earn this esteem of colleagues and to maintain a central position in the communication structure of the system, he or she must make judicious innovation decisions" (Rogers, 2003, p. 283).

\section{The use of case studies with a small sample targeting early adopters}

This research used a case study approach and a small sample of participants due to the high degree of engagement required by both the researcher and the participants. The sample originally included six landowners selected on the basis of the aforementioned criteria; however the drought during the summer of 2014/15 impacted on one participants' ability to commit the necessary time to engage in the research field work. He therefore withdrew, noting that he would like to continue with modelling his property at a later date.

Note that this sample was not intended to be representative of the views held by the Ruamahanga farming community in general, but rather targeted "early adopters" (Rogers, 2003) within that community. It is acknowledged that by targeting this group, an inherent bias has been built into the results. However by focusing on early adopters, the research will achieve a better and deeper understanding (Larkin et al., 2006) of how the information provided through the modelled scenarios will be interpreted by "early adopters" within the community. The hypothesis is that if early adopters from within the farming 
community do not find the tool useful or credible, there is a low likelihood that members of the broader farming community will find it useful or credible.

The literature indicates that the use of case studies with small samples can be particularly useful where:

- the research brings together two disparate fields of knowledge for the first time (Leavy, 1994,)

- the researcher is seeking to establish key themes and patterns from within the data (Rapley, 2011).

Given this research complies with both of these factors, it appears to be ideally placed to use a case study approach with a small sample of participants.

Furthermore, time constraints and the unique nature of the phenomenon to be presented (i.e. information that was confidential to the individual participants), favoured a method that would target a smaller sample and allow for a deeper analysis of the research results (Leavy, 1994; Larkin et al., 2006). In addition, as the research aimed to understand how the research participants interpreted the information, a small sample coupled with indepth analysis aligned well with it.

\subsection{Method: data collection}

The data collection for this process was undertaken through three field visits, data analysis was undertaken through a related but separate process that followed these field visits. The process for the presentation of the LUCI outputs and collection of the data is outlined in Figure 6 and is discussed in more detail in the following section. 


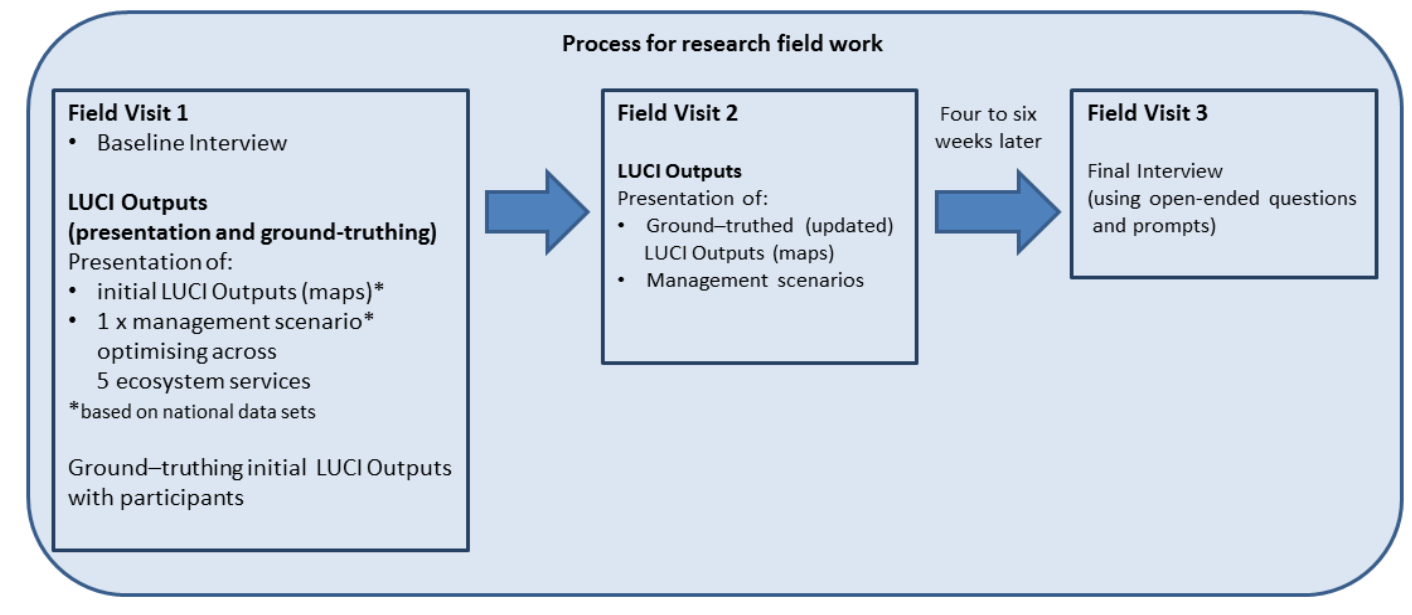

Figure 6: Data collection process

\subsubsection{Field Visit 1: data collection and presentation of the phenomenon}

\section{Baseline interview}

An initial baseline interview was conducted with participants at the beginning of the first field visit. This interview included a suite of five open-ended questions coupled with a series of prompts. Please refer to Appendix A for the schedule of questions and prompts used.

\section{Presentation of baseline maps generated through LUCI}

After an initial baseline interview had been undertaken, participants were presented with baseline maps of their properties (and watersheds). These maps were generated using LUCI version 0.2 , and presented spatially explicit information based on national datasets for: soils, land-use, streams and rivers, hydrology, and topography. LUCl outputs addressed: nutrient loading (nitrogen and phosphorous), sediment delivery, flood accumulation and agricultural production. This information was ground-truthed with the participants in an interactive manner to include elements of local knowledge, changes that may have occurred since the national datasets where produced, and any inconsistencies identified. 


\section{Presentation of scenarios}

In addition, the researcher prepared an optimising scenario, building on the initial baseline maps. While recognising the accuracy limitations of these baseline maps, this scenario was presented to participants to illustrate how alternate land management options could be explored using the $\mathrm{LUCl}$ scenarios generation tool.

\subsubsection{Field visit 2: Presentation of the phenomenon}

\section{Presentation of ground-truthed baseline maps}

Once the accuracy of the baseline maps were improved as much as possible based on participant feedback (referred to in this research as "groundtruthing") further scenarios were prepared and presented to landowners via maps. The scenarios generated for this stage of the research, sought to establish the impact of land-use change on the ecosystem services under consideration. The primary objective of these scenarios was to look for small scale interventions with broad-scale benefits across a range of ecosystem services. Management interventions proposed included targeted vegetation planting and the (re)establishment of wetlands. Participants were also invited to propose possible alternate land-use scenarios including land management options that they might be considering. Baseline maps and scenarios were presented as single service and trade-off maps.

Finally, where possible and based on participant interest, a simple real-time scenario was run to demonstrate the application of the tool in a real-time setting. 


\subsubsection{Field visit 3: Data collection}

\section{Final interview}

Four to six weeks after the completion of the modelling component of this research, final interviews were conducted with the research participants. The interview data collection was undertaken in two stages and based on an Interpretative Phenomenological Approach (IPA) (Larkin et al., 2006).

1. The interviews employed a series of open questions with the interviewer actively engaged in the interview process (Richards and Morse, 2013) to facilitate discussion. The interview questions sought to initiate discussions that would inform the overarching research questions.

In addition, interviewer notes were kept on post interview reflections, context and timing of the interview, and events taking place in the immediate environment.

2. All field visits and interviews were recorded and transcribed. At the end of the field work, a full package of transcripts and maps were provided to participants for a four week period so that they could check and make any necessary amendments or remove any material from the package.

\subsection{Data analysis}

The data analysis was undertaken in two stages and based on IPA (Richards, 2013, Larkin, 2006).

1. The field visit transcripts were coded using NVivo $10^{2}$, and analysed for recurring themes and sub-themes (Richards and Morse, 2013). Firstly,

\footnotetext{
${ }^{2}$ NVivo 10 is a computer software tool designed to support qualitative research analysis, (QSR International, 2014). It was used during the transcript analysis phase of this research.
} 
analysis of individual participants' transcripts was undertaken, followed by analysis of the transcripts in the collective. Methods used for the analysis of the transcripts included: word analysis, matrix analysis and an theme/text analysis. During this process themes and sub-themes were identified and mapped to aid a better understanding of the overarching story emerging from the data. In taking an "interpretative phenomenological approach" to data analysis "we are interested in how they [the participants] understand and make sense of their experiences in terms of their relatedness to, and their engagement with, those phenomena" (Larkin et al., 2006, p. 109).

2. In addition, coding was undertaken to help address the research questions (Richards and Morse, 2013). A key focus of the transcript analysis was to identify any inherent contradictions and anchor points in the data, ensuring that they were not lost in the data aggregation. Anchor points are points in the narratives, or words within the transcripts to which the participants regularly return. They often act as theme markers within the context of the analysis.

\subsubsection{Other techniques considered}

Consideration was given to the use of surveys and focus groups to generate the data on how participants assessed the information in the $\mathrm{LUCl}$ outputs. However, due to the high levels of engagement required for the development (including ground-truthing) of the $\mathrm{LUCl}$ outputs and the nature of the information provided through baseline and scenario modelling, it was felt that a small sample case study approach would be more practical and allow for individual engagement with each of the participants. One-on-one interviews allowed for a degree of confidentiality regarding the information included in the outputs and collecting the data via survey methods would not have 
provided the depth of information that was achieved through a small number of focused interviews (Larkin et al., 2006).

\subsubsection{Data checking}

The data used in the final maps was subject to an extensive process of ground-truthing with the participants to ensure that final scenarios generated were based on sound and accurate baseline information.

All transcripts and maps were provided to participants at the end of the field work component of the research. Participants were given four weeks to advise of any changes, amendments, inaccuracies or material to be removed from the research.

\subsection{Administrative processes}

\subsubsection{Ethics approval}

Ethics approval was granted on 8 December 2013 (application No: 20206 refers). Due to the extended period taken to complete the fieldwork for the research, amendments to the ethics approval were granted on 20 March 2014, 25 June 2014 and on 16 April 2015, (Appendix B.i, refers). These amendments changed the timeframes associated with participant feedback on the field work package. (Refer to Appendix B.ii, and B.iii for the participant information sheet and participant research consent form).

\section{Maintaining participant anonymity}

It was noted in the ethics application that participant anonymity could not be guaranteed, particularly given the extensive use of maps of participant properties as part of this research. However, the researcher undertook to 
make every effort to retain confidentiality. To this end the following steps have been taken:

1. All participants have been given a letter identifier ranging from $A-F$.

2. All participant properties have been given an identifier number, that does not correlate with the letters i.e. Participant A's property is not Property 1.

3. While participants in this research included a mix of males and females, all have been referred to in the masculine in the Thesis.

4. When presenting maps to illustrate a point in this Thesis, where possible watersheds have been used, rather than property boundaries, except where it is necessary to show a map that was presented to the participants. Finally all aerial photography used as a backdrop for the maps have been removed and all site identifiers i.e. homesteads, roads etc. have also been removed from the maps.

\subsubsection{Management of the researcher in the process}

IPA recognises that in undertaking a research project, the researcher will have an active role in the generation and interpretation of the data (Larkin et al., 2006). Acknowledging the researchers pre-determined views is called "bracketing" and involves a process of actively declaring any pre-determined views so that they are fully disclosed and "put to one side" (Dowling, 2007, p. 136), or made overt so that the researcher can approach the data with "fresh eyes" and an inductive approach (Richards and Morse, 2013, p. 218). It is noted that despite the process of bracketing, the researcher is still required to try and reveal the experience of the participant as accurately as possible. However, IPA does acknowledge that the researcher brings their own perceptions and inherent views into the research (Larkin et al., 2006). 


\section{Researcher: full disclosure/positioning}

When undertaking qualitative research it is important for the researcher to consider their own biases and positionality and what influence it may have had over the research process and outcomes. Okely (1998) as cited by Jarviluoma et al (2003) notes "in the context of her study [that] posture refers to the researchers way of situating herself/himself in her/his life experience and situation, style and language in concrete field work situations, as well as in writing"(p. 29).

\section{$\underline{\text { Researcher positionality statement }}$}

I have approached this research assuming that all New Zealanders have a common goal of keeping nutrients on the land, and out of our waterways. The reasons for this common goal may vary among and between community demographics and regions, but it is nonetheless a shared vision. This position has influenced the way that I have approached this research, particularly the field work/participant engagement components of the process. Indeed this position was stated to participants early in the field work process, as a way of creating a common ideal between researcher and participants. This almost certainly will have influenced or framed participant engagement, and it helped to quickly move the conversation between researcher and participant from a potentially adversarial discourse to one of a shared problem solving discourse with most participants.

\section{Researchers background}

My background is in conservation having worked for the Department of Conservation for 15 years or more. My roles have ranged from Strategic and Operational Policy, Treaty Negotiations through to International Negotiations. I have undertaken this research in a part-time capacity whilst working fulltime as a Technical Advisor within the Departments of Conservation's Science and Capability Team. My current position is focused on developing the evidence to understand the broader societal benefits provided by the ecosystems that 
are managed by the Department of Conservation. While the Department has supported my research through the allocation of some study time and contributed towards fees, they have not influenced the topic of research nor the research process itself. Both supervisors for this research were external to the Department of Conservation.

While I have come to this research with a strong conservation ethic, like many New Zealanders, I also eat meat, drink milk and enjoy a high standard of living in what is a developed and prosperous country. Similarly, I have watched the issues of increasing agricultural intensification coupled with increased economic development unfold, alongside increasing concerns about water quality and quantity and impacts on our natural systems.

A key factor to note is that I have a strongly held belief that we are more likely to be able to find a sustainable future working with individual farmers that live and raise their families on the land, than with corporate farms with a business agenda. This research should be considered with this in mind.

There is little doubt that my background working for the Department of Conservation influenced the way that participants engaged with me, despite my research being independent of the department. It will also have influenced the way that I engaged in the research process and indeed my selection of a research topic. Having recognized this early in the process, my conservation background was declared to all participants on their initial field visit, and I went to great lengths not to hold pre-conceived ideas about the research outcomes.

It is fair to say that the research journey that I have taken is not the journey that I had anticipated at its outset. In trying to stay true to my participants and the research process I have had to question my own views and role in this active debate. I have tried to understand the participant's perspectives, the 
inconsistencies in their discourse, and to dig beneath the surface to understand not just what they said, but also why they said it and what they meant. Similarly, I have tried to understand my own biases in order to be able to detect whether and to what degree they were influencing my analysis of the issues arising through the process.

\section{Issues of gender}

Jarviluoma (2003) note that "[o]nly by becoming conscious of his/her gender position is the researcher able to create some distance from the gender perspective from which he/she makes the interpretations" (p. 22)

As stated previously, four of the five research participants were male, and all participants were of European decent. The researchers gender being female and also of European decent will have effected how all participants, both male and female engaged in the research and with the researcher, and how I as researcher engaged with the participants. My decision to take a nonconfrontational approach to the research may have been influenced in part by my gender but also by the fact that engagement in the research process was by mutual consent, and that causing discomfort amongst participants (particularly early in the process) would have been counterproductive to that process. Nonetheless information that was uncomfortable to some participants was presented, but only once a non-threatening relationship had been established.

Implications of researcher positionality for the research finding As stated above I am an academic, a townie (with a background in conservation), a mature female student and a mother. This coupled with the multi-dimensional approach used in this research, must have made both the research and I, an anomaly for many of the participants. These factors will have had implications for their responses and how they engaged in the research. The participants all responded differently to the situation, some 
used the process as an opportunity to voice their concerns about equity of the current public discourse on water quality and farming practices, others found it more threatening and remained more cautious.

I like to believe that by the end of the process, a reasonably high level of trust had been developed between the participants and I (the researcher), and that while engagement in the research had taken precious time, the participants' seemed comfortable with the contributions they had made and the material and information they had received from the process. It is notable that none of the transcripts were altered or withdrawn when returned to participants for checking, indicating a level of trust that I would do the right thing with their words.

A secondary consideration however, is whether the participants trust in the researcher and research process constrained my analysis or findings. I hope not. I was surprised to find just how protective I became of my participants, protecting their anonymity, their right to speak clearly and honestly about their world and the current tensions within that world. I hope that the honesty, trust and courage demonstrated by the participants helps to bridge some of the divide that has occurred between academics, townies and farming folk. Furthermore, I hope that I have been able to find a balance between both worlds. I firmly believe that it is only when we bring these worlds together and operate as an integrated whole that we will break down the current divide and truly move forward on the issue of sustainable land management. 


\subsection{The Participants and study site}

\section{Overview}

The following section will provide information about the study site and participants involved in this research. In effect, the purpose of this section is to set the scene, prior to consideration of the findings and analysis, outlined in the following section.

\subsubsection{Study site}

This section will cover the physical attributes of the Ruamahanga catchment generally as the broader context for this research. It will also consider the eastern shores of Lake Waiarapa in more detail as the study site for this research.

The Ruamahanga catchment is in the lower North Island of New Zealand (Figure refers). The catchment comprises approximately $3,500 \mathrm{~km}^{2}$ and extends from Mt Bruce in the north to Lake Onoke in the south.

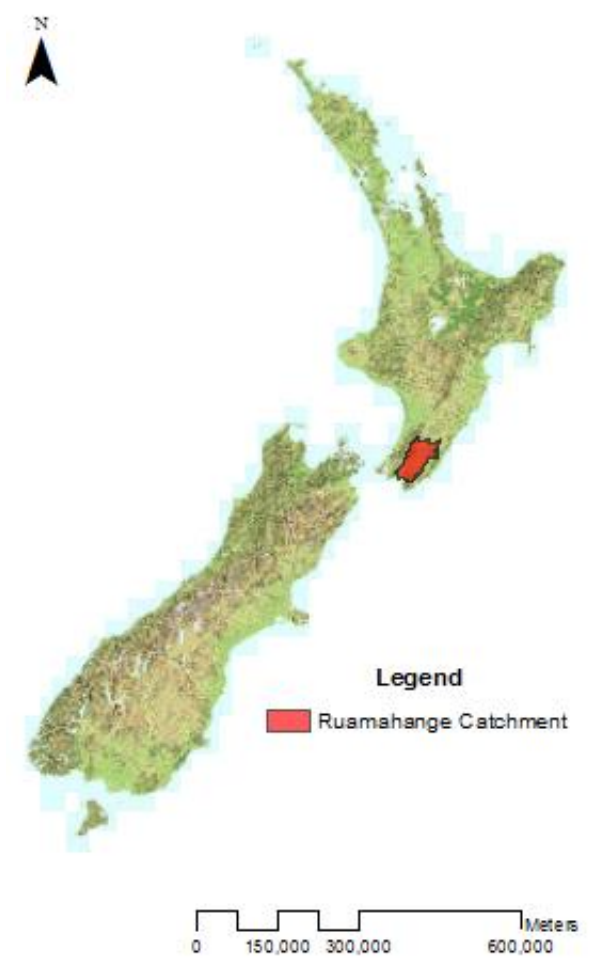

Figure 7: Ruamahanga catchment, south east of the lower North Island 
The Ruamahanga River is the main waterway within the catchment with its headwaters near Mt Dundas in the Tararua Ranges (altitude 1,500m) to the north. The Ruamaganga River changes from a braided river system to a single channel system as it flows through the lowlands, prior to discharge into Lake Onoke. Flood protection works in 1969 significantly changed the nature and course of the lower Ruamahanga River, and as a result it now by-passes Lake Wairarapa where it previously discharged except during flood conditions where it will discharge into Lake Wairarapa via the Oporua Floodway (Cromarty and Scott, 1996).

\section{Lake Wairarapa}

Lake Wairarapa $\left(705 \mathrm{~km}^{2}\right)$ is a shallow lake with a depth of $2.5 \mathrm{~m}$ or less (Cromarty and Scott, 1996). The lake is classified as supertrophic (Perrie and Milne, 2012). Lake Wairarapa receives water from a number of streams along the western lake margin, with the main source of water coming from the Tauherenikau River (Cromarty and Scott, 1996).

\section{Catchment soils}

The soil profile of the eastern edge of Lake Wairarapa is highly variable, ranging from fertile alluvial soils on the river flats, stony, sandy, silty and well drained soils bordering the rivers and streams, through to poorly drained heavier soils in black swamps and around the lake edge (Beadle et al., 2000).

\section{Catchment climate}

The Ruamahanga catchment has a predominantly warm dry climate. Summer temperatures range from $20^{\circ}-28^{\circ} \mathrm{C}$ and sometimes exceed $30^{\circ} \mathrm{C}$ (Boffa Miskell, 2010). Maximum winter temperatures range from $10^{\circ} \mathrm{C}$ (coast) to $15^{\circ} \mathrm{C}$ (inland) with night time temperatures dropping to $1^{\circ} \mathrm{C}$ (coastal) to $3^{\circ} \mathrm{C}$ (inland). Rainfall within the catchment ranges from $1200 \mathrm{~mm}$ (in the west) to $800 \mathrm{~mm}$ (in the east) per year (Boffer Miskell, 2010). 


\section{Catchment land-use}

Sheep and beef farming is the predominant land-use in 2014 with native bush the second largest land-use (Stewart, 2014).

\section{Catchment vegetation}

Current vegetation on the eastern lake shore predominantly comprises: pasture with small remnants of native trees, such as Kahikatea, and Ti Kouka (Cabbage Tree) and divaricating shrubs (Cromarty and Scott, 1996).

\subsubsection{Research participants}

A small sample (5) of participants were used for this research. All of the participants were identified as early adopters (Rogers, 2003) by the Greater Wellington Regional Council. Participants all owned, part owned or managed properties $>150$ ha in South Wairarapa. Four of the participants were dairy farmers with the fifth participant farming a mix of beef and sheep and arable cropping. All participants were of European descent and only one of the participants was female. 


\section{Findings and analysis}

\section{Section overview}

This section of the thesis comprises three parts:

- Part 1 will focus on how LUCI functions, the LUCl outputs, issues with data collection and areas for further development

- Part 2 will consider the participants responses to the interview questions (Appendix A refers). This section will also link the participant's comments to the research questions, and

- Part 3 will consider the themes that arose during the transcript analysis.

Appendix $\mathrm{Ci}$ and Cii provides a breakdown of the themes, final interview questions, research questions and how the analysis links with them in Parts 2 and 3 of the "Findings and analysis" section.

\subsection{Part 1: What is $\mathrm{LUCl}$ and how does it work}

\subsubsection{Mapping and modelling ecosystem services on farms within the Ruamahanga catchment.}

$\mathrm{LUCl}$, an ecosystem service modelling tool was used for this research to run a series of current and potential land-use scenarios for a suite of farms in the Ruamahanga catchment. For the purposes of this research $\mathrm{LUCl}$ was run on a standalone laptop in ESRI ${ }^{\mathrm{TM}} \operatorname{ArcGIS}^{\mathrm{TM}}$ version 10.1. Note that the time of writing this Thesis LUCl development had moved to version 0.5. However to ensure consistency across the research, version 0.2 was used for all the research field work.

Base data used for the generation of LUCl outputs is outlined in Table 3. 
Table 3: Data sources used for this research

\begin{tabular}{|c|c|c|}
\hline & Data used & Source \\
\hline Topography & $\begin{array}{l}\text { 15m Digital Elevation Model, } \\
\text { 5m LiDAR Data (June 2014) } \\
\text { 1m LiDAR Data (September 2014) }\end{array}$ & $\begin{array}{l}\text { LINZ Data Service } \\
\text { Greater Wellington } \\
\text { Regional Council } \\
\text { Greater Wellington } \\
\text { Regional Council }\end{array}$ \\
\hline Soils & Fundamental Soils Layer & LINZ Data Service \\
\hline Land-use & Land Cover Data-base 2 & LINZ Data Service \\
\hline $\begin{array}{l}\text { Rivers and } \\
\text { streams }\end{array}$ & NIWA Streams and Rivers & $\begin{array}{l}\text { National Institute } \\
\text { of Water and } \\
\text { Atmosphere }\end{array}$ \\
\hline Drains & $\begin{array}{l}\text { Drain (vector) data for the } \\
\text { Ruamahanga Catchment }\end{array}$ & $\begin{array}{l}\text { Greater Wellington } \\
\text { Regional Council }\end{array}$ \\
\hline $\begin{array}{l}\text { Rain and } \\
\text { climate data }\end{array}$ & NIWA Rain 1960 - 2006 Raster file & $\begin{array}{l}\text { Victoria University } \\
\text { of Wellington }\end{array}$ \\
\hline Stop banks & $\begin{array}{l}\text { Stop bank (vector) data for } \\
\text { Wairarapa Moana }\end{array}$ & $\begin{array}{l}\text { Greater Wellington } \\
\text { Regional Council }\end{array}$ \\
\hline Fence lines & $\begin{array}{l}\text { Fence lines (vector) data for the } \\
\text { Ruamahanga Catchment }\end{array}$ & $\begin{array}{l}\text { Greater Wellington } \\
\text { Regional Council }\end{array}$ \\
\hline
\end{tabular}

\subsubsection{Modelling process}

The following section provides a summary of how LUCI functions, including inputs and processes (Figure refers). 
Pre-processing step one: generation of hydrologically and topographically consistent DEM

This pre-processing tool reconciles the river network, digital elevation data and rain data to generate a "hydrologically consistent DEM from a standard DEM" (Jackson, 2013b). Stream and river networks can also be generated using this pre-processing tool, or where available a stream and river network can be "burnt in" (Jackson et al., 2013b).

\section{Pre-processing step two: generation of land-use scenario}

The scenario file is then calculated by coupling the hydrologically consistent DEM with soils and land-use information to generate the base information for the ecosystem service analysis (Jackson, 2013b). This method calculates the infiltration capacity of features and elements at the site. Areas of high infiltration and soil moisture holding capacity act as sinks, and overland and subsurface flows are established and flow absorbed by the sinks is deducted (Jackson et al., 2013b). The presence of these sinks or areas of high infiltration capacity in the site can have a significant influence on the dynamics of the hydrology of the site as a whole (Jackson et al., 2013b). Version 0.2 of LUCI provides analysis across 6 different ecosystem services types; these can be loaded as a "batch" (i.e. together) or as individual ecosystem services. The trade-off function in turn builds on the "batch" output (Jackson et al., in press). This step in the process also allows for the users to augment the national data used with site specific information such assite drainage schemes, additional vegetation cover and rehabilitated wetlands etc. In addition, this functionality provides the capability to generate new land-use scenarios, as it provides the means to amend or augment the national data sets. Figure 9 illustrates the various stages for processing $\mathrm{LUCl}$ outputs and the data requirements at each of those stages. 


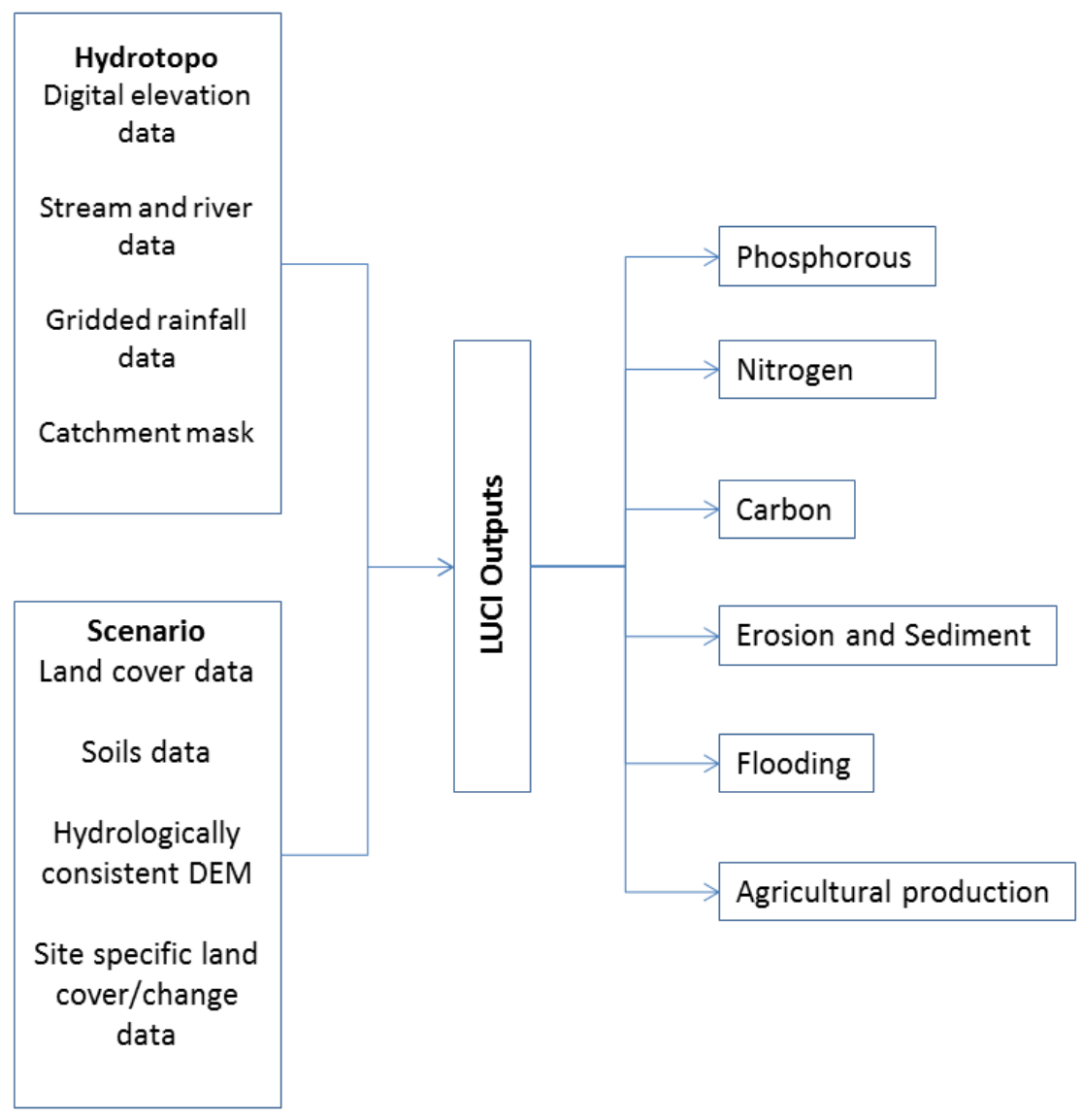

Figure 8: Illustration of $\mathrm{LUCl}$ processing and the data required at the pre-processing stages

\section{Pre-processing: LUCI outputs}

Trade-off maps look across a range of services, and can make the implications of particular management interventions explicit or identify areas where current management practices could be optimised to provide benefits across ecosystem services (Jackson et al., 2013a; 2013b). The trade-off function in LUCl version 0.2 trades off: phosphorous, flooding, carbon, erosion and sediment delivery and agricultural productivity (but not nitrogen).

Trade-offs can be run across $2-5$ services and LUCI version 0.2 can use "an additive option (which treats all services equally), a weighted additive option (which allows the addition of weightings for individual services), a conservative option (which only identifies areas where positive synergies exist) 
and a Boolean option (which enables users to select a combination of additive and conservative options for each service" (Jackson et al., 2013b, p. 78). This research used the conservative option to calculate trade-offs.

\section{Single service outputs: how they are generated}

The individual ecosystem services are generated using the processes detailed in the section below.

\section{Nitrogen calculation in LUCI}

LUCl uses an "export coefficient approach" to calculate the accumulated total nitrogen concentration. Rainfall is routed through the landscape based on topography. The export of nitrogen is calculated based on land cover and land management (Jackson et al., 2013b). The accumulated total nitrogen export is coupled with cumulative flow to provide an estimate of the accumulated total nitrogen concentration (Jackson et al., in press). Accumulated total nitrogen load is then categorised. These categories can be set based on context specific parameters that can be manually inputted into the system. Alternatively, in the absence of site specific categorisation, a set of generic parameters are provided using the maximum allowable nitrogen concentration in drinking water (i.e. $11.3 \mathrm{mg} / \mathrm{L}$ ) as the baseline against which these thresholds or parameters are set. The threshold below which nitrogen is not considered to be of concern (i.e. "low concentration") is $0.1 \mathrm{mg} / \mathrm{L}$. The threshold above which nitrogen is considered to be a significant concern (i.e. "very high concentration") is $10 \mathrm{mg} / \mathrm{L}$. The threshold at which nitrogen is considered to be of medium concern (i.e. "high concentration") is $5 \mathrm{mg} / \mathrm{L}$. Finally, the proportion of dissolved versus particulate nitrogen needs to be inputted manually (Jackson et al., in press).

\section{Phosphorous calculation in LUCI}

Accumulated total phosphorous concentration is calculated in a similar fashion to total nitrogen concentration calculating the water and sediment accumulation and flow routes and taking into account land-use and 
management practices. As is the case for nitrogen, only total phosphorous from diffuse inputs is calculated. Point sources are not considered in LUCI version 0.2 (Jackson et al., in press). Accumulated total phosphorous concentration is then categorised into "low concern", "moderate concern" and "high concern".

Note that as for total nitrogen calculations, the dissolved vs particulate phosphorous needs to be inputted manually.

\section{Flood mitigation calculation in LUCI}

The flood mitigation tool builds on the hydrologically consistent DEM generated during the initial pre-processing process. The LUCl flood mitigation tool uses a "novel algorithm" to discretise units with similar hydrodynamics within the landscape and calculates the infiltration and flow routing based on land-use, topography and soil types, noting that features in the landscape such as vegetation and wetlands can influence the water retention capacity of those areas. The flood mitigation tool identifies sinks or highly permeable areas within the landscape as low risk for flooding and therefore of high value for water absorption (Jackson et al., 2013b). Areas that contribute overland and sub-surface flow to these "high value areas" are identified in LUCl outputs as mitigated features, and flow routes that contribute directly to waterways are identified as "priority areas for change" (Figure 9 refers) (Jackson et al., in press). 


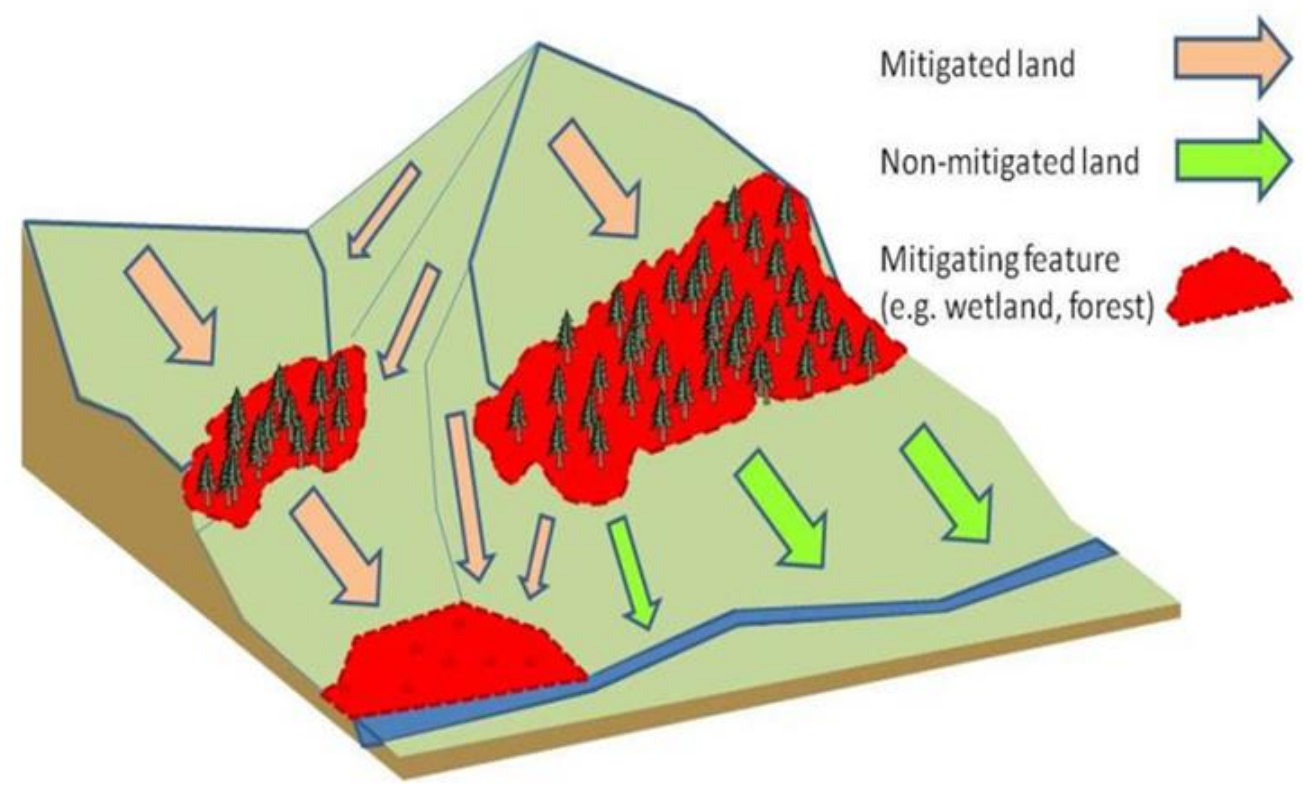

Figure 9: Identification of mitigated land and mitigating features in LUCI Outputs (Jackson et al., 2013a)

A flood accumulation output then categorises outputs into "flood mitigating land" (refer above), "low flood concentration", "medium flood concentration" and "high flood concentration".

\section{Erosion and sediment calculation in LUCI}

LUCl uses the Compound Topographic Index (CTI) which takes into account overland flow magnitude, slope and overland flow concentration to calculate erosion vulnerability (Jackson et al., 2013b). Other factors that influence erosions rates such as the uninterrupted flow into waterways along with the interception of flow and sediment transfer resulting from vegetative cover and soil types are also taken into account through LUCl processing (Jackson et al., 2013b). This functionality allows for the identification of priority sites for management intervention and modelling, and the benefits derived from interventions (such as planting and wetland rehabilitation) for sediment transfer to watercourses. Again areas in the landscape are categorised into "mitigating features", "negligible erosion risk", "moderate erosion risk" and "high erosion risk". 
Agricultural productivity calculation LUCI

The agricultural productivity tool calculates productivity potential based on soil type (i.e. soil fertility), aspect, and water regime (i.e. water logging or free draining). This is coupled with data on the current land management and whether it is fully utilising or over utilising land-use potential (Jackson et al., 2013b). Areas of the landscape are then categorised into "very high value", "high value", "marginal value", and "low value or no value" (Jackson et al., 2013a).

Note that how LUCI processes carbon is not discussed in detail here as carbon maps were not presented to participants due to low carbon prices.

\subsubsection{Presentation of $\mathrm{LUCl}$ outputs (the maps)}

LUCI presents information using a traffic light system with red shading indicating that current land-management is optimal for that area, therefore change in the land management in these areas is likely to have a detrimental effect on the services being investigated in that output. Orange shading indicates that the benefit of land management change for the services being considered is negligible. Light green however, indicates areas where there is opportunity to improve management for one or more of the services being considered in that output. "The thresholds [for the categorisation] can be set based on local knowledge, field observations or aerial photography or through the use of values derived from comparable sites" (Jackson et al., 2013b p. 7). The thresholds used for this research were based on those established from literature on the impact and provisioning of services within the New Zealand landscape (Jackson et al., in press).

\section{Data presented to participants through the modelling process}

This research presented current land-use and scenarios that were modelled for the following single services: nutrients (total accumulated nitrogen load 
and total accumulated phosphorous concentration), flooding, erosion/ sediment delivery, carbon sequestration and agricultural productivity.

The scenarios generated focused on areas identified by LUCI where there was an opportunity to improve one or more ecosystem services through the management interventions under consideration (e.g. planting of vegetation and/or wetland (re)establishment).

All participants were presented with trade-off maps as part of either the first or second field visit. Appendix D provides a breakdown of the combinations of ground-truth, scenario and trade-off maps presented to each of the participants.

\section{Data inputs}

\section{Elevation data}

Initial maps were generated using the datasets outlined in Table 3.

While $\mathrm{LUCl}$ can run on coarser resolution data such as $15 \mathrm{~m}$ data, for field scale analysis the $\mathrm{LUCl}$ developers indicate that $5-10 \mathrm{~m}$ resolution is suitable for most applications (Jackson et al., 2013b). In addition, given the very flat nature of the participant's properties, and the implications that this might have for the functioning of the hydrological algorithms within $\mathrm{LUCl}$, using finer resolution data would provide more accurate and robust outputs at the field scale. Figure11, Figure, and Figure illustrate the different results gained from different resolution data for the same watershed in the research study site. 


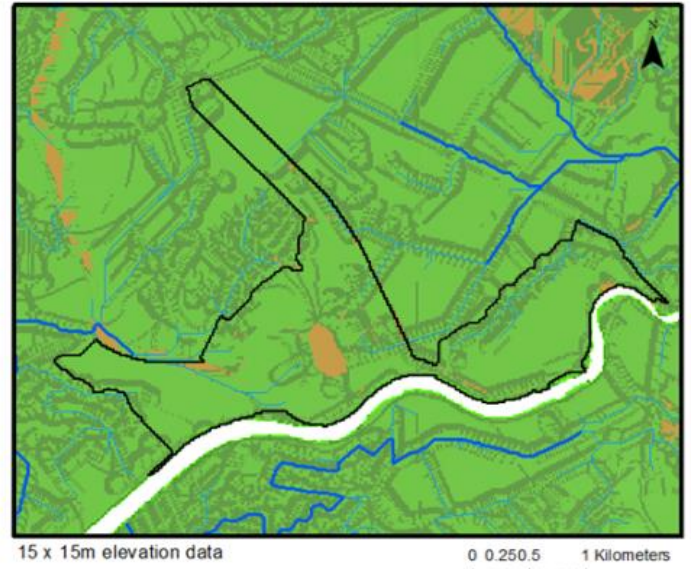

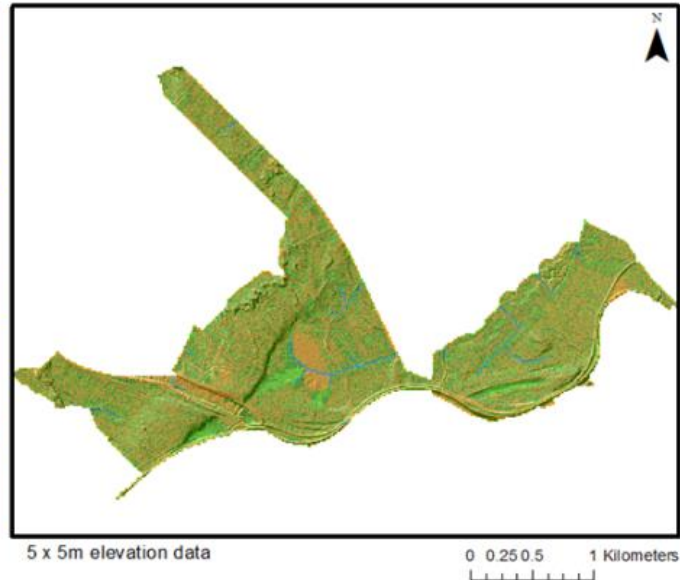

Figure11: LUCl output: $5 \mathrm{~m}$ elevation data: classified accumulated nitrogen load

data: classified accumulated nitrogen load

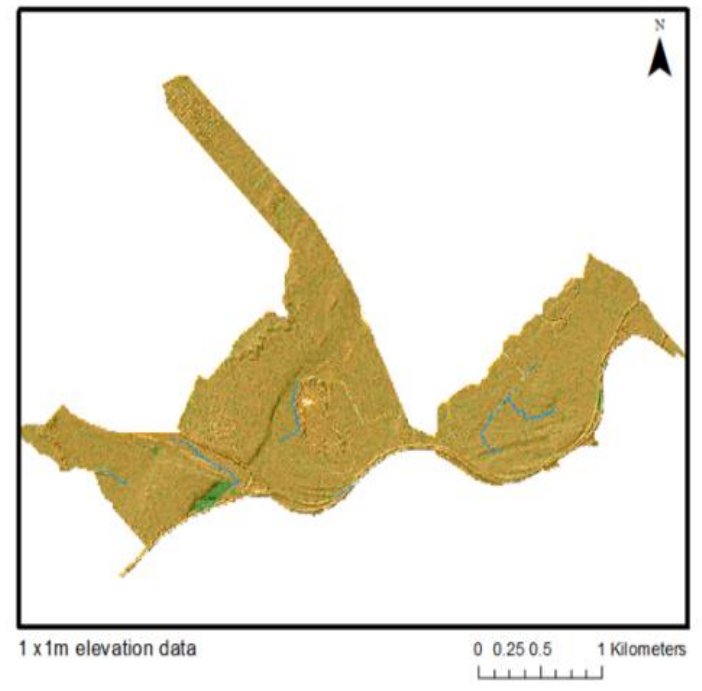

Legend

- Stream

- River

$\square$ Watershed

CL_AccNLoad

Classified Accumulated Total N Load

$\square$ Low to moderate load

High load

$\square$ Very high load

$\square$ Water bodies

Figure 12: LUCI outputs: 1m elevation data: classified accumulated nitrogen load

This research used: $15 \mathrm{~m}, 5 \mathrm{~m}$ to $1 \mathrm{~m}$ resolution data. Finer scale data was used as it became available. Table 4 provides a breakdown of the data used for each of the participant's field visits. This inconsistency in the elevation data used between participants makes it more difficult to compare the participants' perceptions of the LUCl outputs. However, the objective for this 
research was to maximise the accuracy of the LUCl outputs presented to participants, so that we could then assess how participant's responded to both the content and the credibility of the information presented.

Table 4: Elevation data used for the preparation of LUCl outputs for each of the participant field visits

\begin{tabular}{|c|c|c|c|c|}
\hline & Field Visits & $\begin{array}{c}15 \mathrm{~m} \\
\text { elevation }\end{array}$ & $\begin{array}{c}5 \mathrm{~m} \\
\text { elevation }\end{array}$ & $\begin{array}{c}1 \mathrm{~m} \\
\text { elevation }\end{array}$ \\
\hline \multirow{3}{*}{$\begin{array}{l}\text { Participant } \\
\text { A }\end{array}$} & Field Visit 1 & & $\mathrm{v}$ & \\
\hline & Field Visit 2 & & & $\mathrm{v}$ \\
\hline & $\begin{array}{l}\text { Post Field } \\
\text { visit } 2\end{array}$ & & & $\mathrm{v}$ \\
\hline \multirow{2}{*}{$\begin{array}{l}\text { Participant } \\
\text { B }\end{array}$} & Field Visit 1 & $v$ & & \\
\hline & Field Visit 2 & & $v$ & \\
\hline \multirow{2}{*}{$\begin{array}{l}\text { Participant } \\
\text { D }\end{array}$} & Field Visit 1 & $\mathrm{~V}$ & & \\
\hline & Field Visit 2 & & $v$ & \\
\hline \multirow{2}{*}{$\begin{array}{l}\text { Participant } \\
\text { E }\end{array}$} & Field Visit 1 & $v$ & & \\
\hline & Field Visit 2 & v & & \\
\hline \multirow{3}{*}{$\begin{array}{l}\text { Participant } \\
\text { F }\end{array}$} & Field Visit 1 & & & V \\
\hline & Field visit 2 & & & $\mathrm{v}$ \\
\hline & Field visit 3 & & & $v$ \\
\hline
\end{tabular}

Note: Participant $\mathrm{C}$ withdrew from the research due to limited time available as a result of the summer 2014/15 drought $^{3}$.

Issues encountered with the $15 \mathrm{~m}$ elevation data and how they were resolved When the study site was initially modelled using $15 \mathrm{~m}$ elevation data, the results showed a significant proportion of the study site, within the vicinity of

${ }^{3}$ This participant has expressed an interest in having his property mapped at a later date 
Lake Wairarapa as being underwater (Figure refers). These results effectively increased the size of Lake Wairarapa from 7,180ha ${ }^{4}$ to $14,830 \mathrm{ha}^{5}$.

To resolve this issue Lake Wairarapa was clipped from the catchment mask (Figure 14 refers). This allowed for the hydrology in the catchment to flow into the lake, effectively acting as a sink. However this technique limited the modelling of any feedback or hydraulic returns that might naturally occur.

When these results were ground-truthed with the participants, they appeared to be more accurate than the initial LUCI outputs, particularly when drainage data was added.

${ }^{4} 7,180$ ha = taken from Lake Wairarapa layer supplied by Greater Wellington Regional Council ${ }^{5} 14,830$ ha = the western lake edge was taken from the Lake Wairarapa layer supplied by Greater Wellington Regional Council, while the eastern lake edge was taken from the initial LUCl output as the western lake edge was undefined in the initial LUCl outputs. 


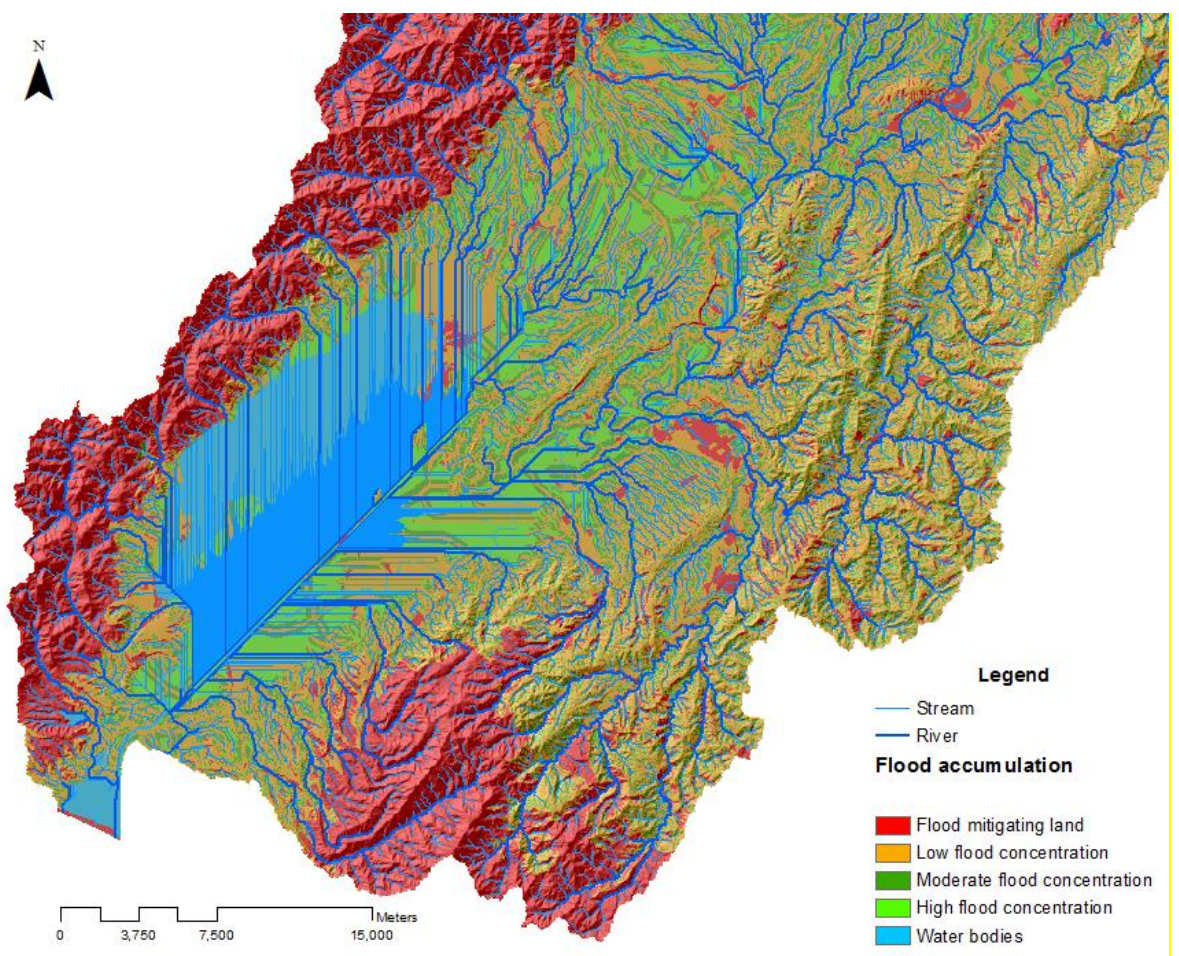

Figure 13: Lower Ruamahanga catchment as initially modelled by LUCI

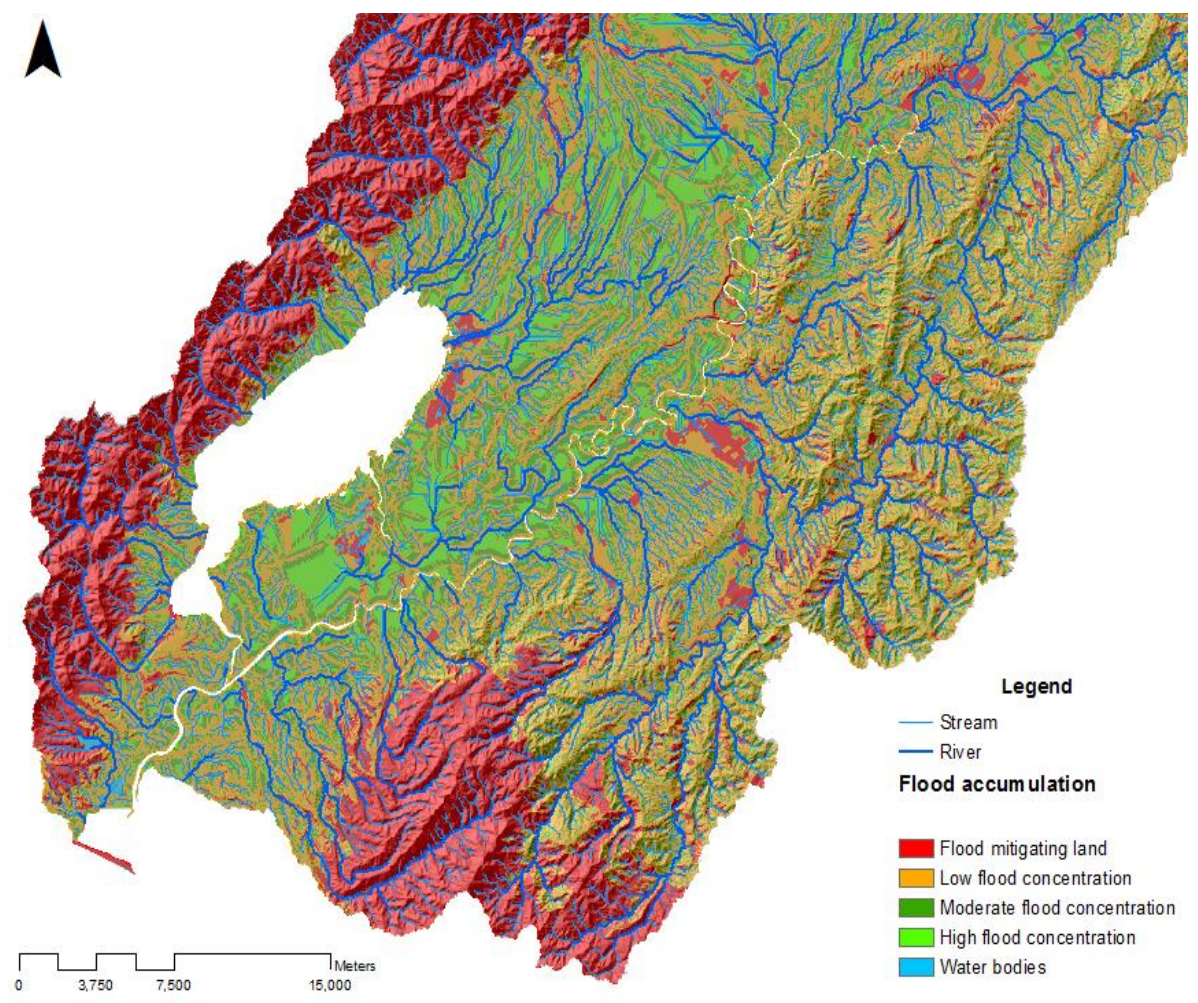

Figure 14: Lower Ruamahanga catchment as modelled after removal of the lake and inclusion of stop banks 
Initial maps developed using the $15 \mathrm{~m}$ DEM (for participant's A and E) were generated using this "technique" to provide a better reflection of current day hydrology in the region. This issue did not recur once we began using finer resolution datasets, refer section below.

\section{Issues encountered with the 5 m elevation data}

In June 2014, the Greater Wellington Regional Council provided access to $5 \mathrm{~m}$ elevation data. While this data was far more detailed and resolved the hydrology related issues around the eastern lake margin (referred to in the section above), it had been generated from aerial imagery captured by two flights of aerial imagery flown during a particularly wet period. Given that the area has an extensive drainage network; it is only flood prone during certain periods of the year. Consequently, the conditions captured by these flights were not typical for the area for the majority of the year. This data limitation was particularly prevalent for properties in close vicinity or abutting the lake margin. A second limitation with this dataset related to the limited extent of the data. Two (participants A and D) of five of the participants properties (and their watersheds) were captured by this data and three properties (participants B, E and F) were only partially captured.

For those participants where their properties and/or watershed were partially captured by the data, several processes were used to merge the $5 \mathrm{~m}$ data with the $15 \mathrm{~m}$ data. When merged, the cell positions did not match either of the original $5 \mathrm{~m}$ or $15 \mathrm{~m}$ elevation data. As expected the merged data depicted a step in the elevation ranging from $10-15 \mathrm{~m}$ at the location where the datasets intercept. However, the size and nature of this step was inconsistent, with the whole surface tilting towards the east, indicating that it was not just the elevation that was compromised, but that the two datasets depicted fundamentally different surfaces. This raised questions about the 
accuracy (and potentially credibility) of both datasets and how you might go about checking, and merging them.

It was beyond the scope of this research to analyse the differences between the surfaces depicted by the $1 \mathrm{~m}, 5 \mathrm{~m}$, and $15 \mathrm{~m}$ data. However, such an analysis would be useful in informing hydrological modellers which dataset is most accurate and it would allow for further research on how to merge two datasets with different resolution.

Fortunately, $1 \mathrm{~m}$ resolution data for the whole Ruamahanga catchment became available and any further maps generated from that point on used that dataset.

\section{National soils data}

The National Fundamental Soils data (FSL) was used as part of the base data for this research. An alternate soils dataset (SMap) was also considered, however, at the time that the field work for this research was undertaken SMap was not easily accessible, nor did it have national coverage.

It is noteworthy however, that two participants referred to SMap noting that it seemed to be a reasonably accurate reflection of the soils on their properties. One of these participants noted that it seemed to be more accurate than the FSL. Conversely, another participant felt that SMap was not accurate for his property.

While it was not possible to compare these two datasets during the course of this research, when SMap achieves national coverage and is more readily available for use, a comparative analysis of the differences between SMap and the FSL coupled with physical ground-truthing would be a very useful line of further research. 
Land-use data

LCDB2 (Land Cover Data-base) was used as the base data for this research.

\section{Streams and Rivers Data}

There are two national level stream and river data layers available from: the National Institute of Water and Atmospheric Research (NIWA), and Land Information New Zealand (LINZ). These datasets were compared, and given that they were reasonably similar, a decision was made to use the NIWA dataset.

\subsubsection{Scenario generation}

The scenarios prepared for participants were generated based on:

- situational factors at the participant's properties (as depicted through $\mathrm{LUCl}$ after the properties had been ground-truthed)

- the management interventions under investigation (wetland rehabilitation and vegetation planting)

- literature on the best use of these management interventions, and

- participant driven options.

Appendix D provides a summary of the range of scenarios generated for participants during the course of the research.

Figures 15, 16, 17 and 18 provide examples of scenarios generated for the participants. However, to protect the participants' anonymity in this document, features that could make the properties identifiable to others (e.g. barns, houses and roads) have been removed. To demonstrate the benefits derived from vegetation for flood mitigation, ground-truthed maps with (Figure 15 refers) and without (Figure 16) existing vegetation were compared. Similarly, a comparison of maps with (Figure's 17) and without (Figure 18) drains demonstrate the nitrogen removal by drains were generated and compared. 


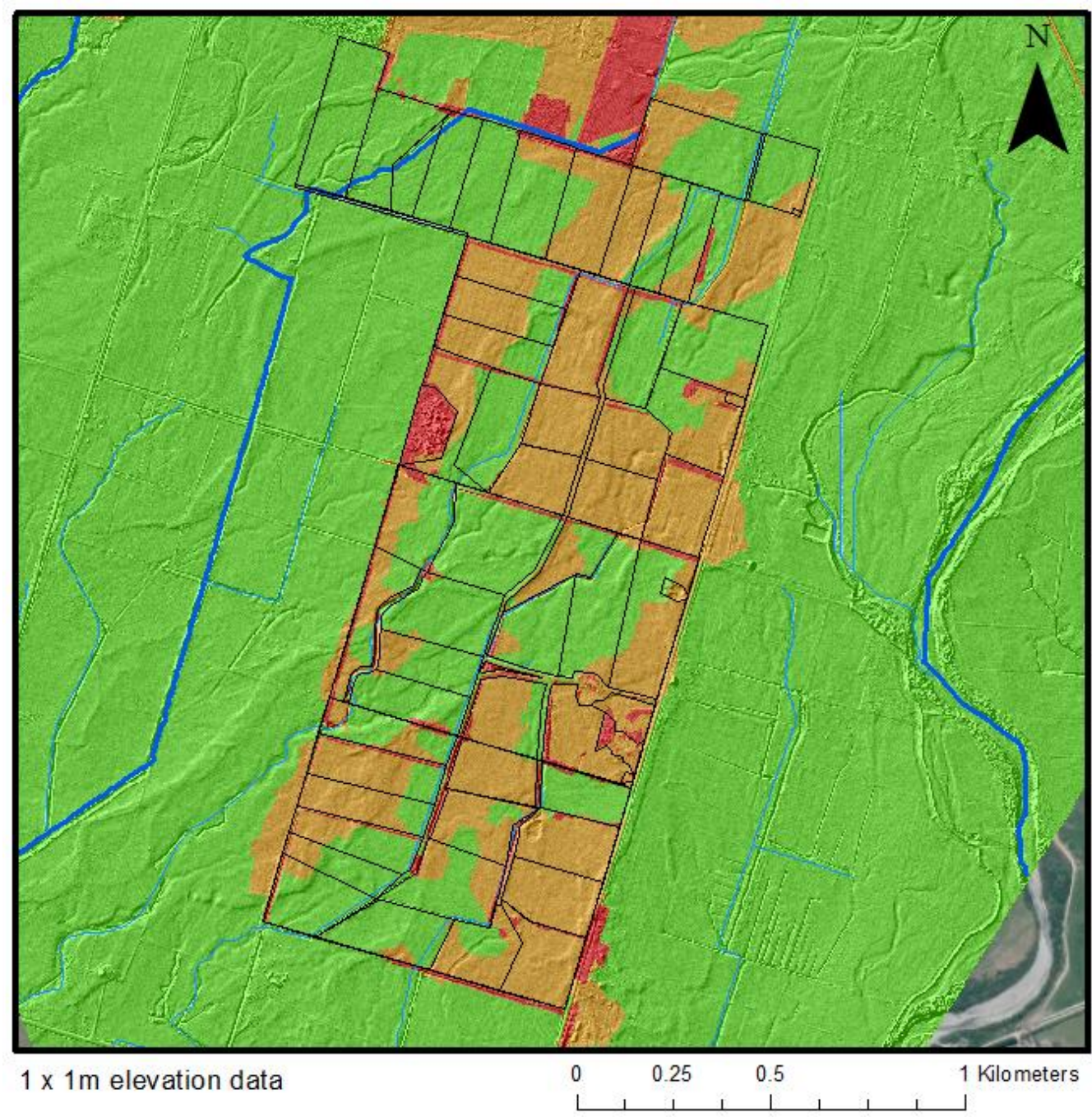

\section{Legend}

$\square$ Fence lines

Stream

- River

Mitigating features

Mitigated features

Non-mitigated features

Water bodies

Figure 15: Flood mitigating features: ground-truthed map with existing vegetation ("mitigating features" refers to vegetation) 


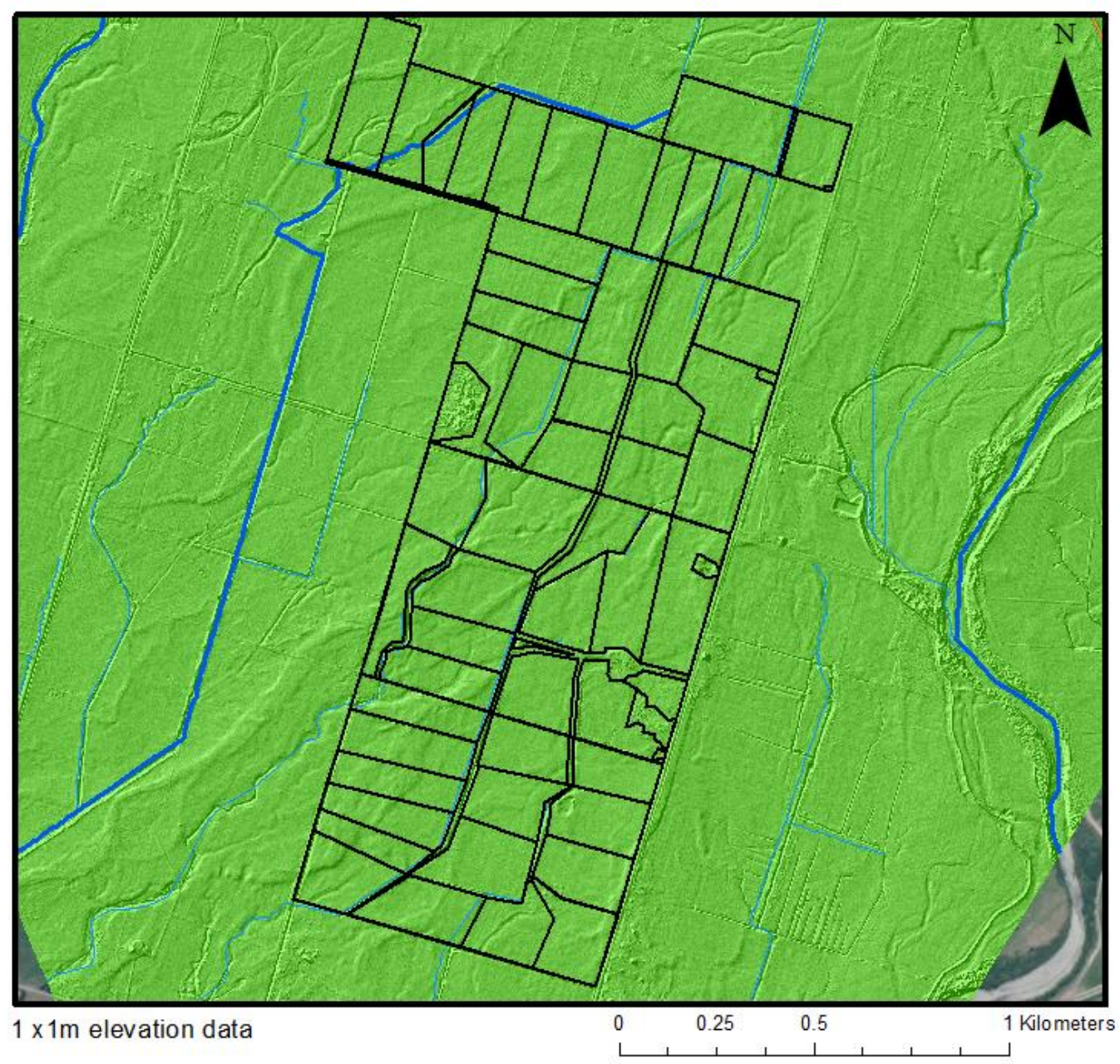

\section{Legend}

$\square$ Fence lines

- Stream

- River

Mitigating features

$\square$ Mitigated features

$\square$ Non-mitigated features

Water bodies

Figure 16: Flood mitigating features: scenario with existing vegetation removed 

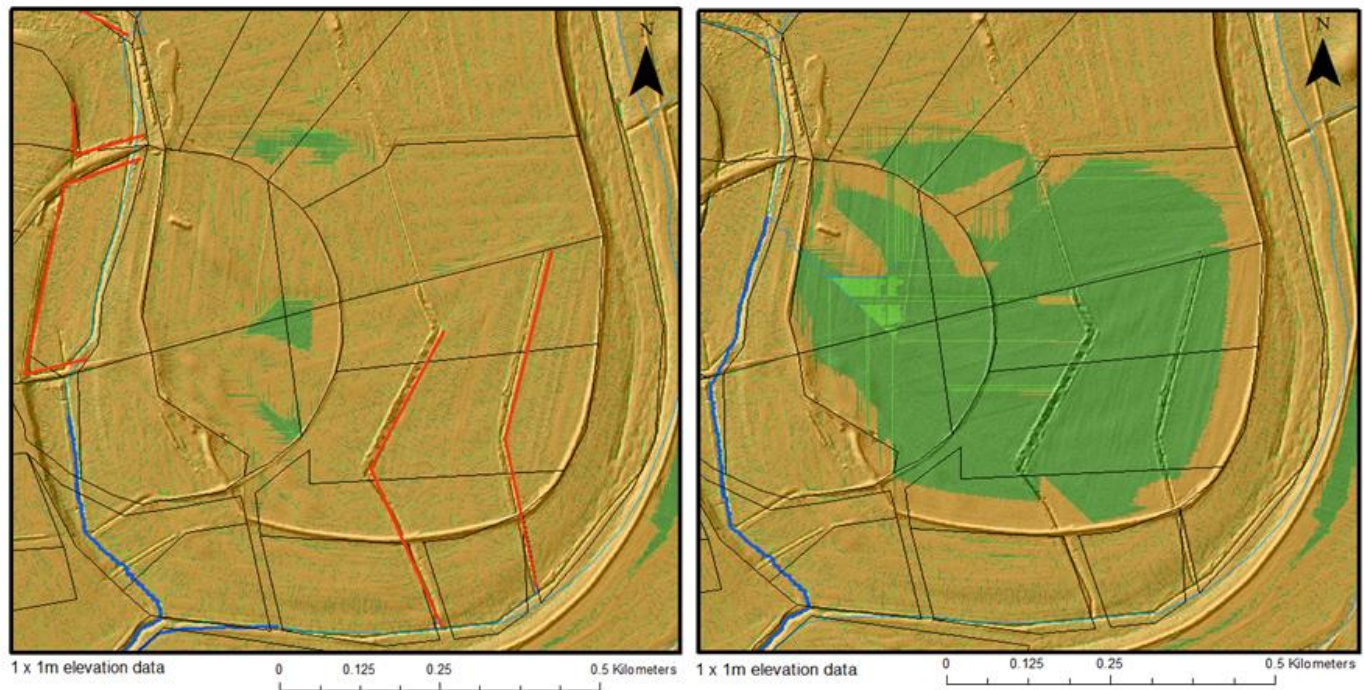

Legend

- Fencelines

- Stream

- River

CL_A ccNLoad

Classified Accumulated Total N Load

$\square$ Low to moderate load

High load

$\square$ Very high load

Water bodies

Figure 17: LUCl outputs: classified accumulated nitrogen load with surface drains

Figure 18: LUCl outputs: classified accumulated nitrogen load with surface drains removed

By-in-large the scenarios generated were initiated by the researcher, with two exceptions. One participant requested that scenarios be generated for drain and stopbank realignment, and additional vegetation planting. The other exception related to the placement of proposed wetlands. In this instance the researcher initially placed a wetland on the property. However, on discussion with the participant, the proposed wetland was moved to an alternate site on the property.

The fact that most of the scenarios were generated by the researcher is a potential limitation of this research as there may have been increased engagement from the participants had they taken a greater role in selecting the scenarios that were real possibilities for them. 
Demonstrating and running a scenario in real time was only undertaken with one participant (D). This was due to a number of factors including:

- insufficient time available at field visits to set up and run the programme i.e. significant amounts of time spent discussing the $\mathrm{LUCl}$ outputs (presented as hardcopy maps), and/or

- participants' were not interested in undertaking this step.

\subsubsection{Ground-truthing process}

As discussed above, the study site was subject to a significant amount of human intervention, not only as a result of the Ruamahanga Diversion but also as a result of local level interventions such as the introduction of drains, water pumping systems, and stopbanks. Unless this information is programmed into $\mathrm{LUCl}$, the programme will model the naturally occurring processes at the site. In this case, data layers on the stopbanks, property boundaries, fence lines and drains for the study site were also included in the pre-ground-truthed maps. When these elements were programmed into $\mathrm{LUCl}$, outputs modelled the routing of water, nutrients and sediments through the landscape taking into account these features. These maps were presented to participants $D$ and $E$ on their first field visit. However, in preparing all other pre-ground-truthed maps for participants ( $A, B$ and $F)$, the researcher developed and included an additional layer of data on vegetation cover based on aerial imagery for the site. This inconsistency across participants is noted and discussed further in the "Limitations" section (section 5.3) of this research.

\subsubsection{Management options under consideration}

Two management options were considered as part of this research, wetland (re)establishment and vegetation planting. These interventions were selected based on: 
- Literature on the impacts of these management interventions on the services being considered within LUCI

- The capability of $\mathrm{LUCl}$ version 0.2 to represent management interventions.

Note that these were the only two management interventions that were considered robustly parameterised for New Zealand in LUCI version 0.2 when this research was initiated.

\subsubsection{Areas for further development}

\section{Overview}

During the course of the field work there was much discussion about the "potential" utility of the LUCI tool for farmers. The focus of these discussion was two-fold, taking into account its utility for others (which is discussed further in Part 2 of this section), and areas where the tool could be developed in the future to make it more comprehensive and useful.

This section will focus on the later and analyse the options for future development as proposed by the participants.

\section{Data collection}

During the course of the research participants discussed areas for future development of $\mathrm{LUCl}$ that would be useful from their perspective as land managers. The data for this section was derived from the participant transcripts. This data was identified during the transcript analysis process, and coded to a "future developments" theme within NVivo. On further analysis of this theme, the text references were further broken down into subthemes for further discussion and consideration. 


\section{Summary of participant responses}

While the interview questions did not specifically address future developments, most participants quickly and voluntarily initiated discussion about potential future developments. This was not generally as a result of frustration, but more the result of a general recognition of the potential of the tool.

On further analysis of the transcripts, a number of sub-themes emerged, these were coded as follows:

- Drains

- Water races

- Irrigation

- Lake levels

- Springs and other water imports

- Wind run

- Financial returns

- Quarterly or seasonal modelling

\section{$\underline{\text { Surface drains and NOVAFLO }}$}

Currently surface drains can be "burned in" to LUCI to force the water to flow in directions that may differ from the natural fall of the land. This is implemented via the DEM-Reconditioning Arc-Hydro tool using the same approach applied by Maiden (2000) as cited in (Jackson et al., 2013b, p. 79), but with code specifically built for LUCl algorithms (Jackson, pers. comm). When land managers are putting in drains they often create fall, to drain the water in a particular direction based on farm management priorities.

Participant $D$ referred to the impact of drains on the natural hydrological processes on his property in an initial interview (prior to ground-truthing and the inclusion of drains within his maps). His comments were as follows: 
One way of doing it is just to forget about the elevation and just, get detailed drainage maps of where the water is going ..... because you can create fall with the artificial drainage, so a machine just puts it in, the water can be going all different ways on stuff [topography] that's dead flat, so I wonder whether that's going to be useful to you, I mean it's all going to end up going the same way eventually, its either going to come into this wetland or go straight out. Um, yeah, maybe that's useful for you I'm not sure. It complicates your job a lot, that's for sure.

By hardwiring this information into $\mathrm{LUCl}$, it is possible to model the hydrological dynamics that result from these management interventions.

Many of the participants in this study were also using subsurface drains such as tile drains or NOVAFLO ${ }^{\mathrm{TM}}$. This is where a network of drains is laid within a metre of the field surface to suck water out of the soil through capillary action. The following quotation from Participant $A$ was taken from an initial interview prior to ground-truthing the LUCI outputs:

......or you could just go in and include drains, because the NOVAFLO ${ }^{T M}$ also causes capillary action, like $90 \%$ of the water...say you've got a pipe in down here, $90 \%$ of the water comes up into the pipe. Everybody has got a perception that it goes in the top of the pipe, but in talking to doctor whoever he was from the university, he said nah, you put a sponge on the bench and watch what happens, like it sucks the water up and it gets heavy in the sides of it, and the pipes are exactly the same, and the water goes down and it hits a layer and comes back up and comes into the pipe....

Including the impacts of NOVAFLO ${ }^{\mathrm{TM}}$ on the hydrological routing of water through these paddocks would be useful. It will also allow for the 
development of mitigation options for land-managers where this practice is having a detrimental effect on the services under consideration.

\section{Water races}

Water races were also raised by participants for a number of reasons. Water races are designed to provide stock with drinking water and as such are not fenced. There is an extensive water race network in South Wairarapa (Perrie and Milne, 2012). There is limited data about the water quality of the water race system, however for the Longwood water race (the system that is within the study site) "water quality monitoring undertaken in 2000-2001 indicated that the condition of water entering Donalds Creek (downstream of the race) was very poor, and bacterial levels increased significantly between the intake and discharge points" (Taylor and Tonkin, 2012. p. 14). It is further noted that these water races have had issues with slumping of the stream banks and siltation as a result of stock access (Watts, 2007 as cited by Perrie and Milne, 2012).

Participant B made the following comments about a local water race:

.....there is the $x x x x x x^{6}$ water race system which diverts water from out of the river, and the water race system was developed at a time when there was no electricity and no water troughs and like now you see pumping. And his question to me was would you be upset if it was closed down. And I said not at all, I would be relieved, because I've got unnecessary water being moved into my property that I don't want and it's often of poor quality, and it's getting heated along the way, and people take samples of the $x x x x x x$ water race to get an indication of the Wairarapa's water quality.

\footnotetext{
${ }^{6}$ Name of the race removed to protect the participants identity and property location
} 
As water races are there to provide water for stock, by-laws prohibit some management interventions that are otherwise considered best practice for water bodies in general, such as fencing off stock and establishing riparian plantings. So while participants have raised the issue of water races as an area requiring further attention, that attention does not require further development work for $\mathrm{LUCl}$. Rather it is a public policy issue relating to the regulations and by-laws around the management and use of water races, and the development of potential alternate management practices to support improved water quality.

Options for improved management suggested by participants ranged from fencing large sections off from stock, but allowing stock access at key points which would be turned into gravel beaches, to riparian planting along water races, particularly the northern side, to reduce the water temperature (Bowler et al., 2012; Parkyn et al., 2003) and reduce nutrient enrichment and overland flow (Jackson et al., 2008).

One participant (B) talked at some length about opportunities to better manage water races whilst still allowing them to perform their function of providing stock with water:

One of the problems with this water race, I think I've mentioned before was the heating of the water. What the council want to do is have a 5 meter boundary from it and no vegetation through it and the water kept clearly running through a channel. But all that is going to do is heat the water up and create algal blooms in the river, and so they had a big fight with the council, and they were just going to go and do something along those lines........ what we should be doing is either shutting the water races down completely or those ones that are operational, have a coverage that... a tree cover on one side and then digger access to the other to keep the water cool, because most of the problem is that the water is being 
polluted. We also need to have beaches, located beaches for stock to have access, but not to spend all day climbing in and out of them. If you put a beach in they do go down and drink, but they don't spend all day, its big enough for one or two cows to drink from, that's fine, because you can get 10, what I mean is that if its big enough for 2 cows to stand in it, alright they might piss in it or crap in it but generally they will [only] go to drink But they will go into a large expanse of water and stand in the middle of it to cool their feet [if given the opportunity].

\section{Irrigation}

The use of irrigation and how this was accounted for in LUCl was raised by participants on a number of occasions. Irrigation was raised because it involves the importation or redirection of water on a property, creating new water collection points or additional pressure on existing accumulation points.

Two participant's ( $A$ and $E$ ) noted the impact of irrigation for winter waterlogging when irrigation is undertaken during summer and autumn, and that different soil types will respond differently to these water inputs.

Participant $B$ noted the variation in soil types within the area and the implications this had for irrigation management:

I've farmed in ... three other regions, l've never seen land where you can literally have a seam of gravel beside a seam of silt. It's almost like there is a dead line there, and you can, and the irrigators there are doing the same amount of water and the waters just pouring through that one and its evaporating from that one and that one's right next to it, and you are scratching you head and thinking why are those two ... you know and it's just the challenge of that type of land really. 
...But when we put a pivot in this area, because we know where all our wet areas are, and so what we've already done is we've nozzled down those areas, so they are behind a nozzle and so we don't put as much water in these areas, so it's more efficient in these areas, it's much more efficient for the guys in the summer. These areas here they are higher nozzle ratings so hopefully if you had a pivot in there, as it went around it would shut off, we would decrease water in certain areas and increase water in others as it goes around. So put twice as much on these areas and half as much on these as it goes around.

Comment's also referred to the way irrigation was regulated, with the standardised application of $4 \mathrm{~mm}$ per day. The wisdom in this was queried because evaporation rates in the region are often more than $5 \mathrm{~mm}$ per day. "We are probably burning $7 \mathrm{~mm}$ per day, which we just can't, like an irrigator won't even keep up with that, so you become very, very inefficient."

\section{$\underline{\text { Lake levels }}$}

Some of the properties in this research were either directly or indirectly impacted by the fluctuation of the levels of Lake Wairarapa?

Participants' $A$ and $E$ both referred to the impact of the lake levels for their properties' drainage and the resulting need to use water pumps:

Participant A: ....our pump station is here, but the free flow water is... like I can turn the pumps off, as long as the lakes low I can turn the pumps off, and the water just flows out through the neighbours.

\footnotetext{
${ }^{7}$ Between 3 and 10 December 2009, water levels fluctuated between 9880 and 10390 mm. These measurements were taken at the barge gates (Perrie and Milne, 2012)
} 
Participant E:

it goes right through the farm it used to

be the back water that used to be gravity feed out to the lake, before we changed everything and flood pumped it, because the lake built up so much that we didn't have the fall.........

At present this information is not being included within $\mathrm{LUCl}$. Understanding how and where dynamic lake levels impact on the hydrological processes on properties would be useful for informing management interventions that might mitigate some of the flow on effects of these impacts. For example, when lake levels back up in drains, it reduces farmers' ability to drain their land during periods of high rainfall.

\section{Springs and other water imports}

At present $\mathrm{LUCl}$ calculates the water accumulated in the watershed based on rainfall data, river and stream data and watershed dynamics (i.e. soil types and topography). However, there were a number of additional water sources within the study site that were not accounted for in LUCl version 0.2. They include springs and aquifers, the effects of irrigation (refer section above) and flood spillways. Including this information within the LUCI modelling process will improve the accuracy of the modelled outputs and help to inform more targeted management interventions, where necessary.

The Wairarapa Moana area is well known for its springs and aquifers. Participant $\mathrm{E}$ refers to the springs in the area in the following statement:

I think he said its only like 9 meters or so [underground], it's a really high aquifer and its beautiful, the water... They did a test in Southern Wairarapa and there was one in $x x x x x x$, and $x x x$ 's one with the purest of water...... 
It is understood that the more recent versions of $\mathrm{LUCl}$ (including $\mathrm{LUCl}$ Version 0.3 and onwards) provide a means to include this information in the baseline data for LUCl outputs (Jackson per comm.).

Wind run

The effects of wind run were not taken into account in $\mathrm{LUCl}$ version 0.2. The Wairarapa region is particularly wind prone (winds of up to $215 \mathrm{~km} / \mathrm{h}$ recorded in Hau Nui in October 1998 (WeatherWatch, 2009)). This has a number of implications for the services being modelled by $\mathrm{LUCl}$ version 0.2 including:

- the effects of wind erosion on sediment delivery

- the increased evapotranspiration resulting from these winds, and - impacts on stock and crop production.

One participant (B) described wind run along the following lines:

If you get a period of strong North Westerlies ..... during that period we've seen the farm, they call it "going off" in the district, when the land starts to go off, because it's got boney strips in it, .... and it dries out on all the ridges and the ridges start to go off first and you can just see it drying very fast, and that's when we start to look at our evaporation rates and they start to get up to 8 - $9 \mathrm{mms}$ per day....

In addition, being able to manage the impact of wind run on stock and crop losses through the targeted planting of shelterbelts may be a significant advantage for farmers. 
Participant (B) noted that:

... we watch for southerlies as well, as they can kill us. And if we are at a point where we are at our peak production, we can lose \$20k just like that...

...so it makes a difference of $2-3$ thousand litres a day - a storm and then there is the recovery from it, just to get back...

There is potential for $\mathrm{LUCl}$ to model wind run and the strategic placement of shelterbelts, which would provide a wider range of benefits across the services currently being modelled under LUCI version 0.2.

Financial and other metrics around ecosystem service trade-offs A number of the participants raised the potential for putting more explicit metrics against the gains and losses associated with various ecosystem services, so that they could better understand the scale of benefits derived from various management interventions.

\section{$\underline{\text { Quarterly or seasonal modelling }}$}

Currently LUCI version 0.2 models a property based on national datasets that use an annual climate average. In addition, the elevation (LiDAR) data can be impacted by when (and under what conditions such as flooding ) the aerial photos were taken. Given the significant seasonal changes at the study site with summer droughts, winter floods, spring north westerly winds, there would be significant benefit in modelling these seasonal variations and their implications for high risk areas on properties. 
Participant A discussed this point in the following statement:

Yeah, like with your wind run, you could put the wind run over the top of this map and like you could put in what the changes are in September, October, November, December, January and February, cause like you get ... say there's a tree line there and that's a northerly or nor westerly flow, so for the winter, yes, that would dry this out and all of a sudden on our production map you'd have the wind flow here, this would increase your production and you'd be decreased through this side, but then in the summer you'd have decreased production round here......

\subsection{Part 2: Findings and analysis: question analysis}

\section{Overview}

This section will consider the participants' responses to the initial baseline interview questions and the final interview questions (refer Appendix A for a copy of the interview questions).

All participant transcripts were coded against the interview questions in order to understand themes and patterns emerging. These packages of text were initially analysed against the interview questions, to ascertain what the participants thought. A deeper analysis was then undertaken to understand why participants responded as they did and what other factors influenced their interpretation of the LUCl outputs.

\subsubsection{Theme 1: Experience of the phenomenon}

\section{Research questions}

Theme 1 will address research questions 1 and 2:

1. Is the information presented through LUCl accessible and compelling? 
2. Is the information presented through $\mathrm{LUCl}$ perceived to be credible and robust?

\section{Data collection}

At the final interview, participants were asked the following question and prompts:

Interview question

Tell me about your experience of the modelling process?

\section{Prompts}

- Can you comment on the accessibility of the information when provided through LUCI?

- How credible/robust did you find the information presented through LUCI?

The following analysis will address the interview question prompts first followed by the overarching question.

\section{Coding protocol}

Comments made as part of the ground-truthing process to amend or improve the accuracy of the outputs have been included as a negative comment on the credibility of the LUCl outputs for the purposes of data collation. This was done because the issues with the accuracy of the initial maps were linked with the perceived credibility of these initial maps in the final interview responses.

\section{Perceived accessibility of the information presented through LUCI}

Initial LUCl outputs (maps) were based on national datasets. This meant that a ground-truthing process was required in order for the maps to be accurate at the field scale, and for existing management interventions which were not included in the national datasets, (e.g. additional plantings, drains and drain pumps) to be reflected in the maps. 
During the ground-truthing process, all of the participants raised concerns about the accuracy of the initial maps. These concerns primarily related to the maps not depicting what they "saw" on their properties, and not reflecting the changes made to the property for management purposes. The heavily modified nature of the site would have been a significant contributing factor to the concerns raised about the accuracy of the outputs early in the research process.

\section{Accessibility of the LUCI outputs: summary of participants' responses}

Participant's responses to the final interview question on accessibility, and comments about the accessibility of the LUCl outputs are summarised in Table 5 below.

Table 5: Participants' views on the accessibility of LUCl outputs

\begin{tabular}{|c|c|c|}
\hline & Complex & Easy \\
\hline Participant A & 1 & 1 \\
\hline Participant B & 1 & 1 \\
\hline Participant D & 0 & 1 \\
\hline Participant E & 0 & 1 \\
\hline Participant F & 1 & 1 \\
\hline
\end{tabular}

Key: Easy = easy to understand, complex = complex and more difficult to understand

By-in-large, participants found that the layout and presentation of the maps were relatively accessible and easy to understand. However, three of the participants ( $A, B$ and $F$ ) made contradictory statements on the issue of accessibility. Participant B noted the following about the LUCI outputs: 
......It was good and yes, it was nice and clear and easy to understand. It's quite straight to the point....

However, this participant later noted that:

...it takes a couple of times to look at it, I thought it was telling me what I know already, but then when I started looking at [it] ....... it's like "what does that tell me", but when you understand how to interpret it better, I can see what you mean, you can see the effect of certain things.

Similarly Participant F made the following comments:

Yes, relatively easy to understand, like I could understand it when you explained what the various colours meant and what the lines meant........

However, the following contradictory statement was made by Participant $F$ during the second field visit:

But also what it highlights is that it's not necessarily in terms that I can easily understand.

Similarly layered comments were also made by Participant A. In summary, participants appear to understand the maps, but struggled with translating the information into what it then meant for them. In presenting the maps, all participants required some explanation (of what the maps were depicting), and translation (of how the information portrayed in the maps related to the functioning of their properties). The explanation required in the first field visit was more extensive, particularly as the concept and modelled outputs were being presented to participants for the first time. This was complicated by the 
accuracy of the maps. By the second field visit, however, the need for explanation and interpretation had reduced significantly.

Of the five research participants, four ( $A, B, E$ and $F)$ commented on the need to assess the maps against reality i.e. to physically ground-truth the information within the maps, and two of the participants ( $B$ and $F$ ) raised the need for $\mathrm{LUCl}$ to work from more localised information. This was illustrated by the following statement:

Participant B: I think the information in it needs to be more localised like rather than just taken off the.... [national datasets]. There is an old saying that there is a gap between academic theory and practical application, there is that little gulf there, and that probably needs bridging. So to get greater understanding, it needs getting onto the land and having a good look around, in some of the areas

Some of the participants undertook physical ground-truthing comparing the maps against their property, or sought additional field visits with the researcher for this purpose. Participant B walked his property with the maps. Another participant (F), sought an additional field visit with both the researcher and the supervisor. As part of this field visit, attendees drove around the participant's property and discussed various elements on the maps and why they were occurring. Discussions also covered intervention options under consideration and their feasibility. The researcher was invited to, and did look around Participant A's property prior to the final interview. Similarly Participant E invited the researcher out to view his property, and the issues that made it unique.

In summary, participants understood what the maps were depicting, however they needed more support in translating what the information meant for 
them and how to implement it. They also needed to check/ground-truth what the maps were telling them against their understanding of the property.

\section{Perceived credibility of the information presented through $L U C I$}

Data collection

Participants were asked:

How credible / robust did you find the information presented through LUCI?

In addition to participants' responses to this question, comments relating to perceived credibility in field visits 1 and 2 were also coded and included in this analysis. This helped to illustrate how participants' views of the credibility of the LUCl outputs changed over the course of the research. Note also that comments made during the ground-truthing process have also been coded and are included in this analysis.

Table 6 provides a breakdown of the number of positive versus negative comments made regarding the credibility of the LUCI outputs, prior to and after the ground-truthing process. This number based analysis allows for a high level overview of the participants' views on the credibility of LUCI outputs, as the process evolved. This numerical approach will be complimented by an in-depth analysis of the participants' views and perceptions as they relate to the credibility of the programme (in the following section).

\section{Summary of participant's responses}

Table 6 provides a summary of participants views on the credibility of the $\mathrm{LUCl}$ outputs both before and after undertaking the ground-truthing process.

While this summary is useful, it does need to be considered in the context of the following discussion as, in isolation, these numbers are to a degree 
misleading. The factors influencing perceived credibility are complex and (particularly for the post-ground truthing) do not necessarily reflect the perceived accuracy of the LUCl outputs and algorithms. Often perceived credibility was a product of whether the participants could accept or act on the management solutions proposed (the following discussion refers).

Table 6: Participants views on credibility of the LUCl outputs prior to and after ground-truthing (GT)

\begin{tabular}{|c|c|c|c|c|}
\hline & $\begin{array}{c}\text { Before GT - } \\
\text { Negative }\end{array}$ & $\begin{array}{c}\text { Before GT - } \\
\text { Positive }\end{array}$ & $\begin{array}{c}\text { After GT - } \\
\text { Negative }\end{array}$ & $\begin{array}{c}\text { After GT - } \\
\text { Positive }\end{array}$ \\
\hline Participant A & 6 & 4 & 5 & 1 \\
\hline Participant B & 2 & 0 & 0 & 1 \\
\hline Participant D & 5 & 0 & 2 & 3 \\
\hline Participant E & 12 & 0 & 3 & 3 \\
\hline Participant F & 6 & 4 & 2 & 0 \\
\hline
\end{tabular}

Based on Table 6 above, perceived credibility increased over the course of the research. However, during the ground-truthing process, more negative than positive comments were made by the participants. To a degree this was anticipated given the flat topography of the area and the large number of human induced changes made to the natural processes in the region (i.e. the use of pumped drains) that were not captured by these initial maps. Notably, Participant E struggled to orient himself in the maps during the groundtruthing process. However, once the maps were updated and landmarks included, Participant E's views on credibility were more balanced between positive and negative. This is illustrated by initial comments on the maps prior to the ground-truthing process:

But I'm a bit, I'm actually, I'm a bit confused there.... 
I really need a ...... farm map with all of our fields and fences and everything on it.

After the ground-truthing process Participant E made the following comment:

.......if I hadn't seen what the council had, it would have been really interesting, but because of, and it was so inaccurate wasn't it, like the first time.....

Participants' B and D both showed concern about the accuracy and therefore credibility of the early maps presented in the first field visit. However, their responses were more positive than negative about the content of the maps after the ground-truthing process. This is illustrated below where both participants compare the maps pre and post ground-truthing:

Participant B: I think when you first presented it to me you were using different information and that seemed a little bit unbalanced, it didn't seem to ring true but looking at the second one it gave me a lot more information.

Participant D: Once correct information was used, it gave an interesting insight to the high risk areas on the farm, and your maps illustrated that pretty well I thought.

Notably participants $\mathrm{A}$ and $\mathrm{F}$ had both positive and negative comments during the ground-truthing process. However, after the ground-truthing process was complete, negative comments significantly outweighed the positive comments. Their (post ground-truthing) concerns are illustrated in the following statements from Participant A: 
....I think the concept of it's awesome, if we can get information

like that back, it's just another whole chapter really isn't it. Like it's still, it needs to go a step further for flat land farms is basically where it's at..........

So when you get a map like that, and this is a really real one, and we were going to sink our money into it, that would be the first one [site] that I would sink my money into.

The initial statement above encapsulates this participant's view that the algorithms used do not yet properly capture the hydrological dynamics on flat land. From the second statement you can see that the participant understands how the information can be used, he just does not think that the information provided in the maps is sufficiently developed for him to use as the basis for investment yet. This does beg the question of whether this participant is showing signs of confirmation bias, i.e. that the information displayed through LUCI is not showing what he expected or hoped and therefore the product is discredited. If this is a common problem among farmers, it may make it difficult to display new or novel information to farmers in a way that they can assimilate with their existing world views. This is explored further in the following section. As a first step to understanding this issue, further work needs to be undertaken to assess the accuracy of the $\mathrm{LUCl}$ outputs, once the degree of accuracy is confirmed, then whether confirmation bias is occurring can be more effectively analysed.

As it is beyond the scope of this research to assess whether LUCl outputs are correct or not, the important issue for this research is that the LUCl outputs are not aligning with Participant A's perceptions of what the outputs should be, and are thus discredited. 
In summary, when taking a high level overview of the change in participants' perceptions pre and post ground-truthing of the maps, the participants' were evenly divided regarding credibility of the $\mathrm{LUCl}$ outputs post ground-truthing with two participants ( $B$ and $D$ ) more positive, two participants ( $A$ and $F$ ) more negative and one participant (E) evenly distributed positive and negative statements.

So how did participants feel about the credibility of the programme outputs and why?

In order to understand how participants felt about the credibility of the LUCI outputs and why, an in-depth text analysis was undertaken. Text coded in NVivo under credibility during ground-truthing and post ground-truthing was analysed. This comparison process looked specifically at the underlying drivers for both the positive and negative comments made by participants.

Nature of the concerns regarding credibility during ground-truthing

\section{Summary of participants' responses}

Participants' comments during the ground-truthing process fell into 4 distinct categories:

- human interventions that altered the natural processes at the study site (such as the inclusion of drains and pumping stations) were not included in base data

- initial elevation data was too coarse for hydrological modelling in flat terrain causing inaccurate representation of the hydrology in the area

- participants unable to orient themselves within the maps (this was because key features such as homesteads and milking sheds had been omitted from some of the early maps).

- Participants' were unable to "see" features such as sub-subsurface water movement on their properties. 
Many of the inaccuracies identified were the result of human interventions on the target properties that were overriding the natural processes being depicted by the LUCl outputs. For example, pump stations and drains were forcing water to move in a direction at odds with the natural fall of the land.

Furthermore, for two of the participants ( $D$ and $E$ ) the initial maps were generated using $15 \mathrm{~m}$ elevation data. Given the flat nature of the properties in the study area, this coarse scale data resulted in some significant inaccuracies in the maps produced. The following participant's statement made at a final interview is illustrative of this point:

Participant D: ....it was credible once you guys came back to us with the correct information, like that LiDAR stuff.......

\section{Positive comments during the ground-truthing process}

There were a number of positive comments made about the accuracy of the information produced in the initial maps presented at the first field visit (refer Table 6). This was primarily where features on the maps tracked with what participants "saw" on their property. This is illustrated with the following statements:

Participant A: Yeah, yeah, yeah, nah like this is interesting because it has showed up, it has showed features on here that are right...

Participant F: Because we do get some water ponding, just about there where there is that green blob......

The final statement above relates to the $\mathrm{LUCl}$ outputs' depiction of points of water accumulation on the maps, with high levels of accumulation identified by a bright green colour. 
Credibility of the maps after the ground-truthing process

\section{Data collection}

Data on participants' perceptions of the credibility of the program after ground-truthing was primarily taken from participants' responses to the final interview prompt on credibility. In addition, relevant statements from field visit's 1 and 2 were also included in this analysis.

\section{Summary of participants' responses}

With the exception of Participant $B$, the remaining four participants all raised credibility concerns about the LUCl outputs post ground-truthing. For two of the five participants ( $A$ and $F$ ) these negative comments were more prevalent than positive comments. Participants' negative comments fell into four categories:

- whether the algorithms that sit within LUCI adequately take into account:

o the hydrological and soil profile dynamics that occur on flat farms

o the nutrient and water uptake of different vegetation types

- whether LUCl's algorithms were supported by sufficient evidence

- whether the soils data was sufficiently robust and the impact this had for the models analysis of nutrient accumulation

- the practicality of the management interventions proposed.

\section{Change in perceived credibility during the research process}

Summary of participants' responses

Negative comments regarding the credibility of the LUCI outputs overall decreased after the ground-truthing process, even for those participants that who retained more negative than positive comments (Participants $A$ and $F$ ). Participant F's concerns primarily related to the evidence base for $\mathrm{LUCl}^{\prime} \mathrm{s}$ assumptions, both in relation to the degree of lateral movement of the hydrology through the landscape, and the role of productive pasture in both nutrient and water uptake. However, Participant A felt that LUCI was not 
adequately taking the lateral movement of water into account, nor the influence of the variations in soil types within the soil profile on that lateral movement. This is illustrated by the following quotes from Participants' $A$ and F.

Participant A: Like I say with stop banks and plantings, it really didn't do a lot. Because, [LUCI] wasn't thinking about that water tracking sideways as such being flat.

Participant F: ....she needs to prove that this lateral movement happens and certain plantings will stop it...

In the case of Participant A, not being able to plant trees on lower elevations on the farm (because it is too wet for trees to survive) meant that vegetation was being planted on the higher points on the property. While this practice has the potential to provide beneficial shading for waterways and reduced wind erosion, neither of these factors was considered in LUCI version 0.2. Therefore, these plantings showed little positive benefit for the ecosystems service's that were under consideration as part of this research. Furthermore, the variation of soil types within the soil profile on Participant A's property may have implications for water movement across the property. This is also not currently considered in LUCI version 0.2 , nor is this level of detail available in national soils datasets.

For Participant $F$, the concept of lateral subsurface water movement through the soil profile was new and he needed further evidence to demonstrate that this phenomenon occurs. As this is a key component of the LUCI hydrological algorithms, (Findings and Analysis: Part 1 refers) this had a negative impact on his perception of the credibility of the model outputs. 
For the remaining participants ( $B$ and $D$ ) however, positive comments about the credibility of the model outweighed the negative comments. By-in-large the positive comments related to where participants could physically observe elements, on their property map, that were the result of underlying processes (such as hydrological routing), with these elements accurately reflecting their understanding of reality.

Participant D: Yeah, they looked very much how I would imagine it should be.

Participant B: It's interesting ah? ...... It's given me an understanding of the weaker areas.

For these participants the LUCl outputs and the scenarios generated were perceived to be credible and useful.

\section{Experience of the modelling process}

Given the phenomenological view that people create their own reality through what and how they decide to interpret (Turner, 2009) this section of the analysis was designed to elucidate: what meanings the participants took from engaging in the process, how they interpreted the information presented to them, and why. Participants were asked about what they thought of the information provided through the modelling process.

\section{Summary of participants' responses}

One participant didn't answer this question. Three participants referred to improving the linkages between what was depicted in the maps and the reality of what was taking place on the property (through physical groundtruthing or using regionalised data such as soils and climate data). Of these three, one participant $(F)$, required more evidence to support the $\mathrm{LUCl}$ 
assumptions and outputs, and both participants ( $\mathrm{B}$ and $\mathrm{F}$ ) felt that the base information needed to be more localised. Similarly, the third participant (D) queried whether the soils data was taken from the Fundamental Soils Layer or SMap, as his understanding was that SMap was more accurate for the region, conversely, Participant B felt that SMap was not an accurate representation of the soils on his property. The final participant (E) felt that the information in the maps was not relevant to him, given the flat and flood-prone nature of his property and the extensive use of flood pumps. This was illustrated by the following statement:

Probably, I'm not overly convinced that, because we have got really low areas, you know, it's all pulled to the flood pump. Which is sort of ... unless you talk about underground water, I can't see the point in trying to plant trees as its being all pulled....

This participant also felt that he had already been provided with similar information by the Regional Council and therefore LUCI was not providing him with anything new. This would indicate that the issue was not with who was delivered the information, but rather what the information included.

\subsubsection{Theme 2: Interpretation of the information}

\section{Research questions}

Theme 2 will address research question 3:

3. How is the information provided through LUCI being interpreted?

\section{Data collection}

At the final interview, participants were asked the following question and prompt: 
Interview question

Tell me what you think of the information provided via the modelling process.

Prompt

What is the information saying to you?

\section{Summary of participants' responses}

Three of the participants ( $A, B$ and $D)$ responded positively to this question. They saw value in the modelling process for planning purposes, and guiding where they should target further investment.

This is illustrated in the following comment:

Participant D: The guts [of it] is once this information is accurate ........ this programme will give us information about how to create sinks essentially.

Participant (B) felt that it would be useful in demonstrating the environmental value of the investment already made on their property, as illustrated in the following statement:

It would be useful information .........it would be another piece of reassuring information to tell $\mathrm{xxxx}$ that we are pointing in the right direction, as best we know...

Another participant $(A)$ suggested that it could be used as a tool to guide farmers when considering the purchase of a farm or additional land. This is illustrated by the following comment: 
...... Like if it's a tool, and if that's available like if you went onto

Wairarapa Viewer, and you could zoom in on every bit and block of land and thought, he looks good, I'll go and see if he wants to sell, because it ticks my box, but if you could put these layers over the top of it, alarm bells might go off or you might say, I'm not into this. But then it becomes a strategic tool, at a higher level ........

Participant (E) felt that the information wasn't anything new for him, but that it may have been useful for the younger generation or someone who had recently acquired new land giving them a head-start in understanding the property's dynamics.

Participant E: ....it depends on how long you have been on the farm, like when we first started farming there weren't discussion groups, and there wasn't these farming papers and things, you just learnt by making mistakes hopefully, and kept making mistakes. I think that now-a-days there's a lot more information and especially if you've got young people coming in, like the next generation, I think they are looking the whole time for specific information and using it, a lot of them. Where as in my generation, a lot of people inherited the farm whether they wanted to be a farmer or not, and they weren't driven the way people are now. They didn't have to be so careful with their finances, if that makes sense. And I think the other thing that it would be useful for is if somebody brought a new farm, you can either go through the learning curve the way we used to in the olden days, or you can actually probably, if you had information like that to pick up straight away, that would put you way ahead for new [farms] .... 
The final participant $(F)$ noted that the process had opened up new concepts that he needed to think about further. He noted that he needed the conceptual framework to be proven with scientific evidence, the statement below refers:

What it's saying to me is that the nutrients move across...laterally across the land, and so it opens up that concept to me, but I would need to see it ground-truthed, and proven. Because it opens up a whole lot of questions about what an active healthy pasture does in the process as well.

\subsubsection{Theme 3: Changes in attitudes and understanding}

\section{Overview}

In order to get a better understand whether engagement in this research had impacted on participants' understanding and attitudes towards ecosystem services and environmental sustainability, participants were presented with a question at both the baseline interview and again at the final interview on both of these issues.

\section{Research questions}

Theme 3 will address research questions 4 and 5 .

4. Are there barriers between information exchange through the modelling process, and the application of that information in land use decisions, if so what are these?

5. How effective is presenting information through modelling processes such as LUCl in influencing environmentally sustainable land-use decisions? 
Understanding of the ecosystem services concept: data collection

Participants were asked questions and prompts for this theme at both the initial baseline interview and again at the final interview.

Baseline interview question

At the baseline interview participants were asked the following question:

How familiar are you with the concept of ecosystems and ecosystem services?

\section{Baseline interview prompt}

- If familiar - Have you considered this concept in the context of your farming operation?

- If not familiar - Are you familiar with the hydrology, soils and nutrient processing capacity of your property (i.e. are you familiar with the concept but by a different name)?

\section{Final Interview question}

"What do you think about the concept of ecosystems and ecosystem services?"

Final interview prompts

- Has understanding increased/stayed the same?

- If familiar - What did you think about how the ecosystem process was depicted through the modelling process?

- If not familiar - What are your thoughts on the ecosystem concept as a result of experiencing it through the modelling process?

Participants' responses to the interview questions were then coded according to familiarity with the concept and how that had changed over the period of the research field work. A matrix query was generated through NVivo, to depict how participants' views had changed. Note, where participants were familiar with the concept of ecosystem services but not the terminology itself, they were coded as "partially familiar". 


\section{Summary of participants' responses}

In summarising this section it was useful to first consider participants base knowledge and how this changed as a result of the research process before considering their thoughts on the concept and its application in farm management.

Has participant understanding of the ecosystem services concept increased, or stayed the same?

Table 7 summarises participants' familiarity with the concept of ecosystem services at the beginning of the research (data derived from the base-line interview), and how that had changed by the end of the modelling process (data derived from the final-interview).

Table 7: Participants' familiarity with the ecosystem services concept as a result of the modelling process

\begin{tabular}{|c|c|c|}
\hline & Increased & Stayed the same \\
\hline Ecosystem Services $=$ F & 1 & 0 \\
\hline Ecosystem Services $=$ PF & 1 & 1 \\
\hline Ecosystem Services $=$ NF & 1 & 1 \\
\hline
\end{tabular}

Key: $\mathrm{F}=$ familiar, $\mathrm{PF}=$ partially Familiar, $\mathrm{NF}=$ not familiar

Three of the five participants $(A, D$ and $F)$ had a better understanding of the concept "ecosystem services" after the modelling process when compared with their initial levels of understanding. For the remaining two participants, understanding stayed the same. Of those two, one participant (E) was partially familiar with the concept prior to engaging in this process and remained so at the end of the process while the other participant (B) was not familiar and stayed the same. 
It is important to note that due to the timing of the field visits, the period between the baseline interviews and the final interviews ranged between 3 and 10 months for the participants (Appendix E refers) and that during this period there was considerable media coverage on the application of the ecosystem services concept through farm management. Therefore, it is not possible to state with certainty that any change in familiarity was a direct result of the modelling process.

What did participants think about the concept of ecosystems services and its application through the modelling process?

There were a range of views expressed by participants on the concept of ecosystem services and its application through the modelling process. While predominately positive, two of the participants ( $E$ and $F$ ) were more ambivalent in their views about the concept as illustrated by the participant quote below:

Participant F: Oh, OK, now I've got a better understanding of that and what do I think about it? Well I understand it and ...... I don't think... like I haven't got an opinion as to whether it's right or wrong or anything like that, it's just it.

Conversely, three of the participants ( $A, B$ and $C$ ) were particularly positive about the concept with comments such as "I think it's got to be good" and "I'm really positive about it". Two of the participants took the conversation a step further as illustrated below:

I think it's a good concept, I think it's a good tool [LUCI], and I think it's a good strategic planning tool.

I think the programme [LUCI] is useful in that respect, and I think you could probably conclude that there is practical measures that 
you can take to enhance ecosystems and enhance locking up nutrients.

These quotes help to illustrate the participants' thinking on how the ecosystem services concept can be applied in the farming context through the application of $\mathrm{LUCl}$.

\section{Role of sustainability in decision-making}

\section{Overview}

In designing this interview question, the researcher sought to establish whether there had been a change in participants' attitudes toward environmental sustainability over the research period.

For this section it was useful to first consider participants' base knowledge and how this changed over the period of the research field work, before considering the participants thoughts on the concept and its application for farm management.

Again, because the field work for this research was undertaken over a period of 3-10 months, staggered across a year, a number of external factors may have influenced participants' attitude within that time. It is therefore not possible to establish a direct causal link between attitude change and engagement in this research.

\section{Research questions}

Theme 3 will address research questions 4 and 5 .

4. Are there barriers between information exchange through the modelling process, and the application of that information in land use decisions, if so what are these?

5. How effective is presenting information through modelling processes such as LUCI in influencing environmentally sustainable land-use decisions? 


\section{Data collection}

Participants were asked questions and prompts for this theme at both the initial baseline interview and again at the final interview.

\section{Baseline interview question}

How significant a role will environmental sustainability play in your land-

using decision-making?

Final interview question

How significant a role will environmental sustainability play in your land-using decision-making?

Final interview prompts

- More significant that previously?

- The same as previously?

\section{Summary of participants' responses}

Table 8 illustrates that at the beginning of the process, four of the five participants ( $A, B, D$ and $F$ ) felt that environmental sustainability played a significant role in the management of their farms while one participant (E) felt that it did not, and this view did not change during the period of the research field work. Notably, two of the participants who felt that environmental sustainability was a significant component of their farm management, felt that that significance had increased over the course of the research; while the remaining two participants felt that it had stayed the same. 
Table 8: Role of sustainability in decision-making prior to and after research field work

\begin{tabular}{|l|c|c|}
\hline & $\begin{array}{c}\text { Sustainability } \\
\text { significant }\end{array}$ & $\begin{array}{c}\text { Sustainability = not } \\
\text { significant }\end{array}$ \\
\hline Increased & 2 & 0 \\
\hline Stayed the same & 2 & 1 \\
\hline
\end{tabular}

On analysis of the text, comments relating to managing production within the limitations of the soils and other environmental constraints were made by two participants ( $A$ and $B$ ). In addition, two of the participants referred to council resistance to them testing new innovative technologies that they believed would reduce environmental impacts. This will be discussed further in Part 3 of this analysis under the section on Innovation and New Technologies.

One of the participants (B) noted that ultimately if the environmental impacts of the farm could not be adequately mitigated, the operation would need to be wound back to the point that it was sustainable (the following statement refers):

I mean that on this farm we are doing a lot of the things that we can do to mitigate it, but at the end of the day it's an agricultural farm and if the water quality is being degraded we'll have to wind back the business, wind back the inputs that we are putting on it, I mean reduce cow numbers [and] balance it back to the point that we can farm.

There was recognition that the participants were already factoring environmental sustainability into their decision-making through decisions to undertake (or not to undertake) further intensification. 
This participant went on to say:

We could increase the production here probably by about another $80-100 \mathrm{~kg}$, but it would be so intensive and so damaging to the environment that it would be unsustainable long-term.

Participant (D) noted their reliance on natural resources for their livelihoods and therefore the need to look after their resource base.

Defining environmental sustainability

While participants were not asked specifically to define what "environmental sustainability" meant for them, four made statements illustrating the way they perceived "environmental sustainability".

.... for us sustainability is simply the ability to do something again and again and again with a perpetual cycle, producing the same results within a margin ...... and it means sustainability for the community involved in farming ...... For us, it's always been about employing local companies to get companies and families working. We try and employ local people, where we can to keep them employed ......... We tend to buy in town, local towns so that to me is about sustainability it's about keeping a whole area alive rather than just your farm.

Another participant had similar views, with the focus of sustainability being on sustaining production into the future.

... I want this farm to produce to the maximum, but I want it to do that for a long time, I don't want to run it out. So I want it to be sustainable. 
It is notable that despite being questioned about the role of "environmental sustainability" in farm management, only one of these participants linked sustainability to the environment. Rather, sustainability was linked to the ability of the farm to continue production in perpetuity. This issue will be discussed further in the discussion section.

\subsubsection{Theme 4: Utility of the model}

\section{Overview}

This stage of the process was designed to understand how useful the model was perceived to be by the participants for both themselves and others and why. In considering "why", the prompt was developed to identify factors influencing participants' perceptions of utility and potentially the tools credibility.

\section{Research question}

Theme 4 will address research question 4:

4 Are there barriers between information exchange through the modelling process, and the application of that information in land-use decisions, if so what are these?

\section{Perceived utility for the participants: data collection}

At the final interview, participants' were asked the following question and prompts:

Interview question

Do you think this modelling will be of use to you in future land-use decisions?

Prompt

Can you list in order of priority which of the following are more important to you when making a decision on the management of your property, and 
give any comments on your reasoning - note there is no right or wrong

answer:

- intuition

- previous experience

- social norms

- short-term financial return

- modelled data through a decision support tool such as LUCI.

\section{Summary of participants' responses to the overarching question}

Participants' responses were predominantly positive, three of the five participants ( $A, B$ and $D)$ saw $L U C l$ as a useful planning tool, though two participants ( $A$ and $F$ ) noted that while LUCI had identified "hot spots"8 on their properties, management interventions to mitigate some of those hot spots had not been identified when using wetland rehabilitation and planting vegetation as management interventions. This information now required further consideration by the participants to consider how to manage the issues identified. The following statement helps to illustrate this point:

It's interesting, because it's made me look at some of those areas and I've thought about how can I do anything with them, and it [the research process] hasn't given me enough for that yet.....

Linked to the above comments, participants suggested that a broader range of management interventions be added to the tool (Finding and Analysis: Part 1 refers).

Participant (B) felt that the tool helped to justify past pro-environmental expenditure on his property. This is illustrated by the following quote:

\footnotetext{
8 "hot spots" refer to areas on the property identified by $\mathrm{LUCl}$ as areas where there is an opportunity to improve provisioning of one or more of the ecosystem services under consideration
} 
So it backs up good decision-making, and it adds a bit of science behind it. So that [you] can see that the decision-making is not just for making it [the property] look pretty, but it shows that there are some true benefits from it, and it shows that the benefits are actually happening. It gives another added edge to it, so that's where I find it useful, to explain what we are trying to do.

Again participants felt that it was a good planning tool and one participant $(A)$ extended that to supporting decision-making on purchasing new or additional land. He queried whether this information would ever be publically available.

Two of the participants were more cautious in their responses, with one (Participant F) stating that:

It's got potential for further exploration and investigation...

The final participant (E) did not feel that the modelled outputs would be useful for them for the following reasons:

..... it's probably not as important there, because we haven't got the effluent problem, and so that's quite important. And with the stand-off areas that we use over there, we really just have to use ...... we can't really be too fussy, because we've got so few places and everything's so wet that rather than put them in the bedroom, you put them somewhere where its wet...

This participant felt that because of their location and outside influences they were limited in the management options available to them. They also noted that: 
Yes, because we get water from everybody else that keeps draining away water, cause [it] all comes very quickly to us.

From these statements it is clear that this participant did not believe that the management options proposed through this process were practical in their circumstances.

\section{Perceived utility for the participants: data collection for the prompt}

In summarising participants' responses to the prompt for the question on utility, a matrix query was run to establish at a high level, an understanding of the patterns emerging regarding the common factors driving decision-making.

Note that while participants were given a number of examples of possible factors, the question was open-ended, allowing them to identify whatever factors they felt important to them when making land-use decisions. In coding responses "information", "evidence", "knowledge" and "data” were coded under "information". Relevant text was selected based on participants' decision drivers. Note that it was not possible to do a summary of how participants ranked decision drivers, as each participant did this task in a different way. Therefore undertaking a collective ranking of these drivers may result in inaccurate and potentially misleading findings. Instead, the researcher used the NVivo matrix query function to create Table 9. Table 9 summarises the number of times that participants referred to their decisiondrivers in all of their transcripts. This was done through a combination of free coding and using the NVivo text search function when looking at the responses to this interview question.

\section{Summary of participants' responses}

Table 9 illustrates the importance of both financial return and information to participants, though it is notable that in the case of financial return, for two of 
the participants $(A$ and $B)$, this issue recurred multiple times in their transcripts. However, it was also raised at least once by four of the five participants. Similarly, the role of "information" was also raised at least once by four ( $A, B E$ and $F)$ of the five participants.

Table 9: Number of times participants referred to specific decision-drivers

\begin{tabular}{|c|c|c|c|c|c|}
\hline & $\begin{array}{c}\text { Participant } \\
\text { A }\end{array}$ & $\begin{array}{c}\text { Participant } \\
\text { B }\end{array}$ & $\begin{array}{c}\text { Participant } \\
\text { D }\end{array}$ & $\begin{array}{c}\text { Participant } \\
\text { E }\end{array}$ & $\begin{array}{c}\text { Participant } \\
\text { F }\end{array}$ \\
\hline $\begin{array}{l}\text { Financial } \\
\text { return }\end{array}$ & 12 & 15 & 0 & 0 & 2 \\
\hline Information & 1 & 6 & 0 & 1 & 4 \\
\hline Intuition & 0 & 1 & 1 & 1 & 0 \\
\hline $\begin{array}{l}\text { Modelling } \\
\text { tools }\end{array}$ & 0 & 2 & 1 & 0 & 0 \\
\hline Practicality & 1 & 0 & 0 & 0 & 1 \\
\hline $\begin{array}{l}\text { Previous } \\
\text { experience }\end{array}$ & 1 & 0 & 1 & 1 & 2 \\
\hline Social norms & 0 & 0 & 1 & 0 & 1 \\
\hline $\begin{array}{l}\text { Environmental } \\
\text { limits }\end{array}$ & 1 & 2 & 0 & 0 & 0 \\
\hline Sustainability & 1 & 1 & 0 & 0 & 0 \\
\hline
\end{tabular}

Two of the participants ( $D$ and F) mentioned social norms, predominantly in the context of what the farm looked like from the road and undertaking planting to improve the perceptions of observers. This information is discussed in greater detail in Findings and Analysis: Part 3. 
Perceived utility to others: data collection

Interview question 2

"Do you think this information/modelling process will be useful to others in the catchment/community in informing land-use decision?"

\section{Prompt}

What weighting do you think this information will be given relative to other resource use decision drivers?

In coding the transcripts for this theme, references to the Greater Wellington Regional Council and councils more generally were collectively coded to "regional councils".

A matrix query was used to generate a table (Table 10 refers) identifying the number of times participants identified other possible users for LUCI (in all of their transcripts).

\section{Summary of participants' responses}

From the data in Table 10, all participants mentioned the potential utility of $\mathrm{LUCl}$ to regional councils. Similarly four out of the five participants noted the potential use of LUCI by farmers with hilly properties, particularly as points of accumulation would be more pronounced.

On closer analysis, one participant (B) felt that $\mathrm{LUCl}$ could be used as an incentivising/information tool for farmers in a catchment to see the benefits that their neighbours are deriving from certain land management practices such as planting vegetation and rehabilitating wetlands. It was noted by one participant $(E)$ that the benefits of using $\mathrm{LUCl}$ may be uneven, for example it may be more useful on some types of farms and not on others. 
Table 10: Utility of LUCI for others: number of times participants referred to LUCI being useful for other potential users

\begin{tabular}{|c|c|c|c|c|c|c|c|c|}
\hline & 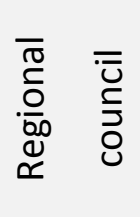 & 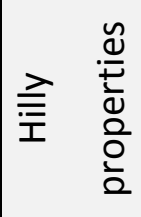 & 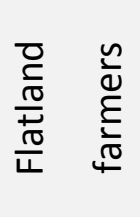 & $\begin{array}{l}\frac{n}{2} \\
\frac{1}{3} \\
0 \\
3 \\
\frac{1}{2}\end{array}$ & $\begin{array}{l}\stackrel{0}{0} \\
\stackrel{5}{7} \\
\stackrel{0}{\nu}\end{array}$ & 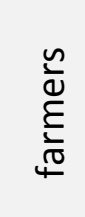 & : & 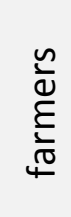 \\
\hline Participant A & 2 & 2 & 2 & - & & - & & - \\
\hline Participant B & 2 & - & - & - & & - & & - \\
\hline Participant D & 3 & 3 & - & - & & - & & 1 \\
\hline Participant E & 1 & 3 & - & 3 & & 2 & & - \\
\hline Participant F & 3 & 1 & 2 & - & & - & . & - \\
\hline
\end{tabular}

This participant (E) also noted that it may be of more use to the "younger generation" or people that are new to their properties as opposed to older farmers that had learnt about the dynamics of their properties through trial and error.

Two of the participants ( $A$ and $F$ ) felt that LUCI had potential, once some outstanding issues (such as an improved evidence-based and physical groundtruthing) had been resolved.

In response to the weighting that this type of information might be given in land-use decisions by other farmers in the community, three participants 
directly responded to this question. Participant E made the following observation:

...... think that in some places, in some types of farms, it would be really, really important, how do you put that? Important I guess, useful, useful. Really, really useful, and then I guess in some places, it may be a waste of time.

In responding to this prompt, the final participant $(F)$ felt that the weighting given to this type of information by others would "depend on regulatory authority uptake of it. At the moment that's OVERSEER, and if LUCI becomes another part of it, then that's something as well".

Another participant (D) noted that these types of tools "are likely to be driven by leading farmers and regional councils".

Finally one of the participants (F) made the following observation in response to this:

......most people are practical people rather than theoretical, and models are for theoretical people. Where-as practical people see the result of their actions, and change their actions accordingly.....

However, this does not accommodate situations where the effect of an action is not immediate (e.g. it can take a long time for the impacts of nitrogen loading to become evident) or where the impacts occur downstream or at a different place (e.g. the cumulative impacts of nitrogen loading in lakes and estuarine areas, resulting from upstream farming practices). Finally, an interesting observation was made by one of the participants ${ }^{9}$ about the less favourable farming practices of others in the farming community:

\footnotetext{
${ }^{9}$ The participant identifier is retained in this case to protect the participant
}

$$
\text { P a g e | } 137
$$


.....the people that are not, are never going to use this system [LUCI] and their farms are just going to be whatever they are ....... and you can pretty much see that from the front gate. Like we are caretakers of the land, we can't take it with us. So you hope that you leave it better than you were before....

With this exception, by-in-large participants were very careful not to comment on others in the farming community. This raises a number of questions about why this might have been the case, whether it relates to comments in Part 3: Findings and Analysis, on fairness and equity. This would be a useful avenue for further research.

\subsection{Part 3: Findings and analysis: thematic analysis}

The following section provides a thematic analysis of the participants' transcripts. Themes include the role of information in influencing decisionmaking; finance, regulation and issues of equity; and the potential role of innovation and new technologies.

\subsubsection{Theme 1: Information}

\section{Overview}

LUCl is essentially a tool for providing information to decision-makers. However, the literature review indicates that while information alone is unlikely to drive pro-environmental decision-making, it is nonetheless an important component of decision-making (Kollmuss and Agyeman, 2002, Fisk and Larson, 2011; Kennedy, 2010; Mackenzie-Mohr, 2000; Stern, 2000). In order to understand the utility of LUCI for influencing decisions, this section will focus on participants' perceptions of the importance of information and how and when it contributes to their decision-making. The role of participant 
generated data and whether it has any bearing on perceived credibility will also be considered.

This section will address the following questions:

- What is the role of information in decision-making?

- How do participants' perception of information and modelled outputs differ?

- How do participants perceptions' of information, evidence and physical ground truthing differ?

\section{Research questions}

Theme 1 of Part 3 will inform research questions 4 and 5.

4. Are there barriers between information exchange through the modelling process, and the application of that information in land-use decisions, if so what are these?

5. How effective is presenting information through modelling processes such as $\mathrm{LUCl}$ in influencing environmentally sustainable land-use decisions?

\section{Data collection}

In drawing together the data for this section, I refer to the results of Table 9 and the number of times participants referred to information as an important factor in influencing decision-making.

Further data for this section was derived from the transcripts and coded to "information", coupled with a "text search" for all references to "information", "info", "knowledge", "evidence" and "data" within the transcripts. In addition, I looked at how participants' perceptions of the credibility of information/data changed as a result of having been directly involved in the ground-truthing of that data. 


\section{Summary of participants' responses}

What is the role of information in decision-making?

Refer to Table 9 for a summary of the number of times participants referred to information in decision-making. In summary, a number of participants referred to information as helping to inform better decision-making. One participant (F) stated that:

It's quite interesting times as far as farming goes, and the environment goes, and animal welfare goes, so the more information that we have the better equipped we are to make decisions. And I guess in your case you're providing a tool, once you have that information.

One of the participants $(A)$ linked information to stewardship, recognising that farmers are reliant on other specialists to inform their decisions and perform their land stewardship duties. This was illustrated through the following statement:

......we are caretakers of the land, we can't take it with us. So you hope that you leave it better than [it was] before, and if we can get information that can help us to make it better, because we are not all tree people, we are not all soil scientists, we're caretakers on a very broad range of things and the more tools we've got to simplify our decisions the better.

Another participant (B) likened information and modelled data to a fall-back plan, for when the pressure comes on, providing an opportunity to think about different options. This was illustrated in the following statement: 
... so when you are getting, or when pressure comes on from the councils, its gives you an alternative to come back to, to say if I do things this way I can change things.

How do participants' perceptions of information and modelled outputs differ? Only one of the participants (F) differentiated between modelled information and information itself, expressing some apprehension about the modelled information. This is illustrated through the following statement:

In the end, that evidence for the ground-truthing of work that's being done is so important. Because I am going to a meeting on Xxxxxx where we are looking at what has been described as a whole lot of models tied together with assumptions. When it starts to effect people you think somebody has got to tidy this up to make sure....... ${ }^{10}$

\section{OVERSEER}

Many of the participants were familiar with the OVERSEER model. Many comments on OVERSEER showed that participants recognized that it was designed as a tool to help farmers but that it was now being used by regulators to measure the performance of farmers/inform regulations/enforce regulations.

Researcher: Oh...OVERSEER?

Participant: Yip, that's the only tool we have, and it was a tool and now it's being used as a ruler, it's only a tool. Unfortunately it's what the people who developed it would never have wanted.

Participants were wary about LUCl eventually being used in the same manner. This is illustrated in the following series of statements. It is notable that

${ }^{10}$ This statement did not refer to $\mathrm{LUCl}$ 
OVERSEER was raised independently by four out of five of the participants (A, $B, D$, and F):

....but I mean OVERSEER is the same, but it's just been picked up by the regional councils to use as a regulatory tool.

That's where OVERSEER was designed as a tool to help farmers as well, but its turning into a regulatory tool.

Nonetheless there was also considerable discussion about how $\mathrm{LUCl}$ and OVERSEER could be made to work together. It was noted that they are similar, but that they have different strengths that could complement each other. This is illustrated in the following comment:

I think that the model [LUCI] is definitely a good tool, I can see a benefit from it for long term strategic planning and for positioning farms for the future. I think it's going to be a must do. OVERSEER is a great tool to but it's more rigid in dealing with imports and exports and it doesn't ..... it shows you what is happening now, but it doesn't show you what the bigger picture is going to be. And so it is more of a here and now one, where this [LUCI] is more of a strategic planning one, and it can show you a deeper understanding I think as well.

Another participant noted the following:

.....but it would be interesting to know exactly how much nitrate is collecting in these target areas. Because OVERSEER is from the whole farm nutrient budget basis from what I understand.... 
How do the participants' perceptions of information, evidence and physical ground-truthing differ? What implications does this have for their views on the credibility of the modelled outputs?

In summary, one participant (E) felt that information was useful where you did not have previous experience to rely on. Another participant (F) linked previous experience to self-generated evidence of a fact. Only one of the five participants (F) focused specifically on the linking of evidence, information and ground-truthing. Modelled information was considered as separate, built from information and tested through ground-truthing to provide evidence of its accuracy. Its credibility therefore depended on the extent to which it had been ground-truthed. This is illustrated by the following statement:

Participant F: Evidence makes the biggest difference and previous experience is generally linked to evidence because you can say this has happened, this has actually happened.

As stated previously (Findings and Analysis: Part 2 refers), four of the five participants raised the issue of ground-truthing the baseline LUCI outputs. Ensuring that the ground-truthed baseline maps closely reflect how the participants perceive their properties to be functioning is a significant element in gaining credibility. Researcher explanation's regarding why the model might be producing certain results (i.e. because it is not accounting for human induced changes to certain parts of the property) did not seem to assist in this process. Rather, the need for the baseline maps to be locked down so that they reflected what was happening "out the kitchen window" was a fundamental step for them to be able to move on to the next phase of generating a scenario with any credibility. Interestingly, the generation of a scenario to illustrate the effects of removing human interventions and how those features (i.e. drains) were altering the functioning of the property was accepted as a scenario, only once the maps had been ground-truthed with 
participants. At this point they quickly moved into a problem resolution frame-of-mind, discussing options around wetland rehabilitation and its practicality at these sites.

To drain further out in the farm, you need this level to be down here ...... unless you have a really low wetland, which would involve quite a lot of earth moving........... Did you say you had some guidelines for creating wetlands ......... because I can see the potential for a wetland there. It's just somehow you've got to get a wetland there that's big enough and low enough.

This participant (F) also noted:

....the more we realise what is coming out [nutrients] and what we should do about it, [and] what good researched options there are, that might not necessarily break the bank.......

Finally, for three of the five participants ( $A, B$ and $F$ ) existing vegetation was removed from the baseline maps, as a scenario to help demonstrate the benefits that the participants were deriving from their existing management practices. Again, this could only be done with any credibility once the initial maps had been ground-truthed and reflected exactly what the participants understood to be accurate depictions of how their farms currently functioned. The following statement illustrates how Participant B interpreted this scenario output:

...it showed us clearly that there were benefits for what we were trying to achieve and so it just gave us an assurance. I would have liked to have had that information ........way back 10 years ago to get things happening faster..... it confirmed what we were thinking. 
In summary, credibility was built through the accuracy of the base-maps, however, even when base-maps were perceived to be accurate, the scenarios were not necessarily perceived to be credible (Table 6 refers). This indicates that for at least two of the participants, either the way that $\mathrm{LUCl}$ generated the scenarios was not perceived to be credible or there were other factors that were influencing their views. An insight as to what those other factors might be can be drawn from the participants' responses to the interview question on decision-drivers (Table 9 refers).

\subsubsection{Theme 2: Finance, regulation and equity}

\section{Overview}

The issues of equity, finance and regulation appeared regularly in the transcripts of three $(A, B$, and $F)$ of the five participants. The underlying concepts of feeling powerless, undervalued or misunderstood appeared to be common underlying factors for some of the participants ( $A$ and $B$ ). It is notable that these issues were not actively searched for in the questions or prompts, but were nonetheless identified in the transcript analysis.

In considering this issue, participants' comments about financial pressures, equity and regulation were analysed separately. Then how these three themes seem to be converging and what role tools such as LUCI play, or could play in this evolving discussion was considered.

\section{Research questions}

Theme 2 of Part 3 will inform research questions 4 and 5.

4. Are there barriers between information exchange through the modelling process, and the application of that information in land-use decisions, if so what are these?

5. How effective is presenting information through modelling processes such as $\mathrm{LUCl}$ in influencing environmentally sustainable land-use decisions? 


\section{Finance}

\section{Overview}

When considering the results of the matrix query on participants' land-use decision drivers, (Table 9 refers) there was a notable number of references to finance from two ( $A$ and $B$ ) of the five participants, with one further participant (F) mentioning finance on fewer occasions. This focus on the role of finance in decision-making for a few of the participants warranted further investigation. In addition, understanding why it was of such importance for some participants and equally, not at all for others also warranted further analysis.

\section{Data collection}

Table 9 provides a breakdown of the number of times participants returned to discussions on finance as a driver for decision-making. In addition, a matrix query was run looking at the participants' time on their properties and decision drivers to establish whether there was a connection between how recently the property was acquired and financial pressures.

A text analysis was then undertaken looking at the references to "finance", "funding", "cost" and "money". Irrelevant text or comments from the researcher were then removed. Colloquial references to financial issues where identified during the coding process with phrases such as "bangs for your bucks" and "return on investment" coded to the "Finance" theme.

\section{Summary of participants' responses}

Refer Table 9 for a summary of how many times participants' referred to finance as a driver for decisions when compared with other decision drivers. From the table it is clear that financial drivers were referred to significantly more often than other decision drivers by two of the participants ( $A$ and $B$ ). Conversely, two of the participants ( $D$ and $E$ ) did not refer to financial drivers 
at all in response to this question, nor in their discussions during the course of the field work. For a fifth participant (F) references to financial drivers were second equal to references to previous experience and information as their key drivers for decision-making.

Analysis of the text indicates that for the two participants ( $A$ and $B$ ) that raised finance most often, management options were carefully weighed up against costs. This process is referred to as a "balancing" process. This is illustrated by the following comments:

So I mean us farmers we always want to put a budget around something and a level of importance...

This was echoed by the third participant (F) who raised finance as a component of decision-making, when he referred to whether "that [is] your best bang for buck environmentally".

The unknown and often unmanageable impact of external factors appeared to be an underlying issue for both participants $A$ and $B$, and was a recurring theme in many of their comments. This is illustrated by the following quotes:

Participant A: ...but it's just ....... if they start putting caps on production, I'll kiss my house goodbye, I'll lose it, and what am I going to get for it, nothing because nobody's going to be able to come here and do production because all of a sudden my $\$ x x x x$ farm is going to turn into a $\$ x x x x x$ farm and....

Participant B: We have to be super-efficient to survive and we are relying on trying to sell our product on the other side of the world. You may as well be trying to ship it to Mars sometimes, and find out what Martians like to eat! So when you get a year like this 
when there has been turmoil in the world and it comes back and reflects on what we are going to get as an income, you start to think "well how can I sharpen up here and do things better", and like for us here, we are starting to run out of ideas.

A second underlying factor for these two participants was the significant financial debt carried by farmers. Again this is best illustrated through their own words in the following statements:

Participant B: That's why we all work in order to make a quid or two, but my problem's been trying to go out there and buying a farm, I never realised how hard you would have to work and how long you would have to work for, and still never truly own the farm.

Participant A: But we can plant species that can take nutrients from here to here in our hot spots, we can mix species and plant types, there are so many tools that we've got if we just know what we are doing. It's just, and we all want to do what is right. But the biggest trouble or underlying thing is money, like the bank......All of us, like we've all got way too much debt.

As the researcher engaged in this discussion, the sense of frustration was palpable on one hand, and weariness on the other.

In order to see whether there was a connection between participants who had raised the issue of finance and how recently they had acquired their farms, a matrix query was run using NVivo (Table 11 refers).

Participants:

Time on property

2 years 
Table 11: Number of years on the property and references made to various decision drivers

\begin{tabular}{|c|c|c|c|c|}
\hline & 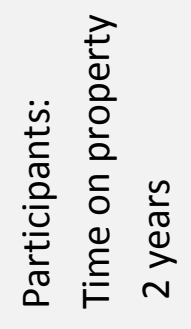 & 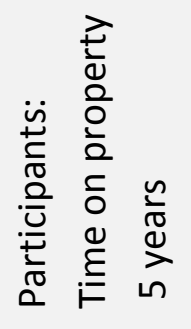 & 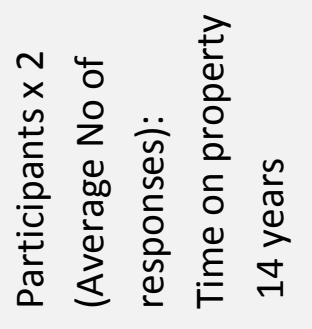 & 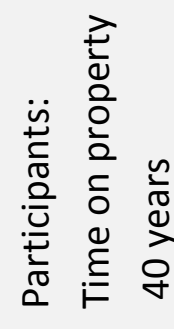 \\
\hline $\begin{array}{l}\text { Financial } \\
\text { return }\end{array}$ & 2 & 12 & 7.5 & 0 \\
\hline Information & 4 & 1 & 3 & 1 \\
\hline Intuition & 0 & 0 & 1 & 1 \\
\hline $\begin{array}{l}\text { Modelling } \\
\text { Tools }\end{array}$ & 0 & 0 & 1.5 & 0 \\
\hline Practicality & 1 & 1 & 0 & 0 \\
\hline $\begin{array}{l}\text { Previous } \\
\text { experience }\end{array}$ & 2 & 1 & 0.5 & 1 \\
\hline Social Norms & 1 & 0 & 0.5 & 0 \\
\hline
\end{tabular}

My suspicion is that the participants that had most recently bought their properties (at current property prices), particularly given the low dairy payouts that have occurred in the last 12 months (refer Table 11) would be the most likely to raise the issue of finance and the pressures associated with financial return, was not conclusive (Table 11 refers). Note however, that this question evolved as part of the analysis process and issues such as ownership and governance arrangements for the properties, participant age, whether the property was a first property, or one of multiple properties all have potential to influence this issue. Unfortunately, the questions and prompts in the initial and final interviews were not constructed to investigate this line of questioning. However, it would be an interesting avenue for further research. 
It is notable that two participants ( $D$ and $E$ ) did not mention finance at all. This issue did not become apparent until after participants $D$ and $E$ had completed their field work. There may have been a temporal component to these themes given their alignment with external events (e.g. drought, reduced dairy prices and the initiation of negotiations over new nutrient discharge limits) during the summer of 2014/15 when the field work for participants $A, B$ and $F$ was undertaken. This is raised again in the discussion section of this document.

\section{Regulation}

\section{Overview}

Given the nature of the comments made by participants in the section on finance (refer section above), deeper analysis was undertaken to assess whether the unknown nature of potential impacts of future regulation were of concern only to the participants who had a significant focus on finance in decision-making, or if these concerns were shared by the other participants.

\section{$\underline{\text { Data collection }}$}

A "regulation" theme was established and relevant text was coded to this theme. In addition, a text search was undertaken on the words "regulation", "compliance" and "regulatory authority". The results of the text search were checked to ensure that they referred to statutory regulation as opposed to environmental regulatory cycles.

\section{Summary of participants' responses}

Based on Table 12, four of the five participants ( $A, B, D$ and $F)$ referred to regulation at least once during the research process. One of those participants $(F)$ referred to regulation on multiple occasions. 
On closer analysis of the text, for one of the participants $(A)$ their concern related to potential pressure being brought to bear on nitrogen loss, despite "not [being] big users". Two of the participants referred to regulation in the context of OVERSEER noting that OVERSEER was a tool developed to support farmers and it was now "being used as a ruler". Participant (B) also referred to compliance and the "rules" changing again in a few years' time. His concerns related to councils being ill equipped to deal with innovative solutions. A further participant (D) noted that the regional council is not overlaying farmers with regulation, but rather "using the carrot and not the stick". The final participant (F) referred to regulation on a number of occasions (refer table above). This participant raised regulation in relation to engagement by external parties with LUCl and noted that he did not know the proportion of nutrients his property was contributing to the waterways when compared with others within the catchment.

Table 12: Number of times participants referred to regulation

\begin{tabular}{|l|c|}
\hline & Regulation references \\
\hline Participant A & 1 \\
\hline Participant B & 2 \\
\hline Participant D & 1 \\
\hline Participant E & 0 \\
\hline Participant F & 4 \\
\hline
\end{tabular}

For two of the participants ( $A$ and $F$ ) concerns about the unknown nature of future regulation and the potential impact it might have on their management options seemed to be an underlying concern.

Participant A: Absolutely, like it's cause we're looking after the worms, the roots, the grasses and we're trying to balance 
everything and we're growing a xxxx load of clover, you know? So hence, the nitrogen is there for the grass to grow and it's just [a] whole cycle... but it's just, I can sense or feel this storm coming, you know the councils, and I'm just afraid they're going to trip me up....

Notably, one participant did not mention regulation at all (Participant E). Ironically participants ( $A$ and $B$ ) were trying to future-proof investments through the development of engineered solutions that went beyond compliance with existing environmental controls, as a way of maintaining some control over the currently murky situation. Both participants noted that council processes were struggling to deal with innovative solutions. This is illustrated by the following statement:

So what we are saying is that we understand that we are over concentrating but that we know now what is causing it, so what we think we should be doing is capturing and processing and using the effluent over a far wider range, and using the nutrients to replace imported phosphates and fertilizer's and they [council officials] just can't get their heads around it. And they keep on coming back and back for more information, and I am beginning to wonder if they don't understand, and they are going to force us to build something that we don't want, or won't work. 


\section{Equity}

\section{Overview}

On analysis of the transcripts, equity was another recurring theme that became evident. An "equity theme" was therefore set up and all references coded to it for analysis.

\section{$\underline{\text { Data collection }}$}

All comments relating to "fairness", "lack of recognition of role in community", and "lack of control over the future" were coded under this theme during the transcript analysis process. Sub-themes were then identified and coded.

Analysis of the coded data was undertaken in two ways, firstly, a matrix query was used to establish how many times participants referred to each of the sub-themes (Table 13 refers). A text analysis looked for patterns and linkages in the sub-themes.

\section{Summary of participants' responses}

Based on Table 13, four of the five participants (A, B, D and $F)$ made comments about the fairness (or lack of fairness) playing out in public discourse at present. The same participants also made reference to issues associated with a lack of control over aspects of their future. A different combination of four participants $(A, B, C$ and $F)$ commented often on innovation, innovative solutions and farmers generally working in the innovation space. This will be discussed further in the following section on new technologies and innovation. 
Table 13: Number of time the participants referred to issues of equity and innovation

\begin{tabular}{|l|c|c|c|c|}
\hline & Fairness & $\begin{array}{c}\text { Control over } \\
\text { future }\end{array}$ & $\begin{array}{c}\text { Lack of } \\
\text { recognition }\end{array}$ & Innovation \\
\hline Participant A & 5 & 5 & 3 & 5 \\
\hline Participant B & 4 & 1 & 6 & 6 \\
\hline Participant D & 0 & 0 & 0 & 1 \\
\hline Participant E & 2 & 3 & 0 & 5 \\
\hline Participant F & 1 & 1 & 0 & 5 \\
\hline
\end{tabular}

It is notable that one of the participants did not discuss issues of equity in any of his transcripts.

\section{Fairness}

There was considerable comment amongst the majority of participants ( $A, B$, $E$ and $F$ ) on the fairness of the public discourse on the environmental impact of the dairy industry at present. Comments such as: "it's where farmers feel victimized" and "the dairy farmers themselves are so gun shy, you feel like a rabbit that's been shot at a lot", are indicative of a perceived lack of equity or fairness in this discourse.

One of the participants (A) noted "you talk to anybody and they think you're a dirty dairy farmer". Ironically this came from the one participant who was not a dairy farmer, indicating that this public perception may be impacting the rural sector beyond the dairy industry.

One participant (B) went on to comment on his experience entering the dairy industry, taking an outsider's perspective on an industry that he now had insider's knowledge of: 
When I started dairying, because I am not from a dairy background, I viewed farmers or dairy farmers, I didn't really know anything about them. But I thought they seemed like fine people, that weren't out there to destroy the world at any cost. And working with them, I have never found that, I have found people that are hungry to make money, but I have found [that] in the cities as well......

The blame game: who is messing up our waterways?

Another issue that was raised on several occasions by some of the participants relates to their perception that the farming industry was being unfairly blamed for the state of the waterways, particularly when they believe that there are other point source pollution impacts on the waterways within the region that are having a greater impact than nutrient run-off.

The following statements serve to illustrate this point:

I mean they are hammering us for a lot of things, but the water don't just come from here.

Look at all this bloody wastage, I mean Masterton, Carterton and Featherston all pumping $x x x x$ [effluent] into the river...

Yeah..... we are farming the land and the local environment, and we don't want to xxxx in our own nests, we fish from the rivers, we are the first to go fishing, not the guy from town. The guy from town wants to go there, but a lot of the farmers, people who work in the country, live in the country, and they like going into our streams and a lot of the farmers are really grumpy about the Ruamahanga River because it is not the farmers who have wrecked it, it's the Masterton City that has wrecked it. And that is 
why it's unsafe, because their effluent system is discharged into it, and has wrecked the water supply.

Three of the participants (A, B and $F$ ) were unclear as to just how much they were contributing to the nutrient problem. It was noted that the council was taking water samples in the area, and where relevant participants were cooperative and interested in the results. However, since the samples were only being collected at a restricted number of points along the waterway, the process did not appear to inform farmers of their relative contribution to the water quality issue. To do this they would need to have regular water samples taken at the entry and exit points for all water sources that traverse their properties.

\section{Control over the future}

Another recurring theme in four of five of the participants' transcripts related to having a "lack of control" over issues that may affect how, when or if they can operate as a profitable farm into the future. Overlaps between this section and the section on finance will be discussed separately below. The following statements from participants illustrate a sense of unease about the future:

I mean what if they start really chasing us hard, I want to be in front of the game and be proactive and xxxx this is what we do, and you know by telling you what we are doing and programming it in here [through LUCI], it [LUCl outputs] say[s] no, this changes the programme for this area...

I don't want to be tarred with a big wide brush, I want to be singled out with a little fine tip, and that's where our goals are for the business. 
...so that's more or less what $x x x x^{11}$ was doing based on the soil structures and soil types, it all sounds very experimental and we seem to be the guinea pigs, the dairy farmers, which is a bit sad because it costs a hell of a lot of money to be experimented with....

Yes I know, it's just that you get given so many... you get told to put effluent where it's gravelly, and stony, and you think surely that would leach more than heavy country, and that's an expert that says that, so......

I can sense or feel this storm coming, you know the councils, and I'm just afraid they're going to trip me up, you know if they start putting caps on production, I'll kiss my house goodbye, I'll lose it, and what am I going to get for it, nothing because no bodies going to be able to come here and do production because all of a sudden my $\$ x x x x^{12}$ farm is going to turn into a $\$ x x x x x$ farm and....

This links to comments made in the previous sections regarding lack of knowledge about what nutrients participant properties were contributing to the waterways, what the new regulations will entail and how this will impact on their ability to operate, with financial implications not just for meeting mortgage payments but also for the value of their properties, should current production levels be deemed environmentally unsustainable.

\section{Lack of recognition}

Another sub-theme that emerged from analysis of the text coded under the equity theme related to a perceived lack of recognition of the role that farmers and the farming industry plays in local and national food and economic security. The following statements from Participant A are

\footnotetext{
${ }^{11}$ Name removed as it could impact on anonymity of the participant

${ }^{12}$ Numbers removed to protect confidential information
} 
illustrative of this point.

We all carry a lot of stress, and then you go through all of that, and all the weather events that we get, and we try to do the best with the stock, and then you get some bloody townie ping you because you've driven some cow xxxx across the road. They have no concept where the $\$$ comes from to drive the towns......

Too much of this stuff like the town versus the country can get [you] too far apart and it's not right, and it's a shame, because basically agriculture is the basis of our country......

Comments relating to the town versus the country and the academics versus the land managers came up regularly. It is likely, however, that misunderstandings occur from all sides. This currently divisive discourse, while possibly necessary to raise the profile of water quality issues needs to now find a common ground upon which to start building solutions to what is effectively a collective problem.

\section{Financial drivers, equity, and regulation: what do they have in common?}

\section{Overview}

In analysing the themes of finance, regulation and equity it became apparent that many of the same participants spoke extensively on these three topics, often as a package of interrelated issues. It was felt that this warranted further analysis in order to try and understand what was the root cause of these collective concerns. It was also notable that one of the participants (D) did not engage in discussion on these topics at all. 


\section{Data collection}

The data for this section drew on the data collected under equity, financial drivers and regulation, as discussed above. A matrix query was run looking at the number of times participants raised the issues of finance, regulation and equity. Note that equity is broken down into sub-themes of "control over future", "fairness" and "lack of recognition".

\section{Summary of theme analysis}

Based on Table 14, four of the five participants' commented on issues of equity (control over future, fairness and lack of recognition). Notably Participant $D$ did not comment on financial issues and his one comment on regulation was as follows "the Greater Wellington Regional Council are not overlaying us with regulation, they are using the carrot and not the stick". Also of note is that Participant E did not refer to finance or regulation but raised equity related issues on a number of occasions. Participants $A$ and $B$ both talked extensively about all of these themes, whereas Participant $\mathrm{F}$ also talked about all of the three themes, but less so than participants $A$ and $B$.

Table 14: Participant references to finance, regulation and issues associated with equity

\begin{tabular}{|c|c|c|c|c|c|}
\hline & 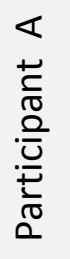 & 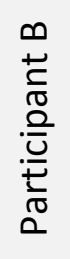 & 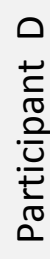 & 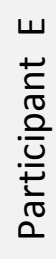 & 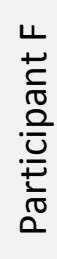 \\
\hline Financial return & 12 & 15 & 0 & 0 & 2 \\
\hline Regulation & 2 & 2 & 1 & 0 & 4 \\
\hline $\begin{array}{l}\text { Control over } \\
\text { future }\end{array}$ & 5 & 1 & 0 & 3 & 1 \\
\hline Fairness & 5 & 4 & 0 & 2 & 1 \\
\hline Lack of recognition & 3 & 6 & 0 & 0 & 0 \\
\hline
\end{tabular}


Why are the issues of finance, regulation and equity forming a collective? Underlying these themes are the more encompassing issues of pressure and control. For some participants, the need for a financial return on their properties (in part owing to debt levels) combined with the potential impact of regulatory controls on production is creating pressure. This, coupled with the negative media and public discourse on the impact of farming on the environment, is creating additional pressures. Finally, a lack of information and knowledge about how farmers (individually) are contributing to the nutrient enrichment of the waterways is also feeding these tensions.

Finally it is notable that for participants A, B and F all field work was undertaken during the spring and summer of 2014/15, a period that was marked by drought, reducing diary returns and the initiation of the regional process to set regulatory controls on water extraction and discharges into waterways. As noted previously, this is indicative of a temporal element to these issues.

\subsubsection{Theme 3: Technology and innovation}

\section{Overview}

LUCl is an emergent ecosystem services GIS based modelling framework. As such, it is a new technology that is being developed to make the ecosystem services trade-offs inherent in land-use decisions transparent. It is also heavily dependent on computer technology, though outputs can be printed as hardcopy maps.

If participants were uncomfortable with new technologies or engaging with computer software this may have acted as a barrier to the participants' ability to engage with and consider LUCls potential use. Therefore, understanding participants comfort levels around computers and with new technologies may 
help to inform the analysis of participants' responses on their experience of the phenomenon. It should also be noted though that a high level of comfort with new technologies is generally a characteristic of the early adopter and innovator diffusion categories (Kamansky, 2011).

\section{Data collection}

As part of the baseline interview undertaken during the first field visit, participants were asked about their comfort levels with new technologies and computer based tools. These responses have been compiled using a matrix query (Table 15 refers).

On analysing the participants' transcripts, comments relating to new innovations and technologies were coded to a "new innovations" theme. Text coded to this theme were then analysed for further sub-themes and patterns.

Table 15: Participant levels of comfort with computers

\begin{tabular}{|c|c|c|c|c|c|}
\hline & 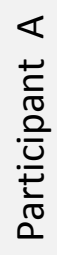 & 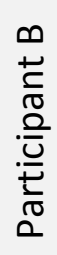 & 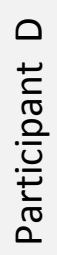 & 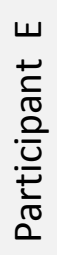 & 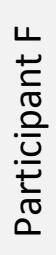 \\
\hline $\begin{array}{l}\text { Comfortable with } \\
\text { computers }\end{array}$ & $Y$ & $Y$ & $Y$ & $\mathrm{~N}$ & $Y$ \\
\hline $\begin{array}{l}\text { Comfortable with new } \\
\text { innovations and } \\
\text { technologies }\end{array}$ & $Y$ & $Y$ & $Y$ & $\mathrm{~N}$ & $Y$ \\
\hline
\end{tabular}

\section{Summary of participants' responses}

Four of five of the participants $(A, B, D$ and $F)$ were comfortable with new technologies. A similar pattern recurred in response to participants' comfort levels around computers, with Participant $E$, the only participant to indicate a level of discomfort with both. 
Deeper analysis of the text coded to the "innovation" theme helped to highlight some interesting issues. Two of the participants ( $B$ and $F$ ) acknowledged their enjoyment of problem solving and one participant (B) noted that they had designed and built machinery for use on the farm. Two participants ( $A$ and $B$ ) also discussed instances where they were involved in engineering or designing innovative solutions to reduce their environmental impacts, but were struggling with council controls.

One participant (B) commented on farmers' tendency to innovate in the following statement:

.....farmers have a lot of time to mull things over in the cow shed ...... Ideas are formed over a period of time, it's an evolutionary process...... most farmers are innovators. We milk large numbers in rotaries and no one else in the world does that, they are starting to, but they are still not doing it as well....

Given some of the challenges that the natural resources sector is facing, balancing production with protecting the natural resource base will be a delicate balancing act that will require a mix of tools such as innovation and new technologies to leverage off the new water quality regulations (section 2.4.1 refers).

One of the concerns raised by participants relates to the practicality of management suggestions and policies being developed by academics and policy makers. Given the farming industry's vested interest in the development of solutions that are both practical and effective, and that, at least amongst early adopters there is a high prevalence on innovation (Rogers, 2003) (as was evident in at least three of the five participants), there is an opportunity for academics and councils to leverage off the innovative 
characteristics of the early adopters in the sector to develop new innovations and support their diffusion through the community. It is only through bridging the gap between the academic theory and practicality that appropriately focused and effective new technologies can be developed.

One of the participants alluded to this issue in the following statement:

Participant F: ...Some people out there are saying "dairy farming is bad, get rid of all of the dairy farmers". But there are also some scientists out there saying "this is a problem, and this is what you can use to mitigate it......

Participant B: .......there is an old saying that there is a gap between academic theory and practical application, there is that little gulf there, and that probably needs bridging....

In summary, to move this discourse forward, all stakeholders (including land managers, policy-makers, councils, scientists, iwi etc.) need to be at the table together. The problem is collective as we all want to maintain our standard of living, and the ecosystem services that we derive from our lands and waters. So the problem is shared, and to move this issue forward, the solution will also need to be shared, for it is only when we get our best minds around the table, that we will be able to bridge the gap between academic theory and practical application. 
$\mathrm{P}$ a g e | 164 


\section{$5 \quad$ Discussion and conclusions}

\subsubsection{Overview}

This section will consider the themes arising from the research analysis and findings in the context of the literature. It will then consider the research analysis and findings in the context of the research questions. A synthesis of the research outcomes will then be provided in the conclusion. Comments about research limitations and future research will also be provided.

\subsubsection{Summary}

This section will explore the role of emerging decision-support tools such as LUCl in facilitating behavioural change in land-use decision-makers. The literature indicates that information alone is insufficient to motivate behavioural change (Kollmuss and Agyeman 2002, Fisk and Larson, 2011; Kennedy, 2010; Mackenzie-Mohr, 2000; Stern, 2000). Understanding how information delivered to land-use decision-makers through tools such as LUCI is considered alongside other decision-drivers will allow practitioners, policy makers and the architects of such tools to manage how information is presented and delivered, to facilitate optimum uptake and diffusion within a community.

The findings from this research indicate that the information uptake for "early adopters" was influenced by the nature, form and process used for the transfer of that information. In addition, a number of site specific, and temporal factors became apparent during the course of the research. These factors appeared to influence participants' perceptions of the information delivered through $\mathrm{LUCl}$. The advent of new water quality regulations and the 2014/15 summer drought illustrate the impact that such events can have on the perceptions of land-use decision-makers and that such events could 
create an environment for increased information uptake and behavioural change.

\subsubsection{Nature, form and process used for information transfer}

The findings of this research indicated that while the information provided through LUCI was considered to be accurate, compelling and useful (for others) by all participants, the participants were evenly split on whether it was credible and useful for them. This apparent disconnect between perceived accuracy and credibility, indicated that there may be other factors that influenced the participants' perceptions of the information's credibility.

During the final interview, participants were asked to identify the factors considered when forming a decision on land-use, and the relative priority given to each of those factors. The responses received for this question indicate that within this group of early adopters there are sub-groups that form their decisions based on different factors, or that apply different weighting to the same factors. While this makes it difficult to align the findings of this research with any one behavioural model (Kollumus and Ayeman, 2002; Bamburg and Mosser, 2007), it aligns with Mackenzie-Mohr's findings that people have a range of values and barriers that influence their decisions about behaviour (Kennedy, 2010; Mackenzie-Mohr, 2011). The research findings also indicated a link between the relative importance of information for participants' decision-making and perceived credibility and utility (for them) of the $\mathrm{LUCl}$ outputs. So for those participants that gave (modelled) information a low ranking, credibility and utility (for them) was similarly given a low ranking. However, for those participants that ranked information highly, or moderately important, utility and credibility were also highly ranked. There was only one exception to this apparent linkage within the research sample (which is discussed further below). 
These findings would indicate that for the sub-group of people that do not value information, when delivered through modelling tools such as $\mathrm{LUCl}$, other means of information transfer (e.g. endorsement by respected peers (Mackenzie-Mohr, 2011; Rogers, 2003) or practical examples of initiatives applying the information) or other mechanisms for behaviour change (e.g. incentives, or regulation) may be required. Therefore, understanding how land-use decisions are made and the various factors that inform those decisions will dictate what tools should be used and the design process for the use of that tool.

It is notable that amongst the two participants that did not rank modelled information highly, both ranked practical experience and one ranked social norms (i.e. information transferred through respected peers) highly. Therefore, designing the process used for information exchange to align with the participants' preferences for the receipt of information, will likely increase information uptake (Mackenzie-Mohr, 2011). This aligns with the framework used in Community-Based Social Marketing (Kennedy, 2010) which works on the premise that to be effective, information exchange needs to be tailored to the information exchange needs of the target individual or community (Mackenzie-Mohr, 2011).

\subsubsection{Nature of the information transferred}

The literature review noted that when information of a negative nature (i.e. identifying a potential problem or issue) is transferred without providing an achievable solution, the target audience can disengage or discredit the information (Mackenzie-Mohr, 2011). This is a recurring problem in the climate change debate where people often display symptoms of "learned helplessness" (Parker and Shapiro, 2008) or "cognitive dissonance" (Whitmarsh, 2011). This may help to explain the anomaly that occurred with Participant A. In this case, the researcher identified areas of nutrient and water accumulation on the property, but was unable to provide management 
scenarios that would resolve those issues. While this participant valued information highly in decision-making, the perceived credibility of the tool reduced significantly when useful management solutions could not be offered.

While all of the research participants appeared to interpret the information included in the LUCl outputs correctly, two of the participants struggled to understand what this meant for them. As such, translating that information into action appeared to be a barrier. This may indicate that information presented on potential management scenarios should be complimented with additional information on how to implement the proposed management interventions e.g. the provision of best practice guidelines, funding options etc. This would align with Mackenzie-Mohr's (2011) findings that to be effective the information provided needs to encompass what needs to be done, and the individual steps needed to undertake that action, all described in a clear and explicit manner. For the participants that did not require this additional information, two had already completed all management interventions recommended and the third did not feel that the information, supplied was relevant for them. Note that this final participant (E) valued intuition and previous experience in decision-making, with no other factors identified as being important in decision-making.

\subsubsection{The influence of site specific and temporal issues}

Richards and Morse (2013) noted that the case study approach is usually "bounded, and studied in its natural setting as a whole" (p. 76) and provides a snap shot of a point in time for the participants. This was the case for this research. While the field work for the research was undertaken over a 12 month period, field work generally took 3-4 months per participant, however for one participant $(A)$ it took 10 months. During that period other factors may have impacted the participants' views of the model, the information being provided and how it aligned with other sources of 
information. Due to the ethics requirement for participant anonymity, it was not possible to facilitate discussion and engagement between participants, though no controls were placed over participants discussing the research outputs with others at their discretion. If, and where this occurred was not monitored as part of this research. In addition, there was significant media coverage of related issues and a number of field days held by the regional council, Dairy NZ and Fonterra during this period. As a result, it was not possible to draw a direct casual linkage between participants' change in attitudes and views during the course of the research and the research itself.

For participants whose field work was undertaken during the summer of 2014/15 the following issues were raised on numerous occasions (analysis section refers): the dairy prices, finance, the advent of new regulator limits and the drought. However, these issues were not raised by the two participants that were interviewed during the winter of 2014. These results indicate that the timing of the field visits may have had a notable impact on the nature and content of discussions, and this may have impacted on perceptions of the modelled outputs.

\subsubsection{Times of change}

Mackenzie-Mohr (2011) noted that during times of change, the opportunity to introduce new behaviours and behavioural change are elevated, as habitual behaviour is often not possible or no-longer appropriate. The advent of new regulatory controls, presents an opportunity for increased information uptake and behavioural change by farmers as they look to understand the impact of the new limits and explore options, tools and management interventions to reduce nutrient discharge. At the time of this research, the impact of the regulations was unknown, however as those impacts become evident there may be an opportunity for increased engagement in new tools and technologies as farmers transition to new management practices. 


\subsubsection{Equity, finance and regulation}

As discussed above, equity, finance and regulation were raised a number of times by the three participants whose field work was undertaken during the summer of 2014/15. The summer of 2014/15 represented a time when a number of uncontrollable factors were collectively impacting on the participants, who at the time had a reduced ability to act, because of reduced available finances and the unknown nature of both the regulations and their own nutrient discharge rates. This aligned with Zimmerman's (1990) findings that uncontrolled adverse events created greater levels of anxiety than controlled adverse events.

A common element in many of the behavioural models is the need for a "perceived behavioural control" or an ability to act (Mackenzie-Mohr, 2011; Ajzen, 1991; Kollmuss and Agyeman, 2002; Hines, 1986) as a prerequisite for pro-environmental behaviour. It is arguable that during this period, the participants had limited perceived behavioural control due to the factors discussed above. Mackenzie-Mohr (2011) argues that presenting negative or threatening information without providing an opportunity to act can result in the target audience becoming anxious, frustrated or disconnected. To a degree this appeared to be playing out amongst the participants during this period. This is illustrated by the following participant's statement:

I can sense or feel this storm coming, you know the councils and I'm just afraid they're going to trip me up......

The risk is that during this period, farmers may become disengaged as a result of lack of control over the situation. Conversely, once the new regulations are set there could be an enhanced opportunity to transfer new information and innovations and influence the establishment of new behaviours and habits, as farmers will be looking for new ways in which to operate within the new nutrient limits. 


\subsubsection{Overarching research questions}

This section considers answers to the overarching research questions which were:

1. Is the information presented through $\mathrm{LUCl}$ accessible and compelling?

2. Is the information presented through LUCI perceived to be credible and robust?

3. How is the information provided through LUCI being interpreted?

4. Are there barriers between information exchange through the modelling process, and the application of that information in land-use decisions, if so what are these?

5. How effective is presenting information through modelling processes such as LUCl in influencing environmentally sustainable land-use decisions?

\section{Was the information presented through $\mathrm{LUCl}$ accessible and compelling?}

One of the recommendations of information transfer proposed by Community-Based Social Marketing is that the information transferred is both vivid and compelling (Mackenzie Mohr, 2011). The research findings indicate that most participants found the information both accessible and compelling. Feedback from participants indicates that the LUCl outputs met this requirement for all but one participant. Orientation within maps was an issue for this participant. This does raise the question about the use of map based information transfer for some people who are not visually oriented. While this was not considered in detail in this research, it would be an interesting avenue for future research.

Is the information presented through $L U C I$ perceived to be credible and robust?

While the participants were evenly split on the question of perceived credibility, the transcript analysis suggests that perceived credibility was influenced by a number of factors in addition to whether or not the model 
was accurately displaying the ecological process taking place on the participants' properties. What became evident was that how (and potentially when) information is presented within a group is as important as what information is presented. This aligns with Mackezie-Mohr's (2011) findings relating to the need to manage the process of information transfer based on a number of behavioural factors. How people process and use information in decision-making appeared to be a factor influencing whether the information presented was perceived to be credible.

Another factor arising from the research findings relates to the impact of the scenario results on the perceived credibility of the tool. When the outputs of scenarios where not able to resolve the issues identified on the property this appeared to impact on the participants perception of credibility of the tool rather than the utility of the management interventions selected. Therefore, limitations in the design of the research (i.e. the range of management interventions under consideration as part of this research) appeared to have a negative impact on perceived credibility and utility of the tool for one of the participants.

Finally, the impact of extensive ground-truthing on perceived credibility was significant. In designing this research it was hoped that by including participants in the development of the base information (i.e. by contributing to the ground-truthing process), they would have increased ownership of the final ground-truthed maps, and that this would have a positive impact on credibility. In the event, the degree of ground-truthing required (due to the heavily modified and flat nature of the research site) appeared to cause frustration rather than co-ownership on the part of some of the participants, particularly for those that were time-poor. This may have negatively skewed the results on credibility prior to and during the ground-truthing process. This was at odds with the literature on co-produced knowledge (or social learning which occurs generally through joint problem solving and the sharing of ideas 
experiences and knowledge) (Berks, 2009) as the basis for co-owned solutions that are more likely to be accepted by the participants (Botequilha-Leitao and Ahern, 2002). However, most participants noted that once the groundtruthing process had been completed, the maps were an accurate depiction of the processes on their property. While interaction with the maps was useful to some degree, the level of interaction and accuracy of the initial maps needs to be considered when designing similar processes in future.

Note that four of the five participants felt that $\mathrm{LUCl}$ outputs had utility for either the farming sector or the local authority currently, and all saw potential for future use and opportunities for its further development.

\section{How is the information provided through LUCI being interpreted?}

Participants understood the information being conveyed in the maps and most interpreted that information post ground-truthing as an accurate depiction of their properties. However, there is still a gulf between what is shown on the maps, the interventions proposed, and how to implement those interventions.

While LUCI identified both issues and possible actions that could be taken (i.e. solutions) in most cases, the next steps on how to go about implementing those solutions were missing from this research, and would need to be included in a package if $\mathrm{LUCl}$ was to be used as a tool to support improved information diffusion and uptake within a community. Incorporating $\mathrm{LUCl}$ outputs within a Community-Based Social Marketing framework would help to address this implementation barrier.

Furthermore, being able to quantify the benefits of management interventions in metrics was identified as an area for additional development that would help participants to better understand the relative benefits derived from the management interventions proposed. This would also help 
to inform cost benefit analysis on the part of the participants.

\section{Are there barriers between information exchange through the modelling process, and the application of that information in land-use decisions?}

Due to the short timeframes associated with this research (i.e. field work was only completed for the last participant in March 2015), it was not possible to establish whether participants actually implemented any of the new management proposals proposed. Therefore for the purposes of addressing this research question, perceived credibility and utility will be used as indicators for potential uptake of the information in future decision-making, because without perceived credibility and utility, uptake is unlikely.

\section{So what were the barriers to credibility and utility?}

Within the "early adopters" group identified for this research, the participants all weighted a range of factors into their decision-making, differently. For those that weighted information (modelled) either highly or moderately important, by-in-large the response to LUCl's credibility was positive. It is notable however, that for the participants that weighted previous experience, social norms and physical ground-truthing as more important, their response on the issue of the credibility of LUCl's outputs was more cautious.

It is proposed that how the information produced through $\mathrm{LUCl}$ is delivered will resolve some of the barriers to the use of that information in decisions (Mackenzie-Mohr, 2011). Furthermore, in line with discussions above, by combining LUCl outputs with Diffusion Theory (Rogers, 2003) (as used in this research) and Community-Based Social Marketing techniques, many of the social barriers to information exchange and use may be more readily overcome. 
Finally, based on the response of participants participating in this research ${ }^{13}$, the importance of not only providing solutions (effective management interventions), but also a means to achieving those solutions (e.g. incentives, finance, best practice guidelines on how to actually undertake the intervention) is more likely to encourage information uptake. The lack of viable solutions caused some frustration for a few of the participants, noting that only two management solutions were considered as part of this research. This supports Mackenzie-Mohr's (2011) findings that presenting threatening information, that is not coupled with an achievable solution, can result in the participant disengaging and/or discrediting the information (Mackenzie Mohr, 2011).

How effective is presenting information through modelling processes such as LUCl in influencing environmentally sustainable land-use decisions?

The LUCl outputs presented to participants were seen as useful by most of the participants. All participants felt that either they or others in the community would benefit from this information. In addition, there were a number of recommendations made for the further development of $\mathrm{LUCl}$, both in its functionality and the number and types of management interventions that it considered. These are listed below in the section on further research and development.

As stated earlier the participants were split on perceived credibility of the $\mathrm{LUCl}$ outputs. For half of the participants, the LUCl outputs were seen as interesting, credible and potentially very useful. However, for the remaining participants, it is important to understand the barriers to uptake of information of this type, given that most participants perceived the final ground-truthed maps as accurate.

${ }^{13}$ Noting the small targeted sample used 
Two barriers identified earlier relate to: the provision of useful solutions; and a means to implement those solutions. Based on the participants' responses to decision drivers, the ranking given to information in decision-making (as opposed to other decision drivers) may also have impact on how effective information of this nature is in influencing decision-making. This was also discussed in a previous section. So if conveying information is only effective for some people, how do you influence the decisions of those that do not value information in decision-making? As discussed in the literature review, incentives have been used to change an outcome or behaviours in the absence of attitude change (Kennedy, 2010), though the sustainability of this solution is a limitation, as once the incentive stops, generally the behaviour does as well (Lokhurst et al. 2011). Regulation is another avenue for changing behaviour without changing attitudes. However there are also limitations with the use of regulation when it or the regulators are not perceived to be credible (May, 2002). The literature review also indicated that mixing and matching behavioural techniques with tools such as regulation and incentives can facilitate compliance with regulation and attitude change whilst receiving incentives. Using this same logic, improving information exchange, particularly for those that do not highly rank information in decision-making may require a mixed-methods approach, incorporating behavioural theory and some of the behavioural methods and tools to facilitate the diffusion of information and new technologies through communities. 


\subsection{Conclusion}

The aim of this research was to establish the degree to which presenting information on land-use trade-offs through a GIS-based framework such as LUCl can impact on the land-use attitudes held by some property owners at the catchment level.

Information alone will not drive behavioural change but it is a prerequisite to behavioural change in most cases. In addition, perceived credibility will not drive decision-making, but without it, no tool will be considered for voluntary adoption by a community. One of the key findings of this research is that perceived credibility is complex and not necessarily rational ${ }^{14}$ and that in considering new information, we bring a host of habits, biases and societal norms which influence how we interpret that information. This makes the job of facilitating optimal uptake of new and/or novel technologies and information complex. Therefore, when considering the diffusion of tools such as LUCI within a community, consideration needs to be given to designing the process for diffusion based on the social structures and the individual characteristics of key individuals within that community. By coupling Rogers' (2003) Diffusion Theory with Community-Based Social Marketing techniques (Mackenzie-Mohr, 2011), a focused community and individual specific programme can be developed to diffuse and integrate the new technology within the target community.

As is often the case with Interpretive Phenomenological research, there were some unanticipated findings that arose out of the thematic analysis of the participants' transcripts. Issues of pressure and perceived lack of control appeared to be impacting on participants particularly during the spring and summer of 2014/15. This became apparent through discourse on finance, regulations and issues of equity within the transcripts. New Zealand is

\footnotetext{
${ }^{14}$ Noting that the limitations associated with using such a small sample of participants and the targeted use of "early adopters".
} 
currently implementing new water abstraction and discharge regulations, which have the potential to impact on the way in which the agricultural sector manages agricultural production. From the transcripts it is clear that the currently unquantifiable nature of this change for the Wairarapa was impacting on the research participants that undertook their field work during this period.

Changes of this nature provide opportunities for behaviour change, as old habits are no longer appropriate and new behaviours and habits are formed (Mackenzie-Mohr, 2011). However, they also have the potential to drive depression, anxiety and disassociation by effected groups (Mackenzie-Mohr, 2011; Zimmerman, 1990). There is an opportunity in New Zealand now for academics and the agricultural sector to work together to innovate and establish new, practical and environmentally sound farming practices. Neither party is likely to be able to capitalise on this change without the support of the other, and the farming community need to be given the opportunity take an active role, if not a leading role in finding those solutions.

Innovative tools such as LUCI are ideally placed to support farmers and the agricultural sector as they move through this period of change, but only if they can be presented in a way that is practical, credible and acceptable to them. Therefore, learning how to work with individuals and communities to navigate inherent biases and leverage off social systems will be key to successful innovation diffusion and uptake.

\subsection{Limitations of this research}

There are a number of potential limitations with this research that should be acknowledged. These limitations can be split into two categories (1) limitations of the data, $\mathrm{LUCl}$ version 0.2 capability and the management 
interventions considered, and (2) limitations in the research design. These will be discussed in the following sections

\subsubsection{Limitations of: the data, the capability of LUCI version 0.2 and the management interventions considered}

\section{Elevation data}

The elevation data used as the basis for this research was not consistent across participants. As new and better data became available, it was used. However, this meant that for those participants whose field work was finished early in the process, only $15 \mathrm{~m}$ or $5 \mathrm{~m}$ elevation data was used, while $1 \mathrm{~m}$ elevation data was used for later field work. It is unclear if and how much of an impact this may have had on participants' perceptions of the LUCI outputs. It is however, noted that the two participants that were more cautious about the credibility of the outputs both had their final ground-truthed maps and scenarios modelled using $1 \mathrm{~m}$ resolution data.

\section{Modelling the lake as a sink}

Field Visit 1 for Participant D and Field Visits 1 and 2 for Participant E used $15 \mathrm{~m}$ elevation data, with Lake Wairarapa clipped from the mask (Findings and Analysis: Part 1 refers). In effect, this meant that the lake was operating as a sink, with no hydrological returns. The impact that this may have had for perceived credibility of $\mathrm{LUCl}$ for Participants $\mathrm{D}$ and $\mathrm{E}$, and the inconsistency of data presented to participants is unclear.

\section{LUCl outputs under representing the benefits of wetlands}

$\mathrm{LUCl}$ version 0.2 , only models the impacts and benefits of wetlands for ecosystem services at their site. This is a significant under-representation of the nutrient removal and flood mitigation benefits that would be gained from a (re)established wetland for the contributing land area and waterways. The impact that this may have had on participant perceptions of the credibility of

$$
\text { P a g e | } 179
$$


LUCl outputs and the management interventions proposed is unclear.

\subsubsection{Limitations in the research design}

\section{The use of a small (non-representative) sample}

This study used a small sample of 5 participants, all of whom were of European descent and all but one were male. Similarly four out of five of the research participants were dairy farmers, with only one participant farming sheep, beef and some arable cropping. Finally, all the properties included in this research were on predominantly flat land. The lack of diversity in this sample means that findings cannot be used to draw conclusions about farmers in New Zealand in general.

\section{Use of early adopters}

Given the small sample of participants for the study, full representation of the farming community was not possible. As a result, the study targeted early adopters, a sub-group within the community with quite specific characteristics (section 3 refers). Early adopters are representative of $13.5 \%$ of the community (Rogers, 2003). This group was selected as they are often used by innovative technology and product developers to understand the potential uptake of new technologies within a community (Kaminski, 2011). As only early adopters were targeted and the sample size is small, results from this study should not be generalized too far. However, the results of this study do provide an insight into how this small targeted group of early adopters responded to the information presented through $\mathrm{LUCl}$ at a specific time and

place. The results of this research should be considered within the context of these limitations.

\section{Timing of the field work}

Timing of the field work spread across a year. For most of the participants, field work was completed within 3-4 months. However for one participant 
the field work was spread across a 10 month period due to competing time commitments for the participant. This time span had potential implications for the participants' retention of information between field visits and exposure to other related information (i.e. through media and field day events).

\subsection{Further research opportunities}

There were a number of opportunities for further research arising from this research. This section will consider these opportunities in three parts (1) further research and development of $\mathrm{LUCl},(2)$ data evaluation, and (3) further analysis of information diffusion within community groups.

\subsubsection{Further research and development}

\section{Further development of LUCI}

As part of this research participants were asked for input on further development opportunities of LUCI. These opportunities are considered in detail as part of the Findings and Analysis: Part 1.

Additional areas recommended for further research include:

- Comparing LUCl outputs (at both the field and catchments scales) across different:

○ terrain types including flat, hilly, mountainous (i.e. high country) terrain

- climatic zones including temperate, tropical, semi-arid and arid climates

- flood and drought conditions (i.e. 20, 50 and 100 year floods and droughts)

○ seasonal variation across the year. 
- Development of some economic valuation or metrics that would inform cost benefit analysis of various management interventions.

\section{Data evaluation}

- Analysis of the differences between surfaces depicted by the $1 \mathrm{~m}, 5 \mathrm{~m}$, and $15 \mathrm{~m}$ elevation data and which dataset is most accurate. This should be coupled with further research merging two different resolution datasets.

- Comparison of the differences between the Fundamental Soils layer and SMap. This analysis should be either physically ground-truthed at a sample of sites and /or tested against landowners understanding of which dataset provides the most accurate information.

\section{Further analysis of information diffusion within community groups}

This research targeted early adopters, and treated information uptake by the participants' in a uniform manner. In the final interview, participants were asked to identify the key factors that drove their decision-making. On analysis of this information there appeared to be a link between perceived credibility and the role of information in decision-making (i.e. those participants that valued information in decision-making highly ranked LUCI credibility).

It is therefore proposed that further research use "early adopters" and plan the process for information exchange based on how the individual participants process their decisions.

At the time of this research, the impact of regulations on information uptake was unknown, however as those impacts become more evident there may be an opportunity for increased engagement in new tools and technologies as farmer's transition to new management practices. The impact of change on 
the uptake of information and new technologies would be interesting to research further. 
P a g e | $\mathbf{1 8 4}$ 


\section{References}

Ajzen, I. (1991) Theory of planned behaviour. Organizational Behaviour and Human Decision Processes, 50, 179 - 211.

Andreason, A.R. (1995). Marketing social change. San Francisco. Jossey Bass.

Alexandratos, N., Bruinsma, J. (2012) World agriculture towards 2030/2050: The 2012 revision. ESA Working paper No. 12-03, Rome, FAO.

http://www.fao.org/docrep/016/ap106e/ap106e.pdf [Accessed 2 June 2015]

Ausseil, A-G. E., Dymond, J.R., Kirschbaum, M.U.F., Andrew, R.M., Parfitt, R.L. (2013). Assessment of multiple ecosystem services in New Zealand at the catchment scale. Environmental Modelling \& Software, 1 - 12.

Bagstad, K.J., Semmens, D.J., Waage, S., Winthrop, R. (2013). A comparative assessment of decision-support tools for ecosystem service quantification and valuation. Ecosystem Services, 5, 27 - 29.

Bamberg, S., Mosser, G. (2007). Twenty years after Hines, Hungerford, and Tomera: A new meta-analysis of psycho-social determinants of pro-environmental behaviour. Journal of Environmental Psychology, 27, 14 - 25.

Basher, L.R. (2013). Erosion processes and their control in New Zealand. In Dymond, J.R. ed. Ecosystem services in New Zealand-conditions and trends. Lincoln, New Zealand: Manaaki Whenua Press.

Beadle, S., Perfect, A., Rebergen, A., Sawyer, J. (2000). Wairarapa Plains Ecological District. Survey report for the Protected Natural Areas Programme. Department of Conservation. www.doc.govt.nz/Documents/gettinginvolved/landowners/wairarapa-plains-pna.pdf [Accessed 15 July 2015]

van den Belt, M., Blake, D. (2014) Ecosystem services in New Zealand agroecosystems: A literature review. Ecosystem Services, 9, 11-5-132.

Berkes, F. (2009). Evolution of co-management: Role of knowledge generation, bridging organizations and social learning. Journal of Environmental Management, 90, 1692 - 1702.

Berl, R.L., Williamson, N.C., Powell, T.E. (1984). Industrial salesforce motivation: A critique and test of Maslow's hierarchy of need. Journal of Personal Selling \& Sales Management, 4 (1), 32 - 39.

Biggerstaff, D. (2008). Interpretative phenomenological analysis (IPA): A qualitative methodology of choice in healthcare research. Qualitative Research in Psychology, 5, 173 - 183. 
Boffa Miskell Ltd. (2010). Wairarapa landscape study 2010. Landscape character description report August 2010. Greater Wellington Regional Council. http://www.gw.govt.nz/assets/councilpublications/Wairarapa\%20Character\%20Study\%20August\%202010.pdf. [Accessed 22 March 2015]

Botequilha-Leitao, A., Ahern, J. (2002). Applying landscape ecological concepts and metrics in sustainable landscape planning. Landscape and Urban Planning, $59,65-93$.

Bower, D.E., Mant, R., Orr, H., Hannah, D.M., Pullin, A.S. (2012). What are the effects of wooded riparian zones on stream temperature? Environmental Evidence, 1(3), $1-9$.

Boyd, J., Banzhaf, S. (2007). What are ecosystem services? Ecological Economics, $63(2-3), 616-626$.

Bullock, J.M., Lobley, M., Wrbka, T., Schwarz, G., Musters, C.J.M. (2012). Towards effective nature conservation on farmland: Making farmers matter. Conservation Letters, 6, 66 - 72.

Burton, R.J.F., Kuczera, C., Schwarz, G. (2008). Exploring farmers' cultural resistance to voluntary agri-environmental schemes. Sociologia Rualis, 48, (1), 16 - 37.

Carbon Forest Services. (2015). Indicative Forest Prices NZUs. http://www.carbonforestservices.co.nz/carbon-prices.htm. [Accessed 2 July 2015]

Carpenter, S. R., Mooney, H. A., Agard, J., Capistrano, D., DeFrise R. S., Diaz, S., Dietz, T., Duraiappah, A. K., Oteng-Yeboah, A., Pereira, H. M., Perrings, C., Ried, W. V., Sarukhan, J., Scholes, R. J., Whyre, A. (2009). Science for managing ecosystem services: Beyond the Millennium Ecosystem Assessment. Proceedings of the National Academy of Sciences, 106(5), 1305 1312.

Chan, K.M.A., Pringle, R.M., Ranganathan, J., Boggs, C.L., Chan, Y.L., Ehrlich, P.R., Haff, P.K., Heller, N.E., Alkhafaji, K., Macmynowski, D.P. (2006). When agendas collide: Human welfare and biological conservation. Conservation Biology, 21, 59 - 68.

Collier, K.J., Cooper, A.B., Davies-Colley, R.J., Rutherford, J.C., Smith, C.M., Williamson, R.B. (1995). Managing riparian zones: A contribution to protecting New Zealand's rivers and streams. Volume 2: Guidelines. Department of Conservation, Wellington, New Zealand. 
Collins, R., McLeod, M., Hedley, M., Donnison, A., Close, M., Hanley, J., Horne, D., Ross, C., Davies-Colley, R., Bagshaw, C., Matthews, L. (2007). Best

management practices to mitigate faecal contamination by livestock of New Zealand waters. A06064; Online publication.

http://Ishs.tamu.edu/docs/lshs/end-

notes/best $\% 20$ management $\% 20$ practices $\% 20$ to\%20mitigate\%20faecal\%20co ntamination-

1299352652/best\%20management\%20practices\%20to\%20mitigate\%20faecal \%20contamination.pdf [Accessed 1 June 2015]

Convention on Biological Diversity (1992). Convention on Biological Diversity. United Nations. https://www.cbd.int/doc/legal/cbd-en.pdf. [Accessed 15 July 2015]

Convention of Biological Diversity (2010). Aichi Biodiversity Targets. United Nations http://www.cbd.int/sp/targets [Accessed 31 May 2015]

Cooper, A.B. (1990). Nitrate depletion in the riparian zone and steam channel of a small headwater catchment. Hydrobiologia, 202, 13 - 26.

Corong, E., Hensen, M., Journeaux, P. (2014). Value of irrigation in New Zealand. An economy-wide assessment. New Zealand Institute of Economic Research and AgFirst Consultants NZ Ltd for the Ministry of Primary Industries, New Zealand.

https://www.google.com/url?sa=t\&rct=j\&q=\&esrc=s\&source=web\&cd=2\&ve d=0CCUQFjABahUKEwjF2cHbt9zGAhWikKYKHc5TCiY\&url=https\%3A\%2F\%2Fw ww.mpi.govt.nz\%2Fdocumentvault\%2F5014\&ei=zvOIVcW6GaKhmgXOp6mwAg\&usg=AFQjCNGBu8Ukhe7Bb WNxQTOoKeyiCCXiBA\&sig2=0IRQJmt ttOGiwtXAML5Dg. [Accessed 15 July 2015]

Costanza, R., d'Arge, R., de Groot, R., Farber, S., Grasso, M., Hannon, B., LimBurg, K., Naeem, S., O’Neill, R.V., Paruelo, J., Raskin, R.G., Sutton, P., van den Belt, $M$. (1997). The value of the world's ecosystem services and natural capital. Nature, 387, 253 - 260.

Chao, Y-L. (2012). Predicting people's environmental behaviour: Theory of planned behaviour and model of responsible environmental behaviour.

Environmental Education Research, 18(4), 437 - 461.

Cromarty, P. \& Scott, D.A. (1995). A directory of wetlands in New Zealand. Department of Conservation, Wellington, New Zealand. http://www.doc.govt.nz/Documents/science-andtechnical/nzwetlands00.pdf. [Accessed 8 February 2015] 
Daily, G.C. (1997). Nature's services: Societal dependence on natural ecosystems. 1718 Connecticut Avenue, N.W., Suite 300, Washington, DC 20009: Island Press.

Daily, G.C., Polasky, S., Goldstein, J., Kareiva, P.M., Mooney, H.A., Pejchar, L., Ricketts, T.H., Salzman, J., Shallenberger, R. (2009). Ecosystem services in decision-making: Time to deliver. Front Ecol Environ, 7(1), 21 - 28.

Dairy New Zealand. (2013). New Zealand Dairy Statistics 2012/13. Livestock Improvement Corporation and DairyNZ Incorporatedhttp://www.lic.co.nz/user/file/DAIRY\%20STATISTICS\%20201213-WEB.pdf. [Accessed 11 July 2015]

David-Colley, R. (2013) River water quality in New Zealand: An introduction and overview. In Dymond, J.R. ed. Ecosystem services in New Zealand-conditions and trends. Lincoln, New Zealand: Manaaki Whenua Press.

Department of Conservation. (2015). Funding - pe putea tautoko. Department of Conservation http://www.doc.govt.nz/get-involved/run-a-project/funding/ [Accessed 5 July 2015]

Dowling, M. (2007). From Husserl to van Manen. A review of different phenomenological approaches. International Journal of Nursing Studies, 44, $131-142$.

Duniber, M., Brown, H., Edmeades, D, Hill, R., Metherell, A., Rahn, C., Thorburn, P., Williams, R. (2013) A peer review of OVERSEER ${ }^{\circledR}$ in relation to modelling nutrient flows in arable crops. The Foundation for Arable Research. http://www.fertiliser.org.nz/Site/faq/fertiliser use tools/what is overseern utrient budgets model.aspx. [Accessed 8 June 2015]

Dymond, J.R., Aussiel, A.G., Shepherd, J.D., Buettner, L. (2005). Validation of a region-wide model of landslide susceptibility in the Manawatu-Wanganui region of New Zealand. Geomorphology, 74, 70 - 79.

Eppink, F.V., Greenhalgh, S., Hart, G. (2015). An exploration of the impacts and dependencies of New Zealand's key export commodities on the ecosystem services provided by New Zealand's native ecosystems. Landcare Research New Zealand Ltd.

Evans, L., Maio, G.R., Corner, A., Hodgetts, C.J., Ahmed, S., Hahn, U. (2012). Selfinterest and pro-environmental behavior. Nature Climate Change. Macmillan Publishers Ltd.

Festinger, L. (1957). A Theory of Cognitive Dissonance. United States of America: Row, Peterson and Company. 
Fichman, R.G. (2006). Information Technology Diffusion: A review of empirical research.

http://tx.liberal.ntu.edu.tw/SilverJay/Literature/!Adoption/Fichman 1992 IC IS IT Diff Review.pdf. [Accessed 5 May 2015]

Fisher, B., Costanza, R., Turner, R. K., Morling, P. (2007). Defining and classifying ecosystem services for decision making. CSERGE Working Paper EDM, No. 0704. http://www.econstor.eu/bitstream/10419/80264/1/571829937.pdf. [Accessed 15 July 2015]

Frisk, E., \& Larson, K. (2011). Educating for sustainability: Competencies \& practices for transformative action. Journal of Sustainability Education, 2, 1-9.

Gaspar, R. (2013). Understanding the reasons for behavioural failure: A process view of psychosocial barriers and constraints to pro-environmental behavior. Sustainability, 5, 2960-2975.

Geneletti, D. (2007). An approach based on spatial multi-criteria analysis to map the nature conservation value of agricultural land. Journal of Environmental Management, 83(2), 228 - 23.

Goodland, R. (1995). The concept of environmental sustainability. Annual Review of Ecology and Systematics, 26, 1 - 24.

de Groot, R.S., Wilson, M.A., Boumans, R.M.J. (2002). A typology for the classification, description and valuation of ecosystem functions, goods and services. Ecological Economics, 41, 393 - 408.

de Groot, R.S., Fisher, B., Christie, M. Aronson, J., Braat, L., Gowdy, J., HainesYoung, R., Maltby, E., Neuville, A., Polasky, S., Portela, R., Ring, I. (2010). Integrating the ecological and economic dimensions in biodiversity and ecosystem service valuation. The Economics of Ecosystems and Biodiversity: The ecological and economic foundations. http://www.teebweb.org/wpcontent/uploads/2013/04/D0-Chapter-1-Integrating-the-ecological-andeconomic-dimensions-in-biodiversity-and-ecosystem-service-valuation.pdf. [Accessed 15 July 2015]

Haines-Young, R., Potschin, M. (2011.) Common international classification of ecosystem services (CICES): 2011 update. European Environment Agency. Contract No: No. EEA/BSS/07/007, November 2011.

Hardeman, W., Johnston, M., Johnston, D., Bonetti, D., Wareham, N., Kinmonth, A.L. (2002) Application of the Theory of Planned Behaviour in Behaviour Change Interventions: A Systematic Review. Psychology \& Health, 17, 123158 
Hargreaves, T. (2011). Practicing behaviour change: Applying social practice theory to pro-environmental behaviour change. Journal of Consumer Culture, 11(1), 79 - 99.

Hekkert, M.P., Surrs, R.A.A, Negro, S.O., Kulmaan. S., Smits, R.E.H.M (2007). Functions of innovation systems: A new approach for analysing technological change. Technological Forecasting and Social Change, 74, 413 - 432.

Herzig, A., Aussiel, A-G. E., Dymond, J.R. (2013). Spatial Optimisation of Ecosystem Services. In Dymond, J.R., ed. Ecosystem Services in New Zealand conditions and trends. Lincoln, New Zealand: Manaaki Whenua press.

Hines, J.M., Hungerford, H.R., Tomera, A.N. (1987). Analysis and synthesis of research on responsible environmental behaviour: A meta-analysis. Journal of Environmental Education, 18, 1 - 8.

Hubble, T.C.T., Docker, B.B., Rutherford, I.D. (2010). The role of riparian trees in maintaining riverbank stability: A review of Australian experience and practice. Ecological Engineering, 36, 292 - 304.

Jackson, B,M., Wheater, H.S., Mcintyre, N.R., Chell, J., Francis, O.J., Frogbrook, Z., Marshall, M., Reynolds, B., Solloway, I. (2008). Flood and Risk Management, $1,71-80$.

Jackson, B,M., Cooper, D., Hall, J., Emmett, B., Bullock, J. (2013a) The provision of ecosystem services in the environmental stewardship scheme. DEFRA Project CTE1004.

Jackson, B., Pagella, T., Sinclair, F., Orellana, B.B., Henshaw, A., Reynolds, B., Mcintyre, N,. Wheater, H,. Eycott, A. (2013b). Polyscape: A GIS mapping framework providing efficient and spatially explicit landscape-scale valuation of multiple ecosystem services. Landscape and Urban Planning, 122, 74 - 88.

Jackson, B,M., Astbury, S., Cooper, D., Maxwell, D., Reuland, O., Trodahl, M. (In press) LUCI Land utilisation and capability indicator. $\mathrm{LUCl}$ help documentation.

Jarviluoma, H., Moisala, P., Vilkko, A. (2003). Introducing qualitative methods: Gender and qualitative methods. Sage Publications. London.

Jones, H., Clough, p., Hock, B., Phillips, C. (2008). Economic costs of hill country erosion and benefits of mitigation in New Zealand. Review and recommendation of approach. Report by Scion (Forest Research Institute Ltd.), New Zealand Institute of Economic Research Ltd. and Landcare Research Ltd. Contract No . 74701 for Ministry of Agriculture and Forestry, Wellington. https://www.mpi.govt.nz/document-vault/81. [Accessed 15 July 2015] 
Kamanski, J. (2011). Diffusion of innovation theory. Canadian Journal of Nursing Informatics, 6(2). http://cjni.net/journal/?p=1444

Kaur, A. (2013). Maslow's need hierarchy theory: applications and criticisms. Global Journal of Management and Business Studies, 3(10), 1061 - 1064

Kennedy, K.L. (2010). Using community-based social marketing techniques to enhance environmental regulation. Sustainability, 2, 1138 - 1160.

Kobayashi, k. (2016). Relational Processing of Conflicting Arguments: Effects on Biased Assimilation. Comprehensive Psychology, 5, 1 - 13

Kollmuss, A., Agyeman, J. (2002). Mind the gap: Why do people act environmentally and what are the barriers to pro-environmental behavior? Environmental Education Research, 8(3), 239 - 260.

Lant, C.L., Ruhl, J.B., Kraft, S.E. (2008). The tragedy of ecosystem services. BioScience, 58(10), 969-974.

Larkin, M., Watts, S., Clifton, E. (2006). Giving voice and making sense in interpretative phenomenological analysis. Qualitative Research in Psychology, 36, 102 - 120.

Let's think about cognitive bias. [Editorial]. (2015, October) Nature, 526, 163

Levy, B (1994). The craft of case-based qualitative research. IBAR, 15, 105 - 119

Lokhorst, A.M., Staats, H., van Dijk, J., van Dijk, E., de Snoo, G. (2011). What's in it for me? Motivational differences between farmers' subsidised and nonsubsidised conservation practices. Applied Psychology: An international review, 60(3), 337 - 353.

Lord, C. G. and Taylor, C. A. (2009), Biased Assimilation: Effects of Assumptions and Expectations on the Interpretation of New Evidence. Social and Personality Psychology Compass, 3 (5), 827-841

Mackenzie -Mohr, D. (2000) Promoting Sustainable Behavior: An Introduction to Community-Based Social Marketing. Journal of Social Issues, 56(3), 543 - 554.

Mackenzie -Mohr, D. (2011). Fostering sustainable behaviour. An introduction to Community-Based Social Marketing. $3^{\text {rd }}$ Edition., Gabriola Island, Canada: New Society Publishers.

Macleod, C. and Moller, H. (2006). Intensification and diversification of New Zealand agriculture since 1960: An evaluation of current indicators of land use change. Agriculture, Ecosystems \& Environment, 115, 201 - 208. 
Maier, S.F., Seligman, M.E.P. (1976). Learned helplessness: Theory and evidence. Journal of Experimental Psychology, 105(1), 3 - 36.

Mansum, H., Zaks, D., Monfreda, C. (2007). Ecosystem goods and services series: Valuation 101. WorldChanging Team. www.worldchanging.com/archives/006048.html. [Accessed 8 June 2015]

Marden, M., Rowan, D., Phillips, C. (2005). Stabilising characteristics of New Zealand indigenous riparian colonising plants. Plant and Soil, 278, 95 - 105.

Maslow, A. H. (1943) A Theory of Human Motivation. Psychological Review, 50, 370 - 396.

Matson, P.A., Parton, W.J., Power, A.G., Swift, M.J. (1997). Agricultural intensification and ecosystem properties. Science, 277, 504-509.

May, P.J. (2004). Compliance motivations: Affirmative and negative bases. Law Society Rev, 38, 41 - 68.

Merleau-Ponty, M. (1964). The primacy of perception. Translated Dallery, A.B. Evanston, Illinois. Northwestern University Press.

Millennium Ecosystem Assessment (2005). Ecosystems and human well-being: Synthesis. Washington, DC: Island Press.

Ministry for the Environment (2008). State of the environment report. http://www.mfe.govt.nz/environemntal-reporting/freshwater

Ministry for the Environment (2008). Summary of the National Policy Statement for Freshwater Management 2014. http://mfe.govt.nz/fresh-water/nationalpolicy-statement/about-nps. [Accessed 12 July 2015]

Parfitt, R.L., Frelat, M., Dymond, J.R., Clark, M., Roygard, J. (2013). Sources of phosphorus in two sub-catchments of the Manawatu River, and discussion of mitigation measures to reduce the phosphorous load. New Zealand Journal of Agricultural Research, 56(3), 187 - 202.

Parker, C.L., Shapiro, S.M. (2008). Climate chaos: Your health at risk: what you can do to protect yourself and your family., Westport Unites States of America: Praeger Publishers Inc.

Parkyn, S.M., Davies-Colley, R.J., Halliday, N. J., Costley, K.J., Croker, G.F. (2003). Planted riparian buffer zone in New Zealand. Do they live up to expectations? Restoration Ecology, 11(4), 436 - 447.

Peattie, K., Peattie, S. (2008). Social Marketing: A pathway to consumption reduction? Journal of Business Research, doi:10.1016/j.busres.2008.01.003 
Perrie, A., Milne, J.R. (2012). Lake water quality and ecology in the wellington region. State and trends. Greater Wellington Regional Council, Publication No. GW/EMI-T-12/139. Wellington.

Peterson, G.D., Cumming, G.S., Carpenter, S.R. (2001). Scenario Planning: A tool for conservation in an uncertain world. Conservation Biology, 17(2) 358 - 366.

Polasky, S., Nelson, E., Pennington, D., Johnson, K.A. (2010). The impact of land-use change on ecosystem services, biodiversity and returns to landowners: a case study in the state of Minnesota. Environ Resource Econ. 48, 219-242.

Prager, K. (2012). Understanding behaviour change: How to apply theories of behaviour change to SEWeb and related public engagement activities. Report for SEWeb LIFE10 ENV-UK-000182. http://www.environment.scotland.gov.uk/media/16539/UnderstandingBehaviour-Change.pdf. Accessed 9 July 2016

QSR International (2014). An overview of NVivo: Software to support qualitative and mixed methods research. http://download.qsrinternational.com/Resource/NVivo10/NVivo-10Overview.pdf [Accessed 20 July 2015]

Quinn, C., Burbach, M.E. (2008) Personal characteristics preceding proenvironmental behaviours that improve surface water quality. Great Plains Research, 18(1) 103 - 114.

Read. C. (2014). OVERSEER ${ }^{\circledR}$ : Taking it forward. In: Nutrient management for the farm, catchment and community. Eds L.D. Currie and C L. Christensen. Occasional Report No. 27. Fertilizer and Lime Research Centre, Massey University, Palmerston North. http://www.massey.ac.nz/ flrc/workshops/14/Manuscripts/Paper Read 201 4.pdf. [Accessed 8 June 2015]

Richards, L., Morse. (2013). Readme first for a user's guide to qualitative methods. $3^{\text {rd }}$ Edition. United States of America: SAGE Publications Inc.

Roberts, L., Brower, A., Kerr, G., Lambert, S., McWilliam, W., Moore, K., Quinn, J., Simmons, D., Thrush, S., Townsend, M., Blaschke, R., Costanza, R., Cullen, R., Hughey, K., Wratten, S. (2015). The Nature of Wellbeing. Conservation for Science, Department of Conservation, Wellington.

Rogers, E. (2003). Diffusion of Innovations, 5th Edition. Simon and Schuster. ISBN 978-0-7432-5823-4. 
Sahin, I. (2006). Detailed review of Rogers' diffusion of innovation theory and educational technology related studies based on Rogers' theory. The Turkish Online Journal of Educational Technology, 5(2), 14 - 23.

Sakhar, S., Pressey, R.L., Faith, D.P., Margules, C.R., Fuller, T., Stoms, D.M., Moffett, A., Wilson, K.A., Williams, K.J., Williams, P.H., Andelman, S. (2006). Biodiversity conservation planning tools: Present status and challenges for the future. Annu. Rev. Environ. Resourc, 31, 123 - 159.

Sbaraini, A., Carter, S,M., Evans, R.W., Blinkhorn, A. (2011). How to do a grounded theory study: A worked example of a study of dental practices. Medical Research Methodology, 11(128).

Spence, A., Pidgeon, N. (2009). Psychology, climate change and sustainable behaviour. Environment: Science and Policy for Sustainable Development. http://www.environmentmagazine.org/Archives/Back\%20lssues/NovemberDecember\%202009/Psych-Climate-full.html

Statistics New Zealand. (2004) Hectares \& farms by land use \& farm type (ANZSIC96) at 30 June 2001. 2002 Agricultural Census Tables. Statistics New Zealand.

http://www.stats.govt.nz/browse for stats/industry sectors/agriculturehorticulture-forestry/2002-agricultural-census-tables/land-use-farmcounts.aspx. [Accessed 15 July 2015]

Statistics New Zealand (2012). What New Zealand actually does for a living: from manufacturing to a services-oriented economy. Statistics New Zealand. http://www.stats.govt.nz/browse for stats/economic indicators/NationalAc counts/Contribution-to-gdp.aspx. [Accessed 1 July 2015]

Statistics New Zealand (2013). Hectares \& farms by land use \& farm type (ANZSIC96) at 30 June 2012. 2012 Agricultural Census Tables. Statistics New Zealand.

http://www.stats.govt.nz/browse for stats/industry sectors/agriculturehorticulture-forestry/2012-agricultural-census-tables/land-use.aspx. [Accessed 2 July 2015]

Statistics New Zealand (2015). Overseas Merchandise Trade: January 2015.

Statistics New Zealand. http://www.stats.govt.nz/browse for stats/industry sectors/imports and e xports/OverseasMerchandiseTrade HOTPJan15.aspx. [Accessed 1 July 2015] 
Steg, L., Vlek, C. (2009). Encouraging pro-environmental behaviour: An integrative review and research agenda. Journal of Environmental Psychology, 29, 309 317.

Stern, P.C. (2000). Toward a coherent theory of environmentally significant behavior. Journal of Social Issues, 56(3) 407-424.

Stewart, A. (2014). Land use and water quality. Greater Wellington Regional Council. http://www.gw.govt.nz/assets/Plans--Publications/Regional-PlanReview/Whaitua/REPORT-Land-use-and-water-quality-16-June-2014.pdf. [Accessed 2 April 2015]

de Snoo, G.R., Herzon, I., Staats, H., Burton, R.J.F., Schindler, S., van Dijk, J., Lokhorst, A.M., Bullock, J.M., Lobley, M., Wrbka, T., Schwarz, G., Musters, C.J.M. (2013). Towards effective nature conservation on farmland: making farmers matter. Conservation Letters, 6(1), 66 - 72.

Tonkin \& Taylor. (2012). Wairarapa water use project water races - Information review. Greater Wellington Regional Council. Job no. 28063.202.

Tscharntke, T., Klein, A,M., Kruess, A., Steffan-Dewenter, I., Thies, C. (2005). Landscape perspectives on agricultural intensification and biodiversity ecosystem service management. Ecology Letters, 8, 857 - 874.

Turner II, B.L., Lambin, E.F., Reenburg, A. (2007). The emergence of land change science for global environmental change and sustainability. Proceedings of the National Academy of Sciences, 104.

United Nations, Department of Economic and Social Affairs, Population Division (2013).World Population Prospects: The 2012 revision, highlights and advance tables. Working Paper No. ESA/P/WP.228. http://esa.un.org/wpp/documentation/pdf/wpp2012_highlights.pdf. [Accessed 2 June 2015]

Vigerstol, K.L., Aukema, J.E. (2011). A comparison of tools for modeling freshwater ecosystem services. Journal of Environmental Management, 92(10) 2403 2409.

Villa, F., Ceroni, M., Bagstad, K., Johnson, G., Krivov, S. (2009) ARIES (ARtificial Intelligence for Ecosystem Services ): a new tool for ecosystem services assessment, planning, and valuation. BioEcon. 1 - 9.

Villa, F., Ceroni, M., Bagstad, K., Johnson, G., Krivov, S. (2014). ARIES (ARtificial Intelligence for Ecosystem Services): A new tool for ecosystem services 
assessment, planning, and valuation. 11Th annual BIOECON conference on economic XXXXX

http://scholar.google.com/citations?view op=view citation\&hl=en\&user=Qr uu7XsAAAAJ\&citation for view=Qruu7XsAAAAJ:Wp0g|r-vW9MC. [Accessed 29 March 2015]

Weather Watch (2009). Our capital and surrounds.

http://www.weatherwatch.co.nz/content/sunday-feature-our-capital-andsurrounds. [Accessed 3 July 2015]

Weeks, E.S., Mason , N., Ausseil, A-G.E., Herzig, A. (2014). Prioritising land-use decisions for the optimal delivery of ecosystem services and biodiversity protection in productive landscapes. In Biodiversity - The Dynamic Balance of the Planet. Ed. Grillo, O. InTech. doi.org/10.5772/58255

Whitmarsh, L. (2011). Scepticism and uncertainty about climate change: Dimensions, determinants and change over time. Global Environmental Change, 21(2) 690 - 700.

Wilcock, R.J., Betteridge, K., Shearman, D., Fowles, C.R., Scarsbrook, M.R., Thorrold, B.S., Costall, D. (2010). Riparian protection and on-farm best management practices for restoration of a lowland stream in an intensive dairy farming catchment: A case study. New Zealand Journal of Marine and Freshwater Research, 43(3), 803 - 818.

World Bank. (2004). How much is an ecosystem worth? Assessing the economic value of conservation. World Bank. Washington, DC.

Zimmerman, M.A. (1990). Toward a theory of learned hopefulness: A structural model analysis of participation and empowerment. Journal of Research in Personality, 24, 71 - 86. 


\section{Appendix A: Research question framework}

\section{Question framework}

Aim of research

The aim of my research is to establish the degree to which presenting information on landuse trade-offs through a GIS-based framework such as LUCI can impact on the land-use attitudes held by some property owners at the catchment level.

\section{Overarching research questions}

1. Is the information presented through LUCI perceived to be credible and robust?

2. Is the information presented through $\mathrm{LUCl}$ accessible and compelling?

3. How is the information provided through LUCI being interpreted?

4. Are there barriers between information exchange through the modelling process, and the application of that information in land use decisions, if so what are these?

5. How effective is presenting information through modelling processes such as LUCI in influencing environmentally sustainable land-use decisions?

\section{Questionnaire protocol}

The interviews will be conducted in two stages.

Stage 1: Baseline interviews: The responses to these questions will be used as a base line to help identify and understand any changes resulting from the modelling phenomenon.

Stage 2: Main interview questions: A series of open ended questions will be used to help respond to the research questions. 
Stage 1: Interview questions

\begin{tabular}{|c|c|c|c|}
\hline $\begin{array}{l}\text { Type of } \\
\text { question }\end{array}$ & Questions & Prompts & $\begin{array}{l}\text { Research } \\
\text { question } \\
\text { addressed }\end{array}$ \\
\hline $\begin{array}{l}\text { Administration } \\
\text { and } \\
\text { introduction }\end{array}$ & $\begin{array}{l}\text { There are no right or } \\
\text { wrong answers to these } \\
\text { questions. They are } \\
\text { intended to help measure } \\
\text { any change resulting from } \\
\text { engagement in the } \\
\text { modelling process. }\end{array}$ & $\begin{array}{l}\text { - Agreement to recording } \\
\text { the interview } \\
\text { - Consent form completed } \\
\text { and what this means in } \\
\text { practice } \\
\text { - Opportunities to review } \\
\text { the transcribed material } \\
\text { - Time on property and } \\
\text { management capacity i.e. } \\
\text { owner operator, } \\
\text { manager etc. }\end{array}$ & \\
\hline Familiarity & $\begin{array}{l}\text { How long have you been } \\
\text { on this property } \\
\text { If not long: } \\
\text { How long have you lived } \\
\text { or farmed in the area }\end{array}$ & & \\
\hline $\begin{array}{l}\text { Ecosystem } \\
\text { service } \\
\text { concept }\end{array}$ & $\begin{array}{l}\text { How familiar are you with } \\
\text { the concept of } \\
\text { ecosystems and } \\
\text { ecosystem services? }\end{array}$ & $\begin{array}{l}\text { - If familiar - have you } \\
\text { considered this concept } \\
\text { in the context of your } \\
\text { farming operation? } \\
\text { - If not familiar - are you } \\
\text { familiar with the } \\
\text { hydrology, soils and } \\
\text { nutrient process capacity } \\
\text { of your property? - i.e. } \\
\text { are you familiar with the } \\
\text { concept but by a } \\
\text { different name? }\end{array}$ & \\
\hline $\begin{array}{l}\text { Innovation / } \\
\text { new } \\
\text { technologies }\end{array}$ & $\begin{array}{l}\text { How do you usually } \\
\text { approach new } \\
\text { technologies and } \\
\text { innovations }\end{array}$ & $\begin{array}{l}\text { - With caution, } \\
\text { - With interest, or } \\
\text { - Anything else in between }\end{array}$ & RQ. 4 \\
\hline Sustainability & $\begin{array}{l}\text { How significant a role } \\
\text { does environmental } \\
\text { sustainability play in your } \\
\text { land-using decision- } \\
\text { making? }\end{array}$ & $\begin{array}{l}\text { - Ideally } \\
\text { - In reality }\end{array}$ & \\
\hline
\end{tabular}


Stage 2: Interview questions

\begin{tabular}{|c|c|c|c|}
\hline $\begin{array}{l}\text { Type of } \\
\text { Question }\end{array}$ & Questions & Prompts & $\begin{array}{l}\text { Research } \\
\text { Question } \\
\text { addressed }\end{array}$ \\
\hline $\begin{array}{l}\text { Administration } \\
\text { and } \\
\text { introduction }\end{array}$ & & $\begin{array}{l}\text { - Agreement to recording } \\
\text { the interview } \\
\text { - Check consent form } \\
\text { completed } \\
\text { - Opportunities to review } \\
\text { the transcribed material } \\
\text { - Time on property and } \\
\text { management capacity i.e. } \\
\text { owner operator, } \\
\text { manager etc. }\end{array}$ & RQ. \\
\hline $\begin{array}{l}\text { Ecosystem } \\
\text { service } \\
\text { concept }\end{array}$ & $\begin{array}{l}\text { What do you think about } \\
\text { the concept of } \\
\text { ecosystems and } \\
\text { ecosystem services? }\end{array}$ & $\begin{array}{l}\text { - Has understanding } \\
\text { increased/stayed the } \\
\text { same? } \\
\text { - If familiar with the } \\
\text { ecosystem concept / } \\
\text { terminology prior to the } \\
\text { modelling - What did } \\
\text { you think about how the } \\
\text { ecosystem process was } \\
\text { depicted through the } \\
\text { modelling process? } \\
\text { - If unfamiliar with the } \\
\text { ecosystem concept/ } \\
\text { terminology prior to the } \\
\text { modelling process - What } \\
\text { are your thoughts on the } \\
\text { ecosystem concept as a } \\
\text { result of experiencing it } \\
\text { through the modelling } \\
\text { process? }\end{array}$ & $\mathrm{RQ}: 1 \& 2$ \\
\hline $\begin{array}{l}\text { Experience of } \\
\text { Phenomena }\end{array}$ & $\begin{array}{l}\text { Tell me about your } \\
\text { experience of the } \\
\text { modelling process. }\end{array}$ & $\begin{array}{l}\text { - How credible / robust did } \\
\text { you find the information } \\
\text { presented through LUCI? } \\
\text { - Can you comment on the } \\
\text { accessibility of the } \\
\text { information when } \\
\text { provided through LUCI? }\end{array}$ & $R Q: 1,2,3,5 \& 6$ \\
\hline Interpretation & $\begin{array}{l}\text { Tell me what you think of } \\
\text { the information provided } \\
\text { via the modelling } \\
\text { process. }\end{array}$ & What is it saying to you? & $\mathrm{RQ}: 3 \& 4$ \\
\hline
\end{tabular}




\begin{tabular}{|c|c|c|c|}
\hline $\begin{array}{l}\text { Type of } \\
\text { Question }\end{array}$ & Questions & Prompts & $\begin{array}{l}\text { Research } \\
\text { Question } \\
\text { addressed }\end{array}$ \\
\hline $\begin{array}{l}\text { Perceived } \\
\text { utility }\end{array}$ & $\begin{array}{l}\text { Do you think this } \\
\text { modelling will be of use } \\
\text { to you in future land-use } \\
\text { decisions? }\end{array}$ & $\begin{array}{l}\text { Can you list in order of } \\
\text { priority which of the } \\
\text { following are more } \\
\text { important to you when } \\
\text { making a decision on the } \\
\text { management of your } \\
\text { property, and give any } \\
\text { comments on your } \\
\text { reasoning - note there is } \\
\text { no right or wrong answer: } \\
\text { - Intuition } \\
\text { - Previous experience, } \\
\text { - Social norms } \\
\text { - Short-term financial } \\
\text { return? } \\
\text { - Modelled data through a } \\
\text { decision support tool } \\
\text { such as LUCl }\end{array}$ & $\mathrm{RQ}: 4 \& 5$ \\
\hline $\begin{array}{l}\text { Perceived } \\
\text { utility to } \\
\text { others }\end{array}$ & $\begin{array}{l}\text { Do you think this } \\
\text { information/ modelling } \\
\text { process will be useful to } \\
\text { others in the } \\
\text { catchment/community in } \\
\text { informing land-use } \\
\text { decision? }\end{array}$ & $\begin{array}{l}\text { What weighting do you } \\
\text { think this information will } \\
\text { be given relative to other } \\
\text { resource use decision } \\
\text { drivers? }\end{array}$ & RQ: 5 \\
\hline Sustainability & $\begin{array}{l}\text { How significant a role will } \\
\text { environmental } \\
\text { sustainability play in your } \\
\text { land-using decision- } \\
\text { making? } \\
\text { - More significant } \\
\text { that previously } \\
\text { - The same as } \\
\text { previously }\end{array}$ & $\begin{array}{l}\text { - More significant that } \\
\text { previously } \\
\text { - The same as previously }\end{array}$ & RQ:4 \\
\hline
\end{tabular}




\section{Appendix B: Ethics documentation}

\section{Appendix B.i: Ethics approval}

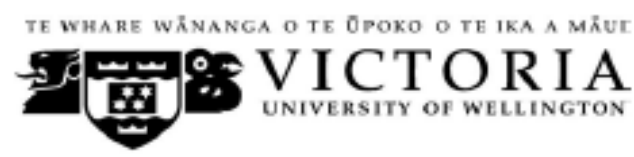

\section{MEMORANDUM}

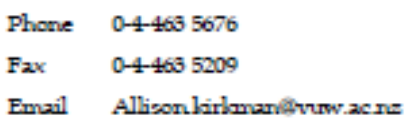

\begin{tabular}{l|l}
\hline TO & Nicola Haydock (Scott) \\
\hline COPY TO & Bethanna Jackson \\
\hline FROM & Dr Allison Kirkman, Convener, Human Ethics Committee \\
\hline
\end{tabular}

\begin{tabular}{l|l}
\hline DATE & 8 December 2013 \\
\hline PAGES & 1 \\
\hline
\end{tabular}

SUBJECT

Ethics Approval: 20206

Modelling land use trade-offs: Facilitating informed and sustainable land use decision-making

Thank you for your application for ethical approval, which has now been considered by the Standing Committee of the Human Ethics Committee.

Your application has been approved from the above date and this approval continues until 18 June 2015 . If your data collection is not completed by this date you should apply to the Human Ethics Committee for an extension to this approval.

Best wishes with the research.

Allison Kirkman

Human Ethics Committee 


\title{
Appendix B.ii: Participant information sheet
}

\author{
Participant Information Sheet
}

\author{
Researcher: Nicola Haydock \\ School of Research: School of Geography Environment and Earth Sciences \\ University: Victoria University of Wellington
}

I am a part-time Masters student in the Physical Geography programme at Victoria University, Wellington. As part of this degree I am undertaking a research project leading to a thesis.

I would like to invite you to participate in my research. Your details have been provided to me by the Greater Wellington Regional Council as a property owner within the Wairarapa Moana Catchment that meets my research participation criteria.

\section{Aim of the research}

The project I am undertaking will examine the utility of Global Information System (GIS)-based decision-support tools such as the Land Use Capability Indicator (LUCI), for informing landowners of the trade-offs inherent in land-use decisions.

$\mathrm{LUCl}$ is a modelling tool that allows users/landowners to better understand the ecosystems present within their catchment and on their properties. Landowners are often reliant on these ecosystems and their services, for ongoing production. Landuse decisions can have unintended outcomes, and this modelling tool seeks to clarify the ecosystem service trade-offs inherent in those decisions. Furthermore, it allows the modelling of potential land-use scenarios that seek to optimize across all ecosystems and their services.

GIS-based modelling tools are relatively new technology. LUCI is one of a number of such tools that has been designed for use at the catchment/farm level. While $\mathrm{LUCl}$ has been extensively tested overseas, it has had limited testing in New Zealand. Therefore, the aim of this research is to better understand the potential use of this tool for New Zealand based landowners and organisations.

This research will take place in two stages.

\section{Stage 1: Initial interview and modelling process}

The researcher will visit participants individually. Dr. Bethanna Jackson (Senior Lecturer, Victoria University, Wellington) research supervisor, may accompany the researcher on some Stage 1 visits. This initial meeting will take around 2 hours and will comprise:

(1) A short interview (30 mins) that will use open-ended questions to establish current farming practices, and current knowledge of modelling tools such as LUCI. Note that this interview will be recorded and transcribed.

(2) LUCI will be used to generate modelled data of:

- the Wairarapa Moana Catchment, your property and the ecosystems that underpin it (current state modelling) including: the hydrology (water retention and yield), carbon sequestration, susceptibility to flooding, sedimentation etc. Most of the information for this process will be generated from national data sets, though you may be asked to ground-truth this data.

- future scenarios of land-use options will be generated 
a) initially these scenarios might model some potential land-use changes that you are currently considering or that you are curious about, they can also be completely fictitious. The intention is to see what this modelling tool can do

b) in addition, a set of future land-use scenarios will be generated that will seek to optimize ecosystem service delivery.

(3) Participants will be asked if they would like to undertake additional scenario modelling work, given that:

- the time available for this first visit may limit the number of options that can be modelled, and

- depending on the nature of the scenarios sought, additional programming may be required.

Any future modelling work will be undertaken in a separate optional field visit that will take place between Stage $1 \& 2$ of this research.

Participants will be given copies of all the maps produced as a result of the Stage 1 modelling process. Please note that the maps and modelling data generated will be retained by the researcher, in perpetuity and may be made available to other parties. As the modelling process generates maps, it may be possible for others to identify your property. Should you wish to limit the release of some or all of the maps and associated data generated in Stage 1 of this research, please let me know when I return for the Stage 2 Interviews. Please note that participants can withdraw themselves or any of the information that they have provided for Stage 1 of the research at any time up 1 June 2014, with no questions asked.

Furthermore the researcher will seek approval from relevant participants for the use of any further maps developed to help illustrate the researchers data analysis, where it relates to their modelling outputs and/or their properties, and is identifiable to them.

\section{Stage 2: Interviews}

Within 6 weeks of the completion of Stage 1, the researcher will meet with research participants to undertake an interview. The researcher may be accompanied by Dr. Bob Frame, co-supervisor, for some of these interviews.

These interviews will be semi-structured, with just a few open-ended questions and prompts. Hopefully they will form broad ranging discussions. The purpose of the interviews will be to get the participants' views of the credibility, utility and accessibility of the information generated and provided through the modelling process (Stage 1 of the research).

The interview itself will take about an hour and will be recorded. If a participant is uncomfortable with any of the interview questions and does not wish to provide an answer, they will not be required to do so, and no explanation will be required. Participants will have an opportunity to review and elaborate on the transcripts developed from their interview recordings, and can withdraw themselves and or any of the Stage 2 interview data that they have provided up until 1 August 2014.

During the research, interview transcripts and recordings will be kept locked and secured. Note that on completion of the research project, the interview recordings and transcripts from both Stage $1 \& 2$ of the research will be destroyed. No other person besides the participant, Dr. Bethanna Jackson (my supervisor), Dr. Bob Frame (cosupervisor), and I will see the transcripts or hear the interview recordings.

The modelling outcomes (maps and associated data) and the interview transcripts will form the basis of my research project and will be analysed and included in a written report/thesis. While some statements and opinions made in the interviews may be 
used in the thesis and associated publications and presentations, all participants names will be replaced with pseudonyms.

It is important to note that even with the precautions outlined above, I cannot guarantee that participation in this research can be kept confidential because of the use of maps to illustrate the modelling outputs (Stage 1 of the research refers). This is covered in the research consent form.

The thesis will be submitted for marking to the School of Geography Environment and Earth Sciences, and deposited in the Victoria University Library. One or more articles will be submitted for publication in scholarly journals. A copy of the final thesis will also be made available to all participants.

Please note that this research project has received approval from the Victoria University Human Ethics Committee.

If you have any further questions or would like to receive further information about the project, please contact me on or at haydocnico@myvuw.ac.nz or my supervisor Dr. Bethanna Jackson, at the School of Geography, Environment and Earth Sciences at Victoria University or bethanna.jackson@vuw.ac.nz.

In the interests of transparency and open communication, please note that I am employed full-time by the Department of Conservation. However, this research is being undertaken in a private/personal capacity.

Nicola Haydock (Scott) 


\section{Appendix B.iii: Participant research consent form}

\section{CONSENT TO PARTICIPATE IN RESEARCH}

Title of project: Facilitating informed land use decisions through the modelling of ecosystem service trade-offs

I have been given and have understood an explanation of this research project, and have had an opportunity to ask questions, all of which have been answered to my satisfaction.

I understand that I may withdraw any information I have provided for Stage 1 of this project before 1 June 2014, and myself or information provided for Stage 2 of the research before 1 August 2014, without having to give an explanation. I note that by these dates, I will have seen and had the opportunity to comment on the Stage 1 modelled data and maps and the Stage 2 interview transcripts, respectively.

I note that prior to completion of the research, the researcher will seek my approval to use any further maps developed by the researcher to help illustrate the data analysis, where it relates to the modelling outputs from my property and is identifiable to me.

I understand that any information I provide through the interviews will be kept confidential to the researcher and the research supervisors, but that the interview analysis results will be used in the thesis and could be used in future publications and presentations.

I agree that while some quotations from the interview transcripts may be used in the thesis and future publications, they will not be attributed to me individually, and that my name will be replaced with a pseudonym in the thesis or any associated publications or presentations. However, I understand that there is a possibility that my involvement in the research may become evident to some parties due to the inclusion of maps generated as a resulting of the modelling process in Stage 1 of the research.

I understand that the data I provide in my interviews will only be used in the context of this research, noting that I will be given the opportunity to review/comment on the content of my transcripts before 1 August 2014.

I note that the recordings of my interviews and my interview transcripts will be destroyed on completion of the research, and that they will be kept securely until that time. 
I consent to the maps generated from the modelled data in Stage 1 being made available to interested parties after 1 June 2014. Furthermore, I note that all maps will be retained by the researcher in perpetuity, unless they have been withdrawn from the research at my request prior to 1 June 2014.

I would like to receive a copy of the thesis when it is completed.

I am aware that while the researcher is employed full-time for the Department of Conservation, that this research is undertaken in a private capacity.

I agree to take part in this research

Signed:

Name of participant: 


\section{Appendix C: Findings and Analysis}

Appendix C.i: Overview of key themes to be considered in Part $2 \mathrm{c}$ of the Findings and analysis

\begin{tabular}{|c|c|c|c|}
\hline Themes & Questions & Prompts & Relevant research questions \\
\hline $\begin{array}{l}\text { 1. Experience of } \\
\text { the } \\
\text { Phenomena }\end{array}$ & $\begin{array}{l}\text { a. Tell me about your } \\
\text { experience of the } \\
\text { modelling process. }\end{array}$ & $\begin{array}{l}\text { - Can you comment on the } \\
\text { accessibility of the } \\
\text { information when provided } \\
\text { through LUCl? } \\
\text { - How credible / robust did you } \\
\text { find the information } \\
\text { presented through LUCI? }\end{array}$ & $\begin{array}{l}\text { 1. Is the information presented } \\
\text { through LUCI accessible and } \\
\text { compelling? } \\
\text { 2. Is the information presented } \\
\text { through LUCI perceived to be } \\
\text { credible and robust? }\end{array}$ \\
\hline 2. Interpretation & $\begin{array}{l}\text { a. Tell me what you } \\
\text { think of the } \\
\text { information } \\
\text { provided via the } \\
\text { modelling process. }\end{array}$ & $\begin{array}{l}\text { What is the information saying } \\
\text { to you?" }\end{array}$ & $\begin{array}{l}\text { 3. How is the information provided } \\
\text { through LUCI being interpreted? }\end{array}$ \\
\hline $\begin{array}{l}\text { 3. Changes in } \\
\text { attitudes and } \\
\text { understanding }\end{array}$ & $\begin{array}{l}\text { a. What do you think } \\
\text { about the concept } \\
\text { of ecosystems and } \\
\text { ecosystem services? }\end{array}$ & $\begin{array}{l}\text { - Has understanding } \\
\text { increased/stayed the same? } \\
\text { - If familiar with the ecosystem } \\
\text { concept / terminology prior to } \\
\text { the modelling - What did you } \\
\text { think about how the } \\
\text { ecosystem process was }\end{array}$ & $\begin{array}{l}\text { 4. Are there barriers between } \\
\text { information exchange through } \\
\text { the modelling process, and the } \\
\text { application of that information } \\
\text { in land-use decisions, if so what } \\
\text { are these? } \\
\text { 5. How effective is presenting }\end{array}$ \\
\hline
\end{tabular}




\begin{tabular}{|c|c|c|c|}
\hline Themes & Questions & Prompts & Relevant research questions \\
\hline & & $\begin{array}{l}\text { depicted through the } \\
\text { modelling process? } \\
\text { - If unfamiliar with the } \\
\text { ecosystem concept/ } \\
\text { terminology prior to the } \\
\text { modelling process - What are } \\
\text { your thoughts on the } \\
\text { ecosystem concept as a result } \\
\text { of experiencing it through the } \\
\text { modelling process? }\end{array}$ & \multirow[t]{2}{*}{$\begin{array}{l}\text { information through modelling } \\
\text { processes such as LUCI in } \\
\text { influencing environmentally } \\
\text { sustainable land-use decisions? }\end{array}$} \\
\hline & $\begin{array}{l}\text { b. How significant a } \\
\text { role will } \\
\text { environmental } \\
\text { sustainability play in } \\
\text { your land-using } \\
\text { decision-making? }\end{array}$ & $\begin{array}{l}\text { - More significant that } \\
\text { previously } \\
\text { - The same as previously }\end{array}$ & \\
\hline $\begin{array}{l}\text { 4. Perceived } \\
\text { utility }\end{array}$ & $\begin{array}{l}\text { a. Do you think this } \\
\text { modelling will be of } \\
\text { use to you in future } \\
\text { land-use decisions? }\end{array}$ & $\begin{array}{l}\text { Can you list in order of priority } \\
\text { which of the following are more } \\
\text { important to you when making } \\
\text { a decision on the management } \\
\text { of your property, and give any } \\
\text { comments on your reasoning - }\end{array}$ & $\begin{array}{l}\text { 4. Are there barriers between } \\
\text { information exchange through } \\
\text { the modelling process, and the } \\
\text { application of that information } \\
\text { in land-use decisions, if so what } \\
\text { are these? }\end{array}$ \\
\hline
\end{tabular}




\begin{tabular}{|c|c|c|c|}
\hline Themes & Questions & Prompts & Relevant research questions \\
\hline & & $\begin{array}{l}\text { note there is no right or wrong } \\
\text { answer: } \\
\text { - Intuition } \\
\text { - Previous experience, } \\
\text { - Social norms } \\
\text { - Short-term financial return? } \\
\text { - Modelled data through a } \\
\text { decision support tool such as } \\
\text { LUCI }\end{array}$ & \\
\hline & $\begin{array}{l}\text { b. Do you think this } \\
\text { information/ } \\
\text { modelling process } \\
\text { will be useful to } \\
\text { others in the } \\
\text { catchment/commun } \\
\text { ity in informing } \\
\text { land-use decision? }\end{array}$ & $\begin{array}{l}\text { What weighting do you think } \\
\text { this information will be given } \\
\text { relative to other resource use } \\
\text { decision drivers? }\end{array}$ & \\
\hline
\end{tabular}


Appendix C. ii: Overview of key themes and patterns to be considered in Part 2 of the Findings and analysis

\begin{tabular}{|c|c|c|}
\hline Themes & Questions to be addressed in the data analysis & Relevant research questions \\
\hline \multirow[t]{3}{*}{ Information } & $\begin{array}{l}\text { What is the role of information in decision- } \\
\text { making? }\end{array}$ & \multirow{7}{*}{$\begin{array}{l}\text { 4. Are there barriers between information } \\
\text { exchange through the modelling process, and } \\
\text { the application of that information in land-use } \\
\text { decisions, if so what are these? } \\
\text { 5. How effective is presenting information } \\
\text { through modelling processes such as LUCI in } \\
\text { influencing environmentally sustainable land- } \\
\text { use decisions? }\end{array}$} \\
\hline & $\begin{array}{l}\text { How do participant's perceptions of } \\
\text { information, and modelled outputs differ? }\end{array}$ & \\
\hline & $\begin{array}{l}\text { How do participant's perceptions of } \\
\text { information, evidence and physical ground- } \\
\text { truthing differ and what implications does } \\
\text { that have for their views on the modelled } \\
\text { outputs? }\end{array}$ & \\
\hline \multirow{4}{*}{$\begin{array}{l}\text { Equity, Finance and } \\
\text { Regulation, what are the } \\
\text { patterns emerging? }\end{array}$} & Equity & \\
\hline & $\begin{array}{l}\text { What is a basis for concerns raised about } \\
\text { equity? } \\
\text { Did participants see the model having a } \\
\text { role in issues of equity, and if so what role? }\end{array}$ & \\
\hline & $\begin{array}{l}\text { Finance } \\
\text { Are financial returns and issues of equity } \\
\text { and regulation related, and if so how? }\end{array}$ & \\
\hline & $\begin{array}{l}\text { Regulation } \\
\text { How do the participant perceive regulation }\end{array}$ & \\
\hline
\end{tabular}




\begin{tabular}{|l|l|l|}
\hline Themes & Questions to be addressed in the data analysis & Relevant research questions \\
\hline New technologies and & $\begin{array}{l}\text { How can innovative farmers be involved in } \\
\text { innovation }\end{array}$ & $\begin{array}{l}\text { finding a middle ground between the } \\
\text { production and environmental } \\
\text { sustainability? }\end{array}$ \\
\hline
\end{tabular}


Appendix D: Maps and scenarios presented to research participant's

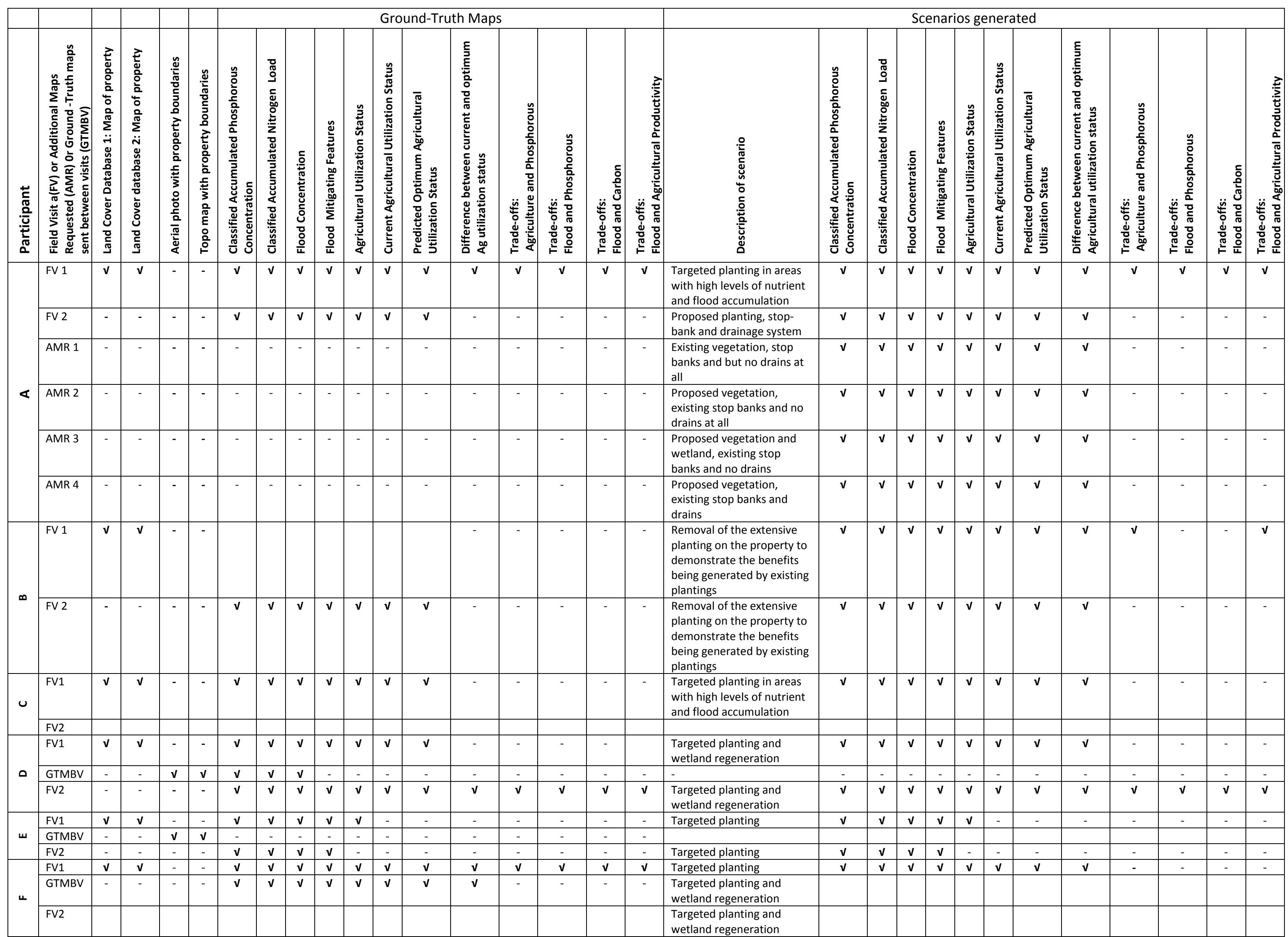


Appendix E: Participant field visits between April 2014 and April 2015

\begin{tabular}{|c|c|c|c|c|c|c|c|c|c|c|c|c|c|c|c|c|}
\hline & & $\begin{array}{l}\text { Field } \\
\text { Visits } \\
(F V)\end{array}$ & 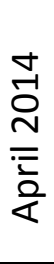 & 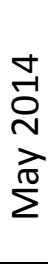 & 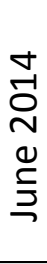 & 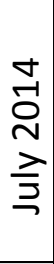 & 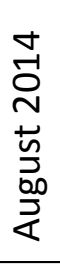 & $\begin{array}{l}\frac{1}{0} \\
\frac{0}{E} \\
\frac{1}{0} \\
\frac{0}{0} \\
\text { ปั }\end{array}$ & $\frac{8}{7}$ & 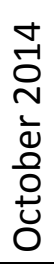 & 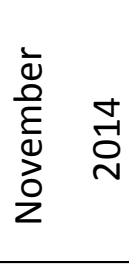 & 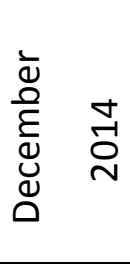 & 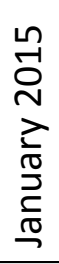 & 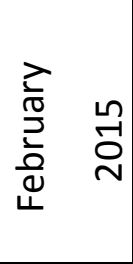 & 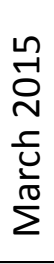 & $\begin{array}{l}\frac{1}{1} \\
\frac{1}{0} \\
\frac{1}{2} \\
\frac{1}{4}\end{array}$ \\
\hline \multirow{3}{*}{ 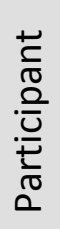 } & \multirow{3}{*}{$\varangle$} & FV 1 & & & V & & & & & & & & & & & \\
\hline & & FV 2 & & & & & & & & & & & V & & & \\
\hline & & FV 3 & & & & & & & & & & & & & & V \\
\hline \multirow{3}{*}{ 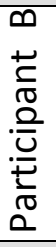 } & \multirow{6}{*}{ D } & FV 1 & & & & & & V & & & & & & & & \\
\hline & & FV 2 & & & & & & & & V & & & & & & \\
\hline & & FV 3 & & & & & & & & & $\sqrt{ }$ & & & & & \\
\hline \multirow{3}{*}{ 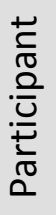 } & & FV 1 & V & & & & & & & & & & & & & \\
\hline & & FV 2 & & & V & & & & & & & & & & & \\
\hline & & FV 3 & & & & & V & & & & & & & & & \\
\hline$\stackrel{ \pm}{\check{E}}$ & \multirow{3}{*}{ ш } & FV 1 & V & & & & & & & & & & & & & \\
\hline$\frac{0}{\frac{U}{4}}$ & & FV 2 & & & V & & & & & & & & & & & \\
\hline $\bar{\square}$ & & FV 3 & & & & & V & & & & & & & & & \\
\hline \multirow{4}{*}{$\begin{array}{l}\frac{\pi}{\frac{\pi}{\pi}} \\
\cdot \frac{0}{\frac{0}{\pi}} \\
\frac{\pi}{\frac{\pi}{\pi}} \\
\frac{0}{0}\end{array}$} & \multirow{4}{*}{ レ } & FV 1 & & & & & & & & V & & & & & & \\
\hline & & FV 2 & & & & & & & & & & & & V & & \\
\hline & & FV 3 & & & & & & & & & & & & & V & \\
\hline & & FV 4 & & & & & & & & & & & & & & $\sqrt{ }$ \\
\hline
\end{tabular}


P a g e | 214 